\title{
Team Learning: A Theoretical Integration and Review
}

\author{
Bradford S. Bell \\ Cornell University \\ Steve W. J. Kozlowski \\ Michigan State University \\ Sabrina Blawath \\ University of St. Gallen
}

\section{Citation:}

Bell, B. S., Kozlowski, S. W. J., \& Blawath, S. (2012). Team learning: A review and integration. In S. W. J. Kozlowski (Ed.), The Oxford Handbook of Organizational Psychology (vol. 2, pp. 859-909). Oxford, UK: Oxford University Press.

Steve W. J. Kozlowski gratefully acknowledges the Office of Naval Research (ONR), Command Decision Making (CDM) Program (N00014-09-1-0519, S.W.J. Kozlowski and G. T. Chao, Principal Investigators) and the National Aeronautics and Space Administration (NASA, NNX09AK47G, S.W.J. Kozlowski, Principal Investigator) for support that, in part, assisted the composition of this chapter. Any opinions, findings, and conclusions or recommendations expressed are those of the authors and do not necessarily reflect the views of ONR or NASA. 


\begin{abstract}
With the increasing emphasis on work teams as the primary architecture of organizational structure, scholars have begun to focus attention on team learning, the processes that support it, and the important outcomes that depend on it. Although the literature addressing learning in teams is broad, it is also messy and fraught with conceptual confusion. This chapter presents a theoretical integration and review. The goal is to organize theory and research on team learning, identify actionable frameworks and findings, and emphasize promising targets for future research. We emphasize three theoretical foci in our examination of team learning, treating it as multilevel (individual and team, not individual or team), dynamic (iterative and progressive; a process not an outcome), and emergent (outcomes of team learning can manifest in different ways over time). The integrative theoretical heuristic distinguishes team learning process theories, supporting emergent states, team knowledge representations, and respective influences on team performance and effectiveness. Promising directions for theory development and research are discussed.
\end{abstract}




\section{TEAM LEARNING: A THEORETICAL INTEGRATION AND REVIEW}

Over two decades have passed since Senge (1990) proclaimed that teams, not individuals, are the fundamental learning unit in modern organizations. During this time, there has been an ongoing shift from work organized around individual jobs to team-based work systems (Devine, Clayton, Phillips, Dunford, \& Melner, 1999; Lawler, Mohrman, \& Ledford, 1995). This transformation in organizational work structures has occurred as organizations have increasingly turned to teams as a means of addressing a variety of emerging pressures and challenges. Teams bring together the diverse skills, expertise, and experience needed to tackle increasingly complex and dynamic organizational problems. They enable more rapid and flexible responses to the technological, economic, and political pressures faced by modern organizations. In addition, teams facilitate collaboration and knowledge sharing across organizational, cultural, and spatiotemporal boundaries.

The emergence of teams as the basic building blocks of organizations has been accompanied by growing interest in the topic of team learning. As teams have grown more central to organizational functioning, there has been a natural interest in understanding the factors that influence team effectiveness (Ilgen, Hollenbeck, Johnson, \& Jundt, 2005; Kozlowski \& Bell, 2003; Kozlowski \& Ilgen, 2006). Team learning has been identified as an important mechanism through which teams develop their performance capabilities, adapt to changes in their environment, and renew and sustain their performance over time. In addition, interest in team learning has been driven by its important role in organizational learning. Research has begun to identify the conditions under which team learning translates into organizational learning (Edmondson, 2002) and has examined the impact of factors within the team environment on learning behavior within organizations. Overall, the growing literature in this area has 
established support for Senge's claim that teams represent the nexus of learning in modern organizations.

Although we have gained significant insight into team learning over the past two decades, research in this area has been plagued by conceptual ambiguities and the absence of a coherent theoretical framework. Wilson, Goodman, \& Cronin (2007), for example, recently highlighted inconsistencies in the conceptualization of team learning across studies and "the disjointed treatment of this fundamental construct" (p. 1054). Similarly, Edmondson, Dillon, and Roloff (2007) argued that research on team learning falls into three distinct bodies of work that address different fundamental questions and offer different conceptualizations of the construct. In addition to these inconsistencies, prior research has not been clear about levels of analysis issues, the processes that underlie team learning, or the distinction between team learning and team performance (Kozlowski \& Ilgen, 2006; Wilson et al., 2007). Although examining team learning from different perspectives and research traditions may be generative (Edmondson et al., 2007), there is also agreement that greater consistency and clarity around the constructs and measures used in team learning research are needed to systematically advance knowledge in this area.

Our goal in the current chapter is to provide a review and integration of the research that has been conducted on team learning over the past two decades. We seek to illuminate what we know about the process of team learning, the outcomes of this process, and the factors that shape it. In particular, our review makes a clear distinction between team learning processes, and the knowledge and other emergent states that result from the process, that ultimately shape team effectiveness.

\section{Review Structure and Focus}

Given the different conceptualizations of team learning that have been introduced in the literature and the divergent perspectives that have been used to explore the construct, it is 
important to clarify the scope and structure of our review. Our purpose is to review the literature that has examined the learning, development, and adaptation of teams, which have been defined by Kozlowski and Bell (2003, p. 334) as:

two or more individuals who (a) exist to perform organizationally relevant tasks, $(b)$ share one more common goals, (c) interact socially, (d) exhibit task interdependencies (i.e., work flow, goals, outcomes), (e) maintain and manage boundaries, and (f) are embedded in an organizational context that sets boundaries, constrains the team, and influences exchanges with other units in the broader entity

Although we adopt a multilevel perspective of team learning and acknowledge its connections with individual and organizational learning, our focus is on teams; we do not review work specifically focused on the role of team learning in organizational learning, nor do we discuss research that has examined individual learning in the context of groups (e.g., collaborative learning) or the individual characteristics that may influence team learning and adaptation (e.g., Ployhart \& Bliese, 2006; Pulakos, Arad, Donovan, \& Plamondon, 2000). Likewise, we review a variety of team processes, emergent states, and outcomes in this chapter, but our focus is on how these mechanisms and outcomes relate to team learning; we do not intend to provide a comprehensive review of the team effectiveness literature.

The theoretical heuristic presented in Figure 1 provides an overview of the structure and focus of our review. In the following section, we begin by discussing the theoretical considerations that form the foundation of our perspective on team learning. These considerations emphasize the multilevel, emergent, and dynamic nature of team learning and we use these foci to guide our analysis of the team learning literature. The core of our review examines three models - goal and action regulation, information processing, and macrocognition - that have been used to examine the processes involved in team learning. Each of these models 
offers a distinct conceptual lens through which to understand the theoretical "engine" of team learning. We then review research that has examined emergent states, such as psychological safety and team efficacy, which support and enable team learning. Our review highlights the dynamic relationship that exists between these states and team learning processes; they are reciprocally entwined and emergent. Finally, we discuss research that has examined the outcomes of team learning, including collective knowledge, shared cognition (e.g., transactive memory, team mental models), team knowledge emergence, and - ultimately - team performance.

\section{Foundation Theoretical Foci}

There are three primary theoretical foci that form the foundation for our perspective on team learning. We use these theoretical foci to guide the identification of material to review (i.e., models of team learning, knowledge outcomes, emergent states, and antecedents). We also use them as critique guides to help highlight where we have made progress and where research attention needs to be devoted to make advances. First, team learning is multilevel in nature, encompassing individual level processes and, simultaneously, team level processes. Second, team learning is not a fixed and static phenomenon, rather it is a dynamic process. Third, team learning is emergent. It is not purely "holistic." It does not just magically manifest as a collective property, it develops, evolves, and emerges over time at the team level. Although these primary considerations are obviously intertwined, there are key aspects of each that merit highlighting.

Team learning is multilevel. Learning is a process of acquiring knowledge, skill, attitudes, or other characteristics that change the potential for behavior (Ford \& Kraiger, 1995). It is axiomatic that learning is a psychological phenomenon and, as such, originates within the individual as entwined cognitive, motivational-affective, and behavioral processes (Kozlowski \& Bell, 2003, 2008). One of the key challenges of conceptualizing learning as a process that is 
collective, is bridging the gap between the origin of learning as a psychological phenomenon and its manifestation in the higher level entity.

Some approaches simply extrapolate from our knowledge of learning as a psychological phenomenon, and assert a parallel process that exists at the team or collective level (e.g., Hinsz, Tindale, \& Vollrath, 1997; Walsh \& Ungson, 1991). Sometimes such extrapolation is based on metaphor, which is a weak form of theorizing (Pinder \& Bourgeois, 1982), other times it may be based on a more formal analogy, but this too, though useful, is not the strongest foundation for theory. Sometimes such extrapolations are characterized as holistic, unique, and indivisible systems. The argument is made that any attempt to decompose the collective phenomenon risks reductionism and should be avoided (von Bertalanffy, 1972). However, we view argument by mere metaphor or analogy as conceptually vague and the holism of general systems thinking to be overstated. The challenge is not to be reductionist, assuming that learning can only be psychological, while also eschewing holism, assuming that systems cannot be meaningfully decomposed (Simon, 1973). The challenge is to conceptualize team learning in a way that encompasses both levels - individual and team - simultaneously.

This is the province of multilevel theory. Rather than the holistic perspective of general systems theory (von Bertalanffy, 1972), multilevel theory is based on more contemporary concepts emanating from complexity theory (Kozlowski \& Klein, 2000). Complexity theory is concerned with understanding how complex, system-level phenomena can emerge from the dynamic interactions of system elements. As Kozlowski (in press) notes, "The focus is on the emergence of complex system behavior, but the focus on the basic elements, entities, or agents is not reductionism. Rather, it is an effort to understand how the 'wholeness' arises without reifying it” (p. 7). From a multilevel theory perspective, team learning is not just about individuals learning together or a team learning as a holistic and indivisible entity, it is about the interplay 
between and within the levels; the way that the team context influences and shapes individual learning and the way that learning simultaneously forms, evolves, and emerges at the team level. Not either / or, but both.

Team learning is dynamic. Learning is a complex process that also encompasses motivation and performance. Learning, motivation, and performance are entwined. As a process, it is axiomatic that learning is dynamic and there are two key dynamic aspects that merit discussion: (1) the process is iterative and (2) it evidences developmental progression.

First, it is a near universal assumption across learning theories that the process is cyclical and iterative. Classical conditioning, operant theory, subjective expected utility theory (and its variants like valence-instrumentality-expectancy theory), and self-regulation theory (and its variants of control theory and social-cognitive theory), among others, all incorporate feedback loops that have implications for subsequent cycles of iteration. For example, a simple regulation heuristic asserts a goal - a desired performance standard - as an energizer of the system. The goal, possibly guided by a strategy, serves to direct effort toward goal accomplishment. Some level of performance results and feedback is compared to the goal standard. Unless the goal is exceptionally simple, performance is typically below standard. Perceptions of progress (e.g., satisfaction) and capability (e.g., efficacy) among other factors influence subsequent effort and / or strategy modification. If progress and capability are adequate, effort is maintained or increased, whereas if progress or capability is inadequate, effort and attention are withdrawn. This cyclic dynamic has rather obvious implications for learning. Kozlowski and Bell (2008) characterize the interconnected iterative cycles of individual and team regulation as the theoretical "engine" of team learning.

Second, learning processes entail a developmental progression. One has to learn simple basics before one can master more complex material. This dynamic progression is another near 
universal aspect of learning and skill acquisition theory (e.g., Anderson, 1987; Fitts and Posner, 1967; Ford \& Kraiger, 1995). For example, as shown in Figure 2, Kozlowski and Bell (2007) formulated a progressive model of knowledge compilation. The model sequences basic to more advanced knowledge (i.e., facts $>$ conditional rules $>$ synthesis $>$ generalization). More importantly, it integrates qualitatively different learning processes to the progressive phases of knowledge compilation. Learning processes for basic knowledge acquisition entail rehearsal and memorization; advanced knowledge compilation necessitates exploration, variability, and reflection. The authors assert, "the acquisition of basic knowledge necessitates encoding and is memory intensive, whereas advanced knowledge and skill acquisition require higher-level selfregulatory and metacognitive processes with an emphasis on integrating cognitive and behavioral skill" (p. 21). The key points that we advance are that learning as a dynamic process cycles and iterates and the nature of learning as a process progressively evolves as knowledge and skills compile.

Team learning is emergent. In a team context, individuals engage in a domain, learn, and acquire progressively more complex knowledge and skill. However, they do not learn in a social vacuum. They are both influenced by and influence the learning processes of their teammates. Individual learning shapes and is shaped by team learning as an emergent phenomenon. "A phenomenon is emergent when it originates in the cognition, affect, behaviors, or other characteristics of individuals, is amplified by their interactions, and manifests as a higher-level, collective phenomenon" (Kozlowski \& Klein, 2000, p. 55).

Teams learn as members exchange ideas, information, and insights, building collaborative knowledge. The process is shaped by the formal workflow structure that necessitates the sharing of relevant information and by informal social exchange as members negotiate their roles. Teams learn as the knowledge acquired via individual learning is shared, 
exchanged, and transmitted. Collaborative learning and the knowledge acquired shapes subsequent individual learning. Team learning is emergent (Kozlowski \& Bell, 2008; Kozlowski $\&$ Chao, in press). Team knowledge that emerges via dynamic team learning processes can manifest as qualitatively different types, composition or compilation, that represent opposing poles of a continuum of emergence (Kozlowski \& Klein, 2000). Composition constructs emerge via linear, convergent processes and compilation forms emerge via divergent, configural or patterned processes.

Composition types of emergence apply to phenomena that manifest through convergent processes by which essentially the same content becomes held or shared across all team members. Composition constructs are isomorphic, in that it is essentially the same construct at the individual and team levels of analysis. The content is the same, the structure is the same, just the referent - individual or team - is different. Composition constructs are structurally equivalent (i.e., identical elemental content) and functionally equivalent (i.e., assume the same role in a model) at both levels of analysis (Kozlowski \& Klein, 2000; Morgeson \& Hofmann, 1999). For example, in terms of team knowledge developed through team learning, theorists have speculated that teams acquire shared mental models of the team, task, equipment, and pattern of exchange that allow team members to coordinate implicitly (Cannon-Bowers, Salas, \& Converse, 1993). Shared mental models emerge as composition constructs.

Compilation types of emergence apply to phenomenon that manifest through divergent processes by which diverse content is combined across team members to form a configuration or pattern. One can liken this configuration to puzzle pieces or to the nodes and links of a network. The unique content fits together to form a meaningful whole. Compilation constructs are functionally, but not structurally, equivalent across levels (Kozlowski \& Klein, 2000; Morgeson \& Hofmann, 1999). Thus, for example, theorists have postulated that teams can create a 
networked memory system - transactive memory - in which distinct knowledge and expertise can be accessed by the team. Team members possess knowledge of each member's unique expertise that enables the team to collectively access knowledge as needed (Mohammed \& Dumville, 2001). Transactive memory emerges as a compilation construct where the pattern of individual team member knowledge comprises the structure of team memory.

\section{Team Learning Process Models}

As we noted in the previous section, team learning processes are multilevel, dynamic, and emergent. In addition, learning is a fundamental human experience -- whether we learn as individuals or as co-acting members of small groups -- that is inextricably entwined with the fundamentals of motivation and performance. The models that we review in this section emphasize some of these aspects more than others. However, in our view, all of the approaches are consistent with our theoretical foci and provide insights into a useful conceptualization of team learning processes. The models we examine include models of goal and action regulation, information processing, and macrocognition. Finally, we should note that this section is by no means intended to capture every possible model that has ever been used in an effort to understand team learning processes. Rather, we have focused our review on those models with a stream of systematic theory development, supportive empirical findings, and / or emerging theory that promises new insights and research opportunities.

\section{Regulation Models}

Overview. Regulatory models are dynamic in that they are cyclical and iterative. At the individual level, regulatory models are the dominant models of learning, motivation, and performance (Kanfer, Chen, \& Pritchard, 2008; Karoly, 1993). There have been several notable extensions to the team level that we review in the material that follows in this section. One important issue to recognize about these models is that there are several key components of the 
regulatory process - goals, goal commitment, strategies, effort, performance, feedback, comparison, and reactions - and different models tend to emphasize some components of the process to a greater extent than others. Obviously, more inclusive models are likely to be more useful. A second, and related, issue is that while there is a substantial amount of heuristic-level commonality among the models, there are some important theoretical distinctions that result from the different emphases of the models. Although these differences have resulted in vigorous conceptual disagreements in individual-level research (i.e., Bandura \& Locke, 2003; Vancouver, 2005), these points have not permeated team level research (at least, not yet).

At the highest heuristic level, Kanfer (1990) has distinguished between goal setting and goal striving processes. Models that emphasize goal setting tend to focus on goal choice (i.e., level of goal difficulty), the nature of goals (e.g., goal content oriented toward learning vs. performance), and goal acceptance (i.e., commitment). Models that emphasize goal striving focus more on action regulation and the cyclical dynamics as one reacts to goal progress, modifies effort and strategies, and further strives to attain the objective. Ultimately, both goal setting and goal striving processes are important for understanding team learning. From our view, an important value of the regulatory approach to team learning is that it is explicitly multilevel, dynamic, and emergent.

Group goal setting. Research on group goal setting represents some of the earliest efforts to apply individual motivation theory to the group level. Although these early efforts were not theoretically deep, the findings from individual level research were by then well established by meta-analytic support (Mento, Steel, \& Karren, 1987) and the early work represented simple extensions to the team level. At the individual level, central tenants of goal setting are that goals should be difficult to achieve, specific, and accepted (Locke \& Latham, 1990). Goal difficulty has an orienting property for effort and specificity is critical for establishing a reference standard 
so that progress toward goal accomplishment can be monitored. It is also important that individuals commit to investing effort to accomplish the goal. Finally, although it is not a central tenant of goal-setting theory, social cognitive theory (Bandura, 1991) places considerable emphasis on the agency provided by self-perceptions of efficacy to support effort investment and task persistence. Some early pioneering research extended the social cognitive framework to the team level of analysis (Prussia \& Kinicki, 1996). However, the most influential aspect of social cognitive theory with respect to team learning has been the considerable work on the concept of collective efficacy, as we shall describe in a subsequent section that addresses emergent states.

An early meta-analysis of group goal setting research (based on 26 effect sizes from 10 studies) reported that, compared to no or low group goals, group goals yielded an effect size equivalent to about a one standard deviation improvement in group performance; a substantial effect (O'Leary-Kelly, Martocchio, \& Frink, 1994). Unfortunately, the pool of qualified primary studies for this early meta-analysis was too small to allow for an examination of moderators that would evaluate the central tenants of goal setting (and other moderators) at the group level of analysis. Nonetheless, a qualitative assessment generally concluded that there was support for expected effects of goals at the group level.

Given that it has been over a decade and a half since this study was published, it is remarkable that it is only recently that the findings of this meta-analysis have been updated. This more recent meta-analysis, based on 30 studies with 76 independent effect sizes, concluded that there was an overall relationship of group goals with group performance $(d=0.56 \pm 0.19, k=49)$ and that specific-difficult group goals were associated with higher performance than nonspecific goals $(d=0.80 \pm 0.35, k=23)$ (Kleingeld, van Mierlo, \& Arends, in press). The analysis also revealed that individually oriented goals (i.e., targeted on individual performance) had a negative effect $(d=-1.75 \pm 0.60, k=6)$, whereas group oriented goals (i.e., targeted on the individual's 
contribution to group performance) were positively related to group performance $(d=1.20 \pm$ $1.03, k=4)$. Although these latter findings are to be expected, they are based on relatively few studies. Surprisingly, an examination of moderating effects for task interdependence, complexity, and participation were null.

Although the findings of Kleingeld et al. (in press) help to clarify the extent to which central tenants of goal setting generalize to the team level, there are additional contingencies that also need to be examined. For example, teams tend to be utilized when tasks are complex, a condition that makes team learning central and salient. At the individual level, there has been a stream of research demonstrating that learning goals (i.e., goals that target specific learning objectives) are superior to performance goals (i.e., difficult and specific performance levels) when individuals have to acquire complex skills (e.g., Kozlowski \& Bell, 2006; Seijts, Latham, Tasa, \& Latham, 2004; Winters \& Latham, 1996). Efforts to examine these contingencies on the effectiveness of goals at the team level have been relatively rare (e.g., Weingart, 1992). Similarly, it is also remarkable that there is very little research that examines the effects of individual-level and team-level feedback on individual and team performance (DeShon, Kozlowski, Schmidt, Milner, \& Wiechmann, 2004). Perhaps this is because feedback does not generate much attention in goal setting research (which tends to be static in orientation), although it is central to the dynamic, iterative, and cyclical aspects of regulation during goal striving. More recent research focused on action regulation has sought to examine a more complex and dynamic interplay among goals, strategies, feedback, and reactions across the individual and team levels of analysis.

Team action regulation, learning, and performance. Models that focus on action regulation processes have tended to be less concerned with the central tenants of goal setting (i.e., the characteristics of goals) and more concerned about (a) the linkages among key 
components of the broader regulatory process including goals, commitment, strategies, effort, performance, feedback, comparison, and reactions; (b) the dynamics of the process as it iterates over time; and (c) the multilevel and emergent aspects of team regulation. DeShon et al. (2004) advanced a multiple goal, multilevel model of individual and team regulation (as a parallel emergent process) in an effort to capture this complexity. Here we describe the theoretical underpinnings of their approach to model team learning and skill acquisition as a dynamic multilevel process.

Teams, of course, can be structured in a variety of different ways that have implications for the nature of the linkage between individual and team goals and performance. For example, in additive tasks, team performance results from a simple pooling of individual contributions such that individuals striving to accomplish their own goals are also contributing to team goal accomplishment (Steiner, 1972). This is the weakest form of team interdependence. In contrast, discretionary tasks entail distinct individual and team goals and an interdependent structure such that team members cannot simultaneously strive to accomplish individual and team goals. In other words, team members have considerable latitude in the extent to which they allocate personal resources to accomplish team objectives, by assisting or backing up a teammate, at the expense of their own goal striving. This is viewed as the most general type of team task structure (Steiner, 1972) and would be consistent with the interdependence structure of many types of project, research, and decision making teams.

Such team task structures entail multiple goals - distinct individual and team goals - that team members must strive to accomplish and necessitates a more complex regulatory model that incorporates distinct goal-feedback loops governing the regulation of individual attention and resource allocation. A heuristic model, shown on the left side in Figure 3, illustrates the interplay of the dual goal-feedback loops that regulate individual and team resource allocation. Resources 
cannot be allocated to both feedback loops simultaneously and, thus, the loops vie for behavioral control. Each goal-feedback loop monitors discrepancies (i.e., comparison) between current performance and their respective goal states and activates behaviors (i.e., strategies, effort) to reduce the discrepancy. Because individual and team performance are distinct in the discretionary task structure, a choice to devote resources toward one feedback loop necessitates the withdrawal of resources devoted to the other loop. Thus, minimizing discrepancies on one loop will increase the magnitude of discrepancies on the other loop. All things being equal and assuming equivalent commitment to both goals, the self-regulation system will monitor both loops and dynamically switch control to the loop that accumulates discrepancies beyond a trigger value (Kernan \& Lord, 1990). In this conceptualization, team regulation is energized by a dynamic process of individual level goal switching. Of course, the environmental context within which the team is embedded may sensitize team members to discrepancies on a particular goalfeedback loop, thereby creating an allocation bias of regulatory resources to either the individual or team level goal.

DeShon et al. (2004) put the dual goal-feedback loop model in action and extrapolated the implications of the dynamic goal switching process for the emergence of a homologous multilevel model that represented parallel individual and team regulatory processes illustrated on the right side in Figure 3. Kozlowski and Klein (2000) have indicated that validating a multilevel homology necessitates (a) conceptually parallel individual and team constructs that meet composition criteria for representation at the team level and (b) functionally equivalent relations linking the parallel constructs at both levels of analysis. Experimental data in which feedback was manipulated to influence the relative salience of the dual feedback loops (i.e., individual feedback, team feedback, both) provided support for the homologous multilevel model and, by inference, the underlying dynamic multiple goal heuristic. Thus, the processes of action 
regulation responsible for individual resource allocation, learning, and performance also emerge and substantially hold at the team level, making multilevel regulation a very basic and useful team learning process model - one that is consistent with our theoretical foci of multilevel, dynamic, and emergent.

Whereas DeShon et al. (2004) focused on multilevel regulation during learning and skill acquisition, Chen, Thomas, and Wallace (2005) focused on multilevel regulation processes at the end of training as a mediator of the relationship between roughly parallel training outcomes at the individual and team levels (i.e., knowledge, skill, and efficacy) and adaptive performance (i.e., an additional performance trial that involved greater component complexity or difficulty relative to prior training). The focus is still on learning, although with emphasis on generalization of skill. As shown in Figure 4, their conceptual model represents a synthesis between Kanfer's (1990) heuristic of goal choice and goal striving phases of self-regulation, coupled with a parallel distinction made by Marks, Mathieu, and Zaccaro (2001) between team transition processes (e.g., goal and strategy selection) and team action processes (e.g., monitoring progress toward goals, coordinating effort, correcting errors). Although the model was not posited as a strict multilevel homology in part due to measurement differences in parallel constructs across levels, aspects of the framework were intended to be conceptually parallel. The results were complex, but in general indicated that viewing regulation as a multilevel process was a useful way to represent the process of skill generalization at the individual and team levels.

Both prior models of individual and team action regulation focused on the multilevel character of the process as team members strive to accomplish individual and team objectives. The emphasis is on a dynamic interplay across the levels with respect to parallelism in constructs and processes. We do not mean to minimize this contribution because we think it is vitally important as a fundamental approach to conceptualizing team learning. However, only so much 
can be accomplished in any one study and in focusing on the parallelism inherent in multilevel models, the prior research neglected the cross level linkages that also bind individual and team regulation. From a cross level perspective, team phenomena - once they have emerged - serve to shape and constrain subsequent individual level phenomena. Process begets structure which constrains subsequent processes (Katz \& Kahn, 1966; Kozlowski \& Klein, 2000).

Building on this perspective, Chen and Kanfer (2006) posited a theoretical model of motivation in teams that places emphasis on this cross level interplay. Research by Chen, Kanfer, Mathieu, DeShon, and Kozlowski (2009) evaluated that model and extended it by also focusing on the dynamics of these cross level regulatory relations. The study reanalyzed the data reported by Chen et al. (2005) and DeShon et al. (2004) to provide replicated evaluations of the model. Whereas the original research had focused on the parallel, multilevel aspects of regulatory processes, these new analyses examined the effects of the cross level linkages on shaping individual regulation that had not been previously examined (see Figure 5). The researchers found consistent support for their hypotheses linking the levels of the regulation system, and emphasizing the team as a context for individual regulatory processes and outcomes. In combination with the prior research, we think this consistent support for the value of an integrated, multilevel and cross-level individual and team regulatory process as a means to conceptualize learning, motivation, and performance is very promising.

Finally, although its genesis is independent of the theory and research previously described, Pritchard and colleagues (Pritchard, Jones, Roth, Stuebing, \& Ekeberg, 1988) developed an application described as The Productivity Measurement and Enhancement System (ProMES) that instantiates, in essence, a team level goal setting and regulatory system to facilitate team productivity. The ProMES system installs the regulatory components of goals, feedback, and incentives that are defined in ways meaningful to team members. The initial 
validation effort for the ProMES application reported substantial improvements in productivity, compared to baseline performance, as each of the components was installed. Feedback was implemented first, yielding a 50\% improvement. Goal setting was next, yielding a $75 \%$ improvement. Finally, incentives were added for a 76\% improvement in productivity. Recently, a meta-analysis was conducted to summarize 83 ProMES implementations (Pritchard, Harrell, DiazGrandos, \& Guzman, 2008). The researchers concluded that the overall effects of ProMES on productivity improvement across a wide range of organizations and different team tasks were substantial and the improvements were potent, in some cases persisting over years.

Action regulation and emergent team processes. A related theoretical perspective takes as its starting point the concept of iterative, episodic task cycles and uses those dynamics to infer which team behavioral processes are relevant and when they are relevant during team action regulation (Marks et al., 2001). Task episodes are conceptualized as a linked sequence of transition and action phases. Transition phases represent periods before or after action (between episodes) where the team is preparing for an upcoming engagement (e.g., planning, anticipating strategies, and setting goals) or evaluating the effectiveness of their action following an engagement. Action phases represent periods when team members are engaged in goal striving (within episodes), by monitoring the overall situation, progress toward goals, coordination, and member actions (e.g., correcting errors, sharing the load, cooperating). There are also interpersonal processes - motivation, conflict management, and affect management - that are important across both phases.

Their conceptualization of team tasks as episodic in nature is consistent with the previously discussed models of team action regulation (e.g., DeShon et al., 2004) and with models that emphasize team learning cycles as the core mechanism of team development and adaptation (Kozlowski, Gully, McHugh, Salas, \& Cannon-Bowers, 1996; Kozlowski, Gully, 
Salas, \& Cannon-Bowers 1996) that we highlight in the next section. However, there are two novel and important aspects of the Marks et al. (2001) conceptualization. First, task episodes are viewed as multifaceted in that teams can be engaged in multiple, distinct transition-action sequences with different rhythms that have to be monitored simultaneously. This adds substantial complexity to the process of team action regulation. Second, Marks et al. use the distinct foci of transition and action phases to structure when particular team "emergent states" or processes are relevant. The processes they consider are synthesized from a stream of prior research on team performance functions (see Fleishman \& Zaccaro, 1992, for a summary) and related research on team behaviors that underlie effectiveness (Marks et al., 2001). This is a parsimonious organizing framework that helps to identify which team behaviors are important, when they are important, and why they are important.

Subsequent meta-analytic research has built on this conceptual framework to propose a hierarchical model such that the specific team behavioral processes proposed by Marks et al. (2001) would form first-order factors; loading onto second-order transition, action, and interpersonal factors; under an overall team process factor (LePine, Piccolo, Jackson, Mathieu, \& Saul, 2008). A meta-analytic confirmatory factor analysis based on 138 studies using 1507 correlations from 147 independent samples provided empirical support for this conceptual structure. In addition, LePine et al. (2008) examined the meta-analytic relationship between the first- and second-order team processes with team performance. They reported corrected correlations for the first-order processes and performance that ranged from .17 (systems monitoring) to .35 (strategy formulation). Of the 10 first-order processes, 9 evidenced corrected correlations with performance in excess of .25 with one-half of them greater than or equal to .30 . As would be expected, the second- and third-order factors also related to team performance. Finally, they also examined the relationships between the second-order factors - transition, 
action, and interpersonal processes - and what Marks et al. (2001) refer to as "emergent states" of team cohesion and group potency. The corrected correlations were substantial (cohesion: .60,.61, .53; potency: .63,.65, .70, respectively).

When considered in conjunction with the theoretical and empirical support highlighted in the prior section, we conclude that there is solid support for action regulation as a basic theoretical engine of team learning processes, that team action regulation behaviors are associated with motivational and affective emergent states (cohesion, potency), and that team action regulation behaviors contribute to team performance. Although it is somewhat more speculative to presume that team action regulation contributes to other cognitive and motivational-affective team processes (emergent states), we think that is likely to be the case. For example, action regulation is known to shape the development of team efficacy (e.g., Chen et al., 2009; DeShon et al., 2004). In addition, there is some evidence that action regulation leads to the development of shared mental models (Mohammed, Ferzandi, \& Hamilton, 2010). In concert, we view the regulatory perspective on team learning to be highly promising.

Team regulation, learning, and development. A series of integrated theoretical frameworks created by Kozlowski and colleagues (Kozlowski, Gully, McHugh et al., 1996; Kozlowski, Gully, Salas et al., 1996; Kozlowski, Gully, Nason, \& Smith, 1999; Kozlowski, Watola, Jensen, Kim, \& Botero, 2009) characterize how individual and team regulatory processes, as we have described in detail above, function as the theoretical "engine" of team learning. Regulation processes propel a developmental sequence of increasing knowledge and skill capability across focal levels - individual, dyadic, and team -- that ultimately culminates in an adaptive, regulating, collective entity. In addition, a key aspect of their approach is the principle that team leaders should play a central role in energizing the regulatory learning process and shaping developmental progression. The cyclical, episodic nature of team tasks 
provides an opportunity for team leaders to harness task cycles and focus regulation and learning around specific, phased developmental goals. As team members acquire basic proficiencies, the team leader transitions the team to focus learning and development on more complex skills sets. As team-level capabilities emerge, the team becomes a self-regulating entity and the leader is able to shift to boundary and environmental monitoring (see also Day, this volume). This metatheoretical perspective has three primary conceptual underpinnings: (1) team tasks are episodic and can be explicitly linked to a regulation cycle; (2) teams, like individuals, progress through a series of phases during which they learn and compile increasingly complex knowledge and skill; and (3) as teams develop, the focal level of learning transitions from individuals becoming proficient to dyads negotiating role exchanges to the team network mapping out a repertoire of its adaptive capabilities.

First, as noted previously, team tasks exhibit episodic dynamics, cycling from low prior to task engagement to high as the team engages the task, and back to low as the cycle concludes. As shown in Figure 6, this episodic dynamic enables a three-part regulatory process that sets desired learning goals during low load, monitors team learning and performance during task engagement, and then facilitates process feedback and reflection as the team transitions from task engagement back to low load (Kozlowski, Gully, McHugh et al., 1996; Kozlowski, Gully, Salas et al., 1996; Kozlowski et al., 2009). Although this model was developed independently of the Marks et al. (2001) episodic model and typology, the frameworks are compatible. With repeated episodes, regulation focused on individual learning and skill acquisition proficiency begins to emerge as a multilevel -- individual and team -- regulation process that encompasses team learning, skill acquisition, and performance (Kozlowski, Gully, Nason, et al., 1999).

Second, similar to the way that individual learning compiles increasingly complex skills, the theorists posit that teams progress through a series of modal learning phases that involve 
qualitatively distinct learning content and outcomes. Regulation is the engine that enables within phase learning and transition to more complex skill acquisition. Third, this is viewed as a process of building and compiling knowledge and skill that also shift across focal levels of emergence from individuals to dyads to teams. Initially, during team formation, new members engage in informal socialization processes to define social structure and space, establishing norms, goals, and a sense of mission. During task compilation, they focus on regulating their individual performance and building their own task proficiency. As they begin to master their own capabilities, they shift to a role compilation process as team members focus on task-driven dyadic interactions to identify role sets, negotiate exchanges, and establish routines to guide interdependence. As teams transition to the last phase in the meta-model, team compilation, members focus on the team network of interdependencies and begin to develop a repertoire of alternative, reconfigurable linkages that enable them to continuously improve for the expected and provide the underpinnings for adaption to the unexpected. Although there are no direct evaluations of this meta-theory, which is synthesized from a broad literature, there is support for the regulatory mechanisms (Chen et al., 2005; Chen et al., 2009; DeShon et al., 2004; Mathieu, Gilson, \& Ruddy, 2006), and there is some support for the principle that progressive shifts in the focal level of development - individual to team - contributes to team adaptability (DeShon, Kozlowski, Schmidt, Wiechmann, \& Milner, 2001).

Conclusion. Self-regulation, in its various incarnations, is the dominant model of individual level learning, motivation, and performance; it has amassed a substantial supporting empirical foundation; and some of its basic principles have been extended in an effort to provide insights about team learning processes. Overall, we think the application of regulation models to the team level evidences considerable promise. As our review documents, we know that difficult and specific team goals prompt similar effects on increasing team performance as those observed 
at the individual level (O’Leary-Kelly et al., 1994; Pritchard et al., 2008). Remarkably, although there is voluminous research on individual goal setting, research on the effects of team goal setting are still quite limited. Not only is there a small empirical foundation overall, it is also remarkable that there is very little team level research examining the major moderating contingency factors (e.g., goal specificity, goal content) of goal setting. O'Leary-Kelly et al. (1994) could not examine these contingency effects in their meta-analysis because there were an insufficient number of primary studies. In the preceding seventeen years, little has changed. Although research on these relationships may not be viewed as plowing new conceptual turf, they are nonetheless important principles to generalize - or to demonstrate boundary conditions in their generalization - to the team level. Conducting the basic work to map the generalization of goal setting principles to the team level is an obvious research target.

Goals, however, are only one part of the learning process. Feedback also plays a critical role in self-regulation. Indeed, there is no process to regulate without feedback to influence subsequent effort and strategy adaptations across goal striving iterations. Yet, remarkably, there is also surprising little research on the effects of feedback on regulation, learning, and performance at the team level as documented by DeShon et al. (2004). Is it better to give team feedback, individual feedback, or both types? In the DeShon et al. (2004) study, individual feedback (only) led to the best individual performance, team feedback (only) led to the best team performance, and those teams receiving both types (individual and team) could not maximize performance on both goal-feedback loops. It is likely that there are ways to augment raw outcome feedback that could help to maximize performance on both goal-feedback loops. Understanding how to better deliver feedback to support individual and team performance is another rather obvious target for systematic research. 
Our review also described a set of related "meta" theoretical frameworks on team learning that extends action regulation to understand (a) team developmental processes and (b) how they can be shaped by team leaders. This meta theory addresses distinctive learning processes and outcomes, and is constructed on a broad base of conceptual integration and related empirical findings. We think it is promising, but it needs to be evaluated, refined, and extended. The "meta" theory incorporates "core" principles that can be used to evaluate the usefulness of the overall frameworks. The team development models by Kozlowski and colleagues focus on regulation as a theoretical engine for team learning, developmental transitions across time and focal levels, and the potential for leaders to shape developmental processes. These core principles are key research foci for evaluating the frameworks. As we highlighted in the review, there is emerging support for multilevel regulation as an engine of team learning. Subsequent research should focus on developmental transitions, shifts in the focal level of development, and the ability of leaders to augment these developmental transitions. In addition to core principles, the meta models can also be used to generate numerous more specific, contextualized models in which specific hypotheses can be examined and boundary conditions established.

Finally, Pritchard et al. (2008) have shown that the ProMES application of principles that underlie action regulation are potent ways to shape team members' ability to improve performance. We presume that learning as a process, collaboration and / or supporting "emergent states," and knowledge components underlie this improvement. Thus, while there is evidence showing the effectiveness of ProMES, we think that basic research to unpack its mechanisms would enhance understanding and would advance applications.

\section{Information Processing Models}

Overview. Early efforts to conceptualize learning at higher levels of analysis relied heavily on information processing theory that grew out of the post World War II explosion of 
interest in the science of cybernetics (Wiener, 1948) which also prompted the cognitive revolution in psychology (e.g., Miller, Galanter, \& Pribram, 1960; Shiffrin \& Schneider, 1977). Cybernetic control systems are based on the negative feedback loop and hierarchically nested layers of control loops (e.g., Carver \& Scheier, 1981; Powers, 1973). This is the same basic system architecture as in self-regulation models, albeit self-regulation models focus more on psychological processes implicated by the control loop and information processing models focus more on the functional components of system control.

In organizational psychology and behavior, information processing was used as a heuristic to understand organizational learning and decision making (e.g., Cyert \& March, 1963). In his review, Huber (1991) described four processes that underlie organizational learning knowledge acquisition, information distribution, information interpretation, and organizational memory - each associated with a set of subprocesses. For example, organizations may acquire knowledge through a variety of activities and behaviors, including experiential learning, vicarious learning, and searching. Together, these processes and subprocesses are proposed to influence the breadth, elaborateness, and thoroughness of organizational learning. Unfortunately, much of the "theory" that underlies this domain is largely based on metaphor and analogies that seek to instantiate information processing components and mechanisms in ephemeral organizational systems and structures (Huber, 1991; Walsh \& Ungson, 1991). There have been, however, more focused efforts to apply the information processing perspective to groups and teams as a framework to understand learning and decision making.

Groups as information processors. In his review of managerial and organizational cognition, Walsh (1995) notes, "The key challenge in considering knowledge structures at the supra-individual level of analysis is to account for the role of social processes in the acquisition, retention, and retrieval of information" (p. 291). Indeed, most information-processing or 
cognitive theories of team learning have focused significant attention on delineating these social and interpersonal processes. Hinsz et al. (1997) provided a narrative review of research that has examined how task-performing groups process information. They suggest that informationprocessing at the group-level "involves the degree to which information, ideas, or cognitive processes are shared, and are being shared, among the group members and how this sharing of information affects both individual- and group-level outcomes" (p. 43). Thus, information exchange and transfer among group members is central to their conceptualization of group information-processing. In addition, they acknowledge the fact that information-processing in groups is inherently a multilevel process; group-level processing is dependent on individual-level processing and individual-level processing is influenced by group-level processes. For example, group information-processing can be influenced by the focus of members' attention (e.g., internally vs. externally), and aspects of the group context (e.g., group size) and interactions (e.g., time pressure) can similarly influence what information becomes the focus of members' attention. Although they highlight some notable interdependencies and interactions across these levels, the review focuses primarily on extending information-processing theory to the grouplevel rather than delineating these multilevel processes.

Hinsz et al. (1997) organize their review based on a generic information-processing model that has emerged from individual-level research in cognitive psychology. Although they acknowledge distinct differences in how individuals and groups process information, they argue that the components of the model serve a useful framework for examining how small groups process relevant and available information to perform cognitive tasks. Thus, they extrapolate the individual-level model of information-processing to explore parallel processes at the group level. The first component of the model, processing objective, recognizes the fact that groups, like individuals, process information in terms of objectives, tasks, missions, or collective goals 
derived from the context. In the attention phase of information processing, group members attend to particular information in order to process it. This information is then evaluated, interpreted, and transformed into a representation through an encoding process that enables the information to enter group memory through the storage process. The retrieval process allows groups to search for and recall necessary information. In the processing work space, groups combine, integrate, and process information on the basis of various rules, strategies, and procedures. Finally, after information is processed, a response is produced that represents the collective will of the group and often the response generates feedback about changes in the situation. After reviewing group research related to each of these components of informationprocessing, they discuss four dimensions of variability that may influence group informationprocessing. For example, they examine how group information-processing is influenced by variability in group members' access to a piece of information (i.e., commonality-uniqueness of information dimension) and variability in cognitive representations among group members (i.e., convergence-diversity of ideas dimension). Ultimately, they argue that group informationprocessing can be conceptualized as a process through which the individual contributions (e.g., information, ideas, cognitive processes) of group members are combined through interaction to produce the group-level outcome.

Building on the work of Hinsz et al. (1997), Ellis and Bell (2005) present an informationprocessing model of team learning (see Figure 7), which they define as " a relatively permanent change in the team's collective level of knowledge and skill produced by the shared experience of the team members" (italics in original, p. 6). However, rather than providing a detailed examination of each component of the model, they focus on describing three conditions that must exist for team learning to occur. The first condition, capacity, refers to the cognitive resources the team brings to the situation. Teams composed of members with higher levels of 
cognitive ability should have greater capacity to collectively process information. The second critical condition for team learning is effective collaboration, which refers to the sharing of knowledge, experience, or ideas within the team. This condition captures the social aspect of learning in teams and collaboration can be influenced by not only the personalities of individual members but also interventions such as team training. The final condition, commonality, suggests that team members must have a common frame of reference or language in order to collaborate effectively and engage in collective learning. Commonality can be influenced by selecting team members who are familiar with one another or by developing shared mental models. Overall, the capacity-collaboration-commonality framework serves to highlight several potential antecedents of information-processing in teams.

In a recent article, Wilson et al. (2007) proposed a cognitive theory of group learning. Similar to Huber (1991), they treat group learning as an outcome that can be defined as, "a change in the group's repertoire of potential behavior" (p. 1044). In addition, they argue that sharing, storage, and retrieval represent the processes through which group learning occurs. Sharing is the process through which knowledge is distributed within the group and members develop an understanding that others have the same knowledge. New knowledge must not only be shared within the team, but it must also be stored and retained so that it can be exploited over time. The final group learning process is retrieval, which means that group members are able to find and access stored knowledge for subsequent use. Wilson et al. (2007) examine not only the independent effects of each of these processes on group learning but also the relationships among these processes. For example, they argue that increasing the breadth of sharing enhances the robustness of group learning by allowing learning to be stored across multiple members' memories and expanding the number of group members who are able to recognize and respond to retrieval cues. 
Information sharing. Each of the conceptual frameworks described above emphasize the importance of communication and information sharing in team learning. These processes distribute new knowledge among group members so that it can become a shared property of the group. Research by Stasser and his colleagues, however, has demonstrated that discussion in groups is often biased in favor of shared information that all members know instead of unshared information that only a single member knows (Stasser \& Titus, 1985, 1987). Research on this phenomenon has relied primarily on the hidden profile task, in which information that supports an inferior decision is predominately shared, whereas information that supports the superior decision is unshared (i.e., unique information is distributed across members).

Group discussion often favors shared information because it has a statistical sampling advantage and a recognition and recall advantage over unshared information (Stasser, Taylor, \& Hanna, 1989). In addition, research has found that members often face social costs associated with establishing the credibility and relevance of unique information (Stasser \& Titus, 2003; Wittenbaum \& Park, 2001). Given the implications of biased information sampling for group decision-making, and potentially group learning, research has focused attention on identifying the factors that influence information sharing. A number of variables within the temporal (e.g., length of discussion), social (e.g., status, expertise, leadership), and task environment (e.g., information load) have been shown to impact the information sharing process (Wittenbaum \& Park, 2001; Wittenbaum \& Stasser, 1996).

In their review of this literature, Mohammed and Dumville (2001) note that there have been few conceptual advances beyond the original information sampling model proposed by Stasser and Titus and they also highlight the need to expand the research to intact organizational teams. Responding to this call, De Dreu (2007) applied a motivated information processing perspective (e.g., De Dreu \& Carnevale, 2003) to examine information-sharing in management 
and cross-functional teams and found that the more team members perceived cooperative outcome interdependence the more information they shared. However, they found that cooperative outcome interdependence increases information sharing only when team members engage in systematic information processing. The authors conclude that cooperation facilitates the constructive exchange of information, but deliberate and systematic information processing is needed to help team members combine and integrate this information to make better decisions and create new problem solutions.

Conclusion. Expansion of information-processing theory to the team-level has helped to elucidate the cognitive processes that underlie team learning and the conditions (e.g., individual characteristics, interventions) that shape these processes. It has also highlighted the important role of communication and information sharing in group learning (Wilson et al., 2007) and has demonstrated that group members often fail to share unique information or to systematically process the information that is exchanged within the group (De Dreu, 2007). However, the information-processing approach to understanding team learning has also been criticized on several grounds. Johnson and Hollenbeck (2007), for example, argue that the extrapolation of individual-level models to understand team-level information processing and learning fails to account for the challenges of learning at the team level. Accordingly, they suggest that, "a true team-level model of learning must incorporate not only the cognitive and affective intrapersonal factors that affect the learning process, but also the social interpersonal factors that exist at the team level" (italics in original, p. 319). Critics have also cited the use of metaphorical explanations of collective learning processes, such as dialogue, as vague and superficial (e.g., Rowe, 2008), and others have called for more attention to the dynamics that characterize the diffusion of individual knowledge to the collective (e.g., Tompkins, 1995). 
There is some evidence that research has begun to address these issues. The cognitive theory of group learning presented by Wilson and colleagues (2007) is more explicit about issues surrounding levels of analysis and time. They argue that group learning should be conceptualized and measured at the group-level of analysis and treatments of group learning need to examine changes over time so as to be able to examine important learning processes (e.g., forgetting) and to distinguish group learning from related constructs (e.g., decisionmaking). This is a step in the right direction and future work should continue to develop a multilevel, dynamic theory of information-processing in teams. Given that past research on information-processing and information sharing has focused primarily on small, ad-hoc groups performing cognitive tasks, it will also be important to expand work in this area to different types of teams situated in organizational settings. Sole and Edmondson (2002), for instance, examined how geographically dispersed, cross-functional development teams access, combine, and apply situated knowledge, or knowledge that is grounded in site-specific work practices. They found that situated knowledge plays a critical role in dispersed team learning, but the ease of accessing this information varies depending on whether the information is situated locally (i.e., at the same site as the problem) or remotely (i.e., located elsewhere). By studying teams outside of the laboratory, we can begin to identify the barriers that different types of teams face to sharing and processing information.

\section{Macrocognition}

Overview. The term macrocognition was coined by Cacciabue and Hollnagel (1995) to describe cognitive functioning in naturalistic decision-making contexts (Klein, Ross, Moon, Klein, Hoffman, \& Hollnagel, 2003) and is a concept with roots in human factors and cognitive engineering psychology. In this conception, macrocognition is contrasted with the microcognition of "standard laboratory paradigms for psychological research" (p. 81). Much like 
the distinction between naturalistic decision-making and classical decision making (Salas, Rosen, \& DiazGranados, this volume ), the primary distinctions that are emphasized are (a) naturalistic, situated cognition and decision making in field settings versus contrived cognition and decision making in the lab; (b) decision making that is complex, time pressured, with ill-defined goals, and high uncertainty versus decision making that conforms to well defined, reductionist, and rational theoretical models; (c) and the use of naturalistic observation-description and qualitative analysis versus experimentation and quantitative analysis (Klein et al., 2003). These authors frame macro and microcognition as complementary, but with distinct differences in their paradigms, methodologies, and research foci.

Klein et al. (2003) also note that macrocognition is often collaborative, in that decisions are made in team contexts, and is dynamic and emergent over time, although these themes are not explicitly developed. Given our theoretical foci, we think that macrocognition and microcognition need not be regarded as distinct paradigms or locations for research, but rather as different, but complementary, levels in a complex multilevel system of situated individual cognition and emergent team cognitive processes that underlie collaborative decision making in teams.

Macrocognitive knowledge building processes. Theorists have recently begun to hone this perspective. In particular, Fiore, Rosen, Smith-Jentsch, Salas, Letsky, and Warner (2010; see also Fiore, Smith-Jentsch, Salas, Warner, \& Letsky, in press) developed a theoretical framework, a "meta-model," for understanding team macrocognitive processes in complex collaborative decision making. What makes this macrocognitive theory useful for understanding team learning is that it focuses on knowledge building processes - the acquisition, transformation, and adaptation of knowledge in teams - and its use to solve unique, complex, and challenging problems. Another important aspect of the model is that it distinguishes learning processes and 
the knowledge that results from that process. Thus, it is consistent with our "meta" perspective. Moreover, it is conceptually consistent with our theoretical foci in that it is explicitly multilevel, dynamic, and emergent.

Fiore et al. (2010) define macrocogition as a process whereby internalized knowledge that has been acquired by individual team members is transformed through collaborative knowledge building into externalized knowledge that is shared by all team members. Their metamodel is shown in Figure 8. This transformation process is multilevel. Individual knowledge building processes (i.e., learning as a process) yield internalized knowledge held by team members. Team knowledge building processes transform that internally held knowledge into externalized team knowledge that can be applied to solving the problem. In other words, knowledge is first acquired and learned by individual team members and then, through collaboration, sharing, and externalization it is acquired and held by the team as a collective. The process is dynamic with multiple feedback loops as individual knowledge building and team knowledge building and externalization, incrementally build the knowledge capacity of the team. And, the process is emergent as individual knowledge is shared, acquired by other team members, and manifests as externalized team knowledge.

The framework also incorporates a series of problem solving phases as teams transition across knowledge construction, problem model development, team consensus, and outcome evaluation and revision (Letsky, Warner, Fiore, Rosen, \& Salas, 2007). Their conceptualization of these transitions as phases (rather than stages) is consistent with Kozlowski, Gully, Nason, et al. (1999). That is, the transitions across phases are viewed as continuous with partial overlap at transition points rather than the hard discontinuous shifts of stages. Phases describe modal activity and allow for some movement back and forth. In their model, the knowledge construction phase centers on the acquisition of relevant problem domain information by team 
members, the problem model development phase addresses the development of shared understanding, the team consensus phase is focused on achieving agreement on a solution, and the outcome evaluation and revision phase concerns validating the agreed upon solution and making adjustments as necessary.

Conclusion. Although there are not as yet direct empirical tests of the meta-model, phase model, or the derived propositions, the frameworks are intended to organize a broad-based program of multidisciplinary research on collaborative, macrocognitive team decision making (see Letsky \& Warner, 2008). In addition, there are several research thrusts that encompass, for example, communication processes (Cooke, Gorman, \& Preston, 2008), shared mental model convergence (McComb, 2008), and meaning creation (Rentsch, Delise, \& Hutchinson, 2008). More recently, Kozlowski and Chao (in press), and their research team (Kozlowski, Chao, Grand, Keeney, Braun, \& Kuljanin, 2011), have developed a macrocognitive knowledge typology that is designed to capture the key process components of the macrocognition metamodel. We will describe the measurement typology in a subsequent section on team knowledge outcomes and representations. However, the key point is that their typology is explicitly designed to capture team knowledge development as a multilevel, dynamic, and emergent phenomenon that results from macrocognitive processes. This macrocognitive framework can synthesize regulation-based learning and progressive knowledge development, it examines the dynamics and emergence of knowledge from the individual to the team level, and it can capture different forms of team knowledge emergence ranging from composition to compilation forms.

Collectively, we think this research program has great promise for building an integrated theory, a coupled research paradigm, and an aligned measurement system that can address macrocognition as a multilevel, dynamic, and emergent phenomenon; our foundation theoretical foci. One key aspect of the team knowledge building conceptualization is its emphasis on the 
process of externalization. Externalization encompasses what might be considered "typical" processes like communication and information exchange, but it also considers "artifacts" that team members create to help capture knowledge and foster shared meaning. For example, in an effort to promote understanding of a problem space, a team member might draw a map; another might notate information on the map in way that contextualizes it, and another member might use that contextualized information to infer new knowledge and create shared meaning. This sort of collaborative and iterative conceptualization of team learning and meaning creation is relatively unique to macrocognition and it brings a novel and valuable perspective to the set of learning process models we have reviewed. Overall, we think this approach is conceptually quite promising. We hope to see a stream of systematic empirical research, tools, and applications unfold in the not too distant future.

\section{Team Emergent States}

In this section, we examine the team emergent states that support the theoretical engines of team learning, development, and adaptation reviewed above. How teams regulate their actions, share and process information, and construct shared meaning is shaped by the team context or climate, in particular the motivational and affective states that emerge within the team over time. Emergent states, such as team goal orientation and team efficacy, represent compositional properties of a team that shape the processes (e.g., information sharing, experimentation) that underlie team learning. At the same time, these states emerge from the interactions and iteration dynamics inherent in team learning that then support or constrain learning processes and knowledge outcomes. An over reliance on cross-sectional designs has meant that past research has typically focused on how these states impact team learning and performance. However, there are emerging efforts to explore, both conceptually and empirically, the dynamic and cyclical relationships between team learning and the emergence of these states. 
In the sections that follow, we examine four emergent states that have received considerable attention in the team learning literature, are supported by a stream of systematic theory development, and are generating a growing body of empirical findings.

\section{Goal orientation}

Goal orientation is a construct that originated in the educational literature to explain differences in how individuals approach achievement situations (e.g., Dweck, 1986). The original theory proposed two, independent types of goal orientation: learning and performance. A learning orientation is characterized by a desire to increase one's competence by developing new skills and mastering new situations. Individuals with a learning orientation tend to pursue what researchers have called an adaptive response pattern, characterized by persistence in the face of failure, feedback seeking, the use of more complex learning strategies, and the pursuit of difficult and challenging tasks (Bell \& Kozlowski, 2002). In contrast, a performance orientation reflects a desire to demonstrate one's competence and to be positively evaluated by others (Farr, Hofmann, \& Ringenbach, 1993). Performance orientation is often associated with a maladaptive response pattern in which individuals are more likely to withdraw from tasks in the face of failure, have less interest in difficult tasks, and exhibit a tendency to seek less challenging tasks on which success is likely. Subsequent work integrated traditional conceptualizations of mastery and performance goals with classic achievement motivation theories, which differentiate between activities that are oriented toward the attainment of success (approach) and those that are directed toward the avoidance of failure. The result has been the separation of performance orientation into two distinct motivational orientations, one focused on approaching success (performance-approach orientation) and the other focused on avoiding failure (performanceavoid orientation) (e.g., Elliot \& Church, 1997; VandeWalle, 1997). 
Over the years, there has been considerable debate around whether goal orientation should be conceptualized as a trait or a state. The emerging consensus is that it is both. Individuals possess dispositional goal orientations characterized by the chronic pursuit of a particular type of goal (e.g., learning, performance-avoid) in different situations across time (DeShon \& Gillespie, 2005). However, the goals that individuals adopt during an achievement situation can also be influenced by situational factors. As Button, Mathieu, and Zajac (1996, p. 28) state, "dispositional goal orientation will predispose individuals to adopt particular response patterns across situations, but situational characteristics may cause them to adopt a different or less acute response pattern for a particular situation." Situational factors, such as goals or task framing, can induce different types of goal orientation, and these situational inducements often interact with individuals' dispositional goal orientation to influence individuals' learning processes and outcomes (Bell \& Kozlowski, 2008; Kozlowski \& Bell, 2006).

A recent meta-analysis by Payne, Youngcourt, and Beaubien (2007) provided convincing evidence of the importance of goal orientation for learning and performance. In general, learning orientation demonstrated a positive relationship and performance-avoid orientation a negative relationship with self-regulatory constructs, such as self-efficacy and learning strategies. In addition, learning orientation was positively related to learning, academic performance, and job performance, and performance-avoid orientation was negatively related to learning and task performance. The relationships between performance-approach orientation and self-regulation and learning were more mixed, but the consequences of performance-approach orientation were generally trivial.

Although goal orientation has historically been studied at the individual-level of analysis, these findings have attracted the interest of team effectiveness researchers and have sparked efforts to extend goal orientation to higher levels of analysis (Gully \& Phillips, 2005). It is 
important to note that researchers have adopted two different approaches to examining goal orientation within teams (Porter, 2007). The first approach treats goal orientation as a team composition variable. These studies measure individual team members' goal orientations, aggregate these scores to the team level, and examine how these scores relate to team processes and performance. This is a bottom-up approach that assumes that team members' goal orientations combine to create a compositional property of the team. The second approach examines goal orientation as a collective, emergent state (Porter, 2007). These studies often rely on the same measures used in the compositional studies, but shift the referent to the team level. Thus, collective goal orientation is viewed as a shared, team-level perception - a climate-like construct - that influences team process and performance. It is assumed that collective goal orientation emerges through both top-down (e.g., organizational climate) and bottom-up (e.g., interactions between team leaders and members) processes (Gully \& Phillips, 2005; Porter, 2007), although these processes have received little research attention to date. Below we briefly review the findings from studies that have examined goal orientation in teams from these two different perspectives.

One of the first studies to examine goal orientation as a team composition variable was conducted by Porter (2005), who examined the relationship between goal orientation in teams and several team processes and outcomes. The study involved four-person student teams performing a command and control simulation, and goal orientation was measured at the individual level and mean scores were used to aggregate learning and performance orientation to the team level. The results revealed that learning orientation was significantly and positively related to collective efficacy, team commitment, and backing up behavior, but did not exhibit a significant relationship with task performance. The effects of performance orientation were contingent on the team's task performance and the outcome examined. Specifically, 
performance orientation was negatively related to efficacy among teams that performed poorly, but was unrelated to efficacy among teams that performed well. However, performance orientation was positively related to commitment among teams that performed well and unrelated to commitment among those teams that performed poorly. LePine (2005) examined how team goal orientation (again using the mean of individual member scores) influenced the adaptation of 3-person student teams performing a decision-making simulation. Halfway through the experiment, a communication channel between two team members deteriorated, which necessitated that teams adapt their role structures in order to perform effectively. The results revealed that adaptation was influenced by a combination of team goal difficulty and team goal orientation. In particular, when teams had difficult goals, they were especially likely to adapt when comprised of members with high learning orientation and especially unlikely to adapt when comprised of members with high performance orientation. Supplemental analyses suggested that teams composed of members with high levels of learning orientation were more likely to adapt because they were more cooperative and more likely to engage in constructive learning activities (e.g., sharing problem information, analyzing alternative ways to approach the task) during the change.

Several studies have also examined team goal orientation as a shared, team-level perception that reflects an aspect of group climate. Bunderson and Sutcliffe (2003) examined the effects of team learning orientation on the performance of 44 business unit management teams in a Fortune 100 consumer products company. In this study, team learning orientation was measured by asking team members to assess the extent to which their team engages in various learning-related activities, such as taking risks on new ideas. The results revealed that the effect of team learning orientation on performance was inverse curvilinear, indicating that learning orientation improves performance to a point beyond which too much emphasis on learning 
begins to compromise team effectiveness. In addition, they found that the effects of learning orientation on performance were moderated by a team's past performance, such that teams with low performance benefit more from a stronger learning orientation than do teams with high performance. These findings are consistent with the notion that low performing teams should use learning activities to find new solutions, whereas high performing teams should continue to exploit those solutions that have worked in the past. DeShon et al. (2004) examined the effects of team learning and performance orientation on the regulation activities of 79 three-person student teams performing a simulated radar task. They found that team learning orientation was positively related to team goal commitment and team efficacy, and this positive effect was stronger for those teams that received team feedback (either alone or combined with individual feedback). Team performance orientation had a significant, positive relationship with team efficacy, although this relationship was weaker for those teams that received both individual and team feedback. Finally, a recent study by Porter, Webb, and Gogus (2010) examined the effects of team learning and performance orientation on the adaptive performance of teams performing a command and control simulation. The authors found that when teams had slack resources, team learning orientation led to performance improvements across the three trials, but team performance orientation only led to smaller improvements between the second and third performance trials. For those teams that did not have slack resources, team learning and performance orientations interacted to affect performance. Specifically, team learning orientation had little effect on performance improvements for those teams low in performance orientation. But, among those teams that were high on performance orientation, team learning orientation was negatively related to initial performance improvements but positively related to later performance improvements. 
Conclusion. Overall, these studies provide preliminary evidence that goal orientation has an important influence on team learning, performance, and adaptability, yet there remain a number of important questions surrounding team goal orientation. One important issue that warrants greater attention concerns the effects of goal orientation on team learning and performance over time. Several of the studies reviewed above either showed that the effects of team goal orientation vary across time (e.g., Porter et al., 2010) or mentioned time as a potential boundary condition of their findings. Bunderson and Sutcliffe (2003), for example, note that the effects of team learning orientation may be different when examined over longer time frames. High performing teams that emphasize learning may compromise some efficiency in the near term, but be better equipped to respond to market shifts and environmental challenges over the long term. In addition, future research should focus on elaborating a multilevel model of team goal orientation that includes consideration of potential cross-level effects (Gully \& Phillips, 2005). For instance, a recent study by Hirst, Van Knippenberg, and Zhou (2009) found that individual goal orientation and team learning behavior interacted to influence the individual creativity of employees in research and development teams. Team learning behavior activated the creative tendencies of those dispositionally inclined to learn, which led to higher levels of employee creativity. However, similar to the findings of Bunderson and Sutcliffe (2003), they found that learning orientation has diminishing returns for individual creativity above a certain point. Future research should also explore the contingencies that influence the effects of learning and performance orientation. The studies reviewed above suggest that team feedback, goal difficulty, prior performance, and resources all have the potential to shape the effects of team goal orientation on team learning, performance, and adaptation. These and other potential moderators need to be integrated into a systematic theory that can be subjected to targeted research designed to provide insight into the factors that serve as contingencies of the team goal 
orientation - team learning relationship. Finally, future research needs to further examine the implications of conceptualzing team goal orientation as a compositional variable versus as a shared, emergent state and should also consider the potential interactive effects of these two types of team goal orientation on learning and performance.

\section{Psychological Safety}

Because much of the early research on team learning was conducted in the laboratory, very little attention was focused on understanding how learning processes in teams are affected by managerial and contextual factors (Edmondson et al., 2007). However, as studies sought to extend these laboratory findings to real workgroups in field settings, researchers began to investigate the role of leader behavior and group climate in shaping team learning. One of the constructs to emerge from this work was team psychological safety, which is defined as "a shared belief that the team is safe for interpersonal risk taking" (Edmondson, 1999, p. 354). Psychological safety creates a supportive interpersonal climate that enables team members to engage in critical learning behaviors, such as raising concerns, experimenting, sharing information, and revealing mistakes. Cannon and Edmondson (2001), for example, argue that two capabilities increase the chances that teams will learn from failure: members must be able and willing to take risks and they must be able to confront failure directly rather than covering it up. Similarly, Burke, Salas, Wilson-Donnelly, \& Priest (2004, p. i101) state, "The ability to speak up in a non-threatening and respectful manner (deference to expertise) is a hallmark of learning organizations and the teams within them."

The importance of psychological safety in shaping team learning was first discussed by Edmondson (1996) in a study where she examined group-level factors that affect drug error rates in hospital units. Contrary to expectations, quantitative survey data revealed that unit error rates were positively associated with nurse manager direction setting and coaching, members' 
perceptions of unit performance, and the quality of interpersonal relationships in the unit.

Edmondson proposed that these unexpected results may be due to the fact that better teams created a climate of openness that facilitates the discussion of error, which would increase reported error rates. Qualitative interview and observational data provided support for this hypothesis and suggested that nurse manager behaviors may be particularly important for creating a team climate in which members can openly discuss and learn from their own and others mistakes.

In a subsequent study designed to further explore these findings, Edmondson (1999) used quantitative and qualitative data gathered from 51 work teams in a manufacturing company to test a model of team learning. This study formally introduced the construct of team psychological safety and positioned it as a key mediator of the relationship between structural team inputs and team learning behaviors. The results revealed that both context support (i.e., adequate resources, information, and rewards) and team leader coaching influenced psychological safety, which in turn was associated with learning behaviors indicative of a team learning process. In addition, these learning behaviors mediated the relationship between team psychological safety and team performance.

The fact that these early studies pointed to leaders as having a critical influence on team learning led to research aimed at further exploring leader actions that promote and inhibit team psychological safety. Edmondson, Bohmer, and Pisano (2001), for example, studied 16 hospitals implementing a new technology for cardiac surgery. Although senior management support was not associated with implementation success, they found that team leaders (i.e., surgeons) played a critical role in facilitating a successful team learning process. In particular, effective team leaders encouraged speaking up by reducing power differences in the team and motivated effort by framing the technology as a team innovation project and conveying the benefits of the new 
technology for patients (see also Edmondson, 2003). In another study, Nembhard and Edmondson (2006) examined the effects of leader inclusiveness, or the extent to which leaders invite and appreciate others' contributions, on psychological safety in neonatal intensive care units. The results revealed that team members perceived higher levels of psychological safety when physician leaders were seen as more inclusive and welcoming of others' ideas. In addition, higher status medical professionals (e.g., physicians) perceived greater psychological safety than lower status professionals (e.g., nurses and respiratory therapists). However, leader inclusiveness moderated the effects of professional status on psychological safety, such that the disparity in psychological safety between high and low status professionals was greater when leader inclusiveness was low. Finally, the authors found that psychological safety mediated the relationship between leader inclusiveness and team engagement in quality improvement work.

Conclusion. Together these studies have solidified the importance of members' perceptions of psychological safety for team learning and performance and have also demonstrated the important role of leaders in shaping these perceptions. As work in this area continues, one issue worth examining concerns the importance of psychology safety for learning across different types of teams. Edmondson (2003), for example, suggested that psychological safety may be particularly important for learning and performance in interdisciplinary action teams (e.g., surgical teams), because the expertise and power differences inherent in such teams have the potential to undermine the coordination that is essential to team success. In addition, researchers have proposed that team trust, which is related to but distinct from psychological safety, may be particularly important for learning and performance in geographically dispersed teams (e.g., Cohen \& Gibson, 2003; Kirkman, Rosen, Tesluk, \& Gibson, 2006). However, in a study that examined collective learning across five different types of teams (e.g., production teams, middle management teams), Edmondson (2002) concluded that team type was not 
associated with team learning patterns and that members' interpersonal perceptions were uniformly an important predictor of learning and change across the different types of teams. Thus, more research is needed to determine whether the effects of psychological safety on team learning are dependent on the team and task context (Edmondson et al., 2007). Future research also needs to devote greater attention to understanding the temporal dynamics that surround the development of psychological safety in teams. Edmondson (1999), for example, proposed a selfperpetuating cycle in which perceptions of psychological safety make team members more willing to report and discuss errors in the future, which in turn should reinforce the belief that mistakes will not be held against them. However, the cross-sectional design of the study did not allow for a formal test of this feedback loop. Edmondson and colleagues (2001) used qualitative techniques to examine how activities at different stages of the implementation process contributed to the development of psychological safety, but research has not yet conducted an empirical test of their conclusions. Future research that uses quantitative data to examine psychological safety over time has the potential to contribute valuable insight into the dynamics that surround the emergence of psychological safety perceptions as well the critical antecedents and consequences of these perceptions at different stages of a team's lifecycle.

\section{Team Efficacy}

Self efficacy refers to an individual's belief in his or her capability to perform a specific task (Bandura, 1977; Gist, 1987). It represents a comprehensive judgment of beliefs in one's capability to mobilize the motivation, cognitive resources, and actions needed to achieve a particular level of performance in goal accomplishment (Bandura, 1997). Self efficacy is important because it leads to upward goal revision after initial goal levels are accomplished (Phillips, Hollenbeck, \& Ilgen, 1996), it boosts persistence in the face of difficulties and challenges, and it fosters adaptation to increasing task complexity (Kozlowski, Gully, Brown, et 
al., 2001). Meta-analytic findings have shown that self efficacy is a strong predictor of individual task performance across a variety of domains (Stajkovic \& Luthans, 1998). Given these important findings for self efficacy at the individual level of analysis, parallel concepts of team efficacy (sometimes referred to as collective efficacy) and group potency have been proposed.

Team efficacy refers to a team's belief that it can successfully perform a specific task (Lindsley, Brass, \& Thomas, 1995). Self and team efficacy are distinct in their unit of focus (Gully, Incalcaterra, Joshi, \& Beaubien, 2002). However, team efficacy is not simply an aggregate of self efficacy across team members; rather, it represents a team-level property that is shared, consensual, and held in common across group members and it may be different than individuals' own self-perceptions of competence (Kozlowski \& Ilgen, 2006). Bandura (1997) proposed that, similar to self efficacy, team efficacy influences what a team chooses to do, how much effort is devoted to the activity, and the persistence of the team in the face of failure. Group potency has been defined as a generalized collective belief that the group can be effective (Shea \& Guzzo, 1987). Most researchers acknowledge that team efficacy and group potency are similar constructs. However, whereas team efficacy is task specific, group potency represents a shared belief about the general effectiveness of the group across multiple tasks and contexts. A meta-analysis by Gully et al. (2002) found that both team efficacy and group potency had a positive relationship with team performance and that effect sizes were comparable across the two constructs. In addition, the relationship of team efficacy with team performance was stronger when it was appropriately examined at the team level rather than the individual level of analysis. Moreover, team interdependence moderated the team efficacy-performance relationship, such that team efficacy was a more important contributor to team performance when interdependence 
was high than low. The relationship between group potency and performance, however, was not moderated by team interdependence.

Although most of the research on team efficacy has focused on its relationship with team performance, researchers have recently begun to explore the role of team efficacy as a potential enabler of team learning. Edmondson (1999) suggested that team members may only be motivated to reveal errors and speak up when they believe the team is capable of using this new information to generate useful results. In addition, it has been argued that team efficacy should influence a team's ability to regulate team processes and share and process information (DeShon et al., 2004; Gully et al., 2002; Van den Bossche, Gijselaers, Segers, \& Kirschner, 2006). Yet, empirical research examining the relationship between team efficacy and team learning has failed to yield a clear pattern of results. Edmondson (1999), for example, found some support for a positive relationship between team efficacy and team learning behavior, but the significance of this relationship depended on the measure of team learning behavior (self-reported vs. observer-assessed) and the other antecedents included in the model (e.g., psychological safety). In addition, she failed to find evidence that team efficacy mediates the effects of context support and leader behavior on team learning. Van den Bossche et al. (2006) found that group potency was significantly and positively related to the learning behaviors of 75 student project teams. However, these results need to be interpreted cautiously since both group potency and team learning behaviors were assessed through self-report measures collected on a single survey administered at the end of the course. In a study examining student learning groups in a college software class, Hsu, Chen, Chiu, and Ju (2007) found that task-specific computer collective efficacy (assessed through a consensus measure) had a significant and positive effect on the teams' software learning performance, after controlling for prior team performance and general computer collective efficacy. In contrast to the studies reviewed above, however, the authors did 
not examine team learning behaviors and it is, therefore, unclear whether the effect of collective efficacy on team performance was due to differences in learning behavior or other team processes.

Researchers have also examined the relationship between team-efficacy and emergent outcomes of team learning, such as shared mental models, again with somewhat mixed results. Peterson, Mitchell, Thompson, and Burr (2000) examined collective efficacy and shared mental models among 26 college student groups. The results revealed that collective efficacy measured early in the semester was positively related to shared mental models later in the semester, but the extent to which mental models were shared among members early in the semester did not predict collective efficacy later in the semester. Mathieu, Rapp, Maynard, and Mangos (2010) suggest that shared mental models may not have predicted collective efficacy in the Peterson et al. (2000) study because the students had no history of working together and many were unfamiliar with the task they performed. Thus, the student teams may not have had enough opportunity for shared mental models to develop early in the semester. Indeed, using a sample of 43 Navy airtraffic control teams, who on average had worked together for over six years, Mathieu et al. (2010) showed that shared task mental models significantly predicted collective efficacy and that collective efficacy mediated the relationship between shared task mental models and team effectiveness. It is important to note, however, that shared team mental models were unrelated to collective efficacy.

Conclusion. The research reviewed above provides some preliminary evidence that team efficacy may represent an important enabling condition for team learning. Yet, the mixed findings of these studies also highlight the need for more work in this area. Emerging research suggests that there are both similarities and dissimilarities in the antecedents and outcomes of efficacy beliefs across different levels of analysis. Goal orientation, past performance, and 
achievement motivation/team drive, for example, have been shown to predict efficacy at both the individual and team levels (Chen et al., 2002; Chen et al., 2009; DeShon et al., 2004). Yet, Chen et al. (2002) also found that experience positively predicted self efficacy, but team expertise did not relate to team efficacy. Thus, although the findings of individual-level research on the efficacy-learning relationship may serve as a valuable guide for research in this area, we need to be careful about generalizing these findings to the team level. For example, feedback has been identified as having an important influence on efficacy and learning at both the individual- and team-levels of analysis (e.g., DeShon et al., 2004; London \& Sessa, 2006). However, different types of feedback (e.g., public vs. private, team vs. individual) may have different effects on efficacy and learning at the individual and team level (c.f., Deshon et al., 2004). Another important direction for future research is to examine team efficacy-team learning relations over time. Not only is longitudinal research important for establishing causal relationships between team efficacy and team learning, but it can also provide insight into reciprocal relationships that may exist between team efficacy and emergent team learning outcomes, such as shared mental models and collective knowledge.

\section{Cohesion and Conflict}

Research on team cohesion dates to the early work of Festinger (1950), who defined cohesiveness as, "the resultant of all the forces acting on the members to remain in the group" (p. 274). Festinger also suggested that there are three facets that comprise cohesion - member attraction (i.e., interpersonal attraction), group activities (i.e., task commitment), and prestige or group pride. Research findings have provided support for this multidimensional view of cohesion and have demonstrated the importance of cohesion for team effectiveness. A metaanalysis by Beal, Cohen, Burk, and McLendon (2003) found that all three dimensions of cohesion significantly related to group performance and the effect sizes for the different 
dimensions were not significantly different from each other. In addition, cohesion was more strongly related to performance behaviors than performance outcomes and was more strongly related to measures of performance efficiency than measures of performance effectiveness. Moreover, the cohesion-performance relationship became stronger as team workflow (i.e., interdependence) increased. Another recent meta-analysis by Chiocchio and Essiembre (2009) provides some preliminary evidence that cohesion-performance relationships may vary across different types of teams (e.g., project vs. product teams) and team settings (e.g., organizational vs. academic). However, more research is needed to tease apart the effects of team type and team setting on the relationship between different types of cohesion and team performance.

Whereas cohesion has generally been found to enhance team performance, research has offered somewhat mixed perspectives on the effects of conflict on team effectiveness. On the one hand, it has been argued that conflict and divisiveness have the potential to undermine teammember satisfaction, interfere with team information processing, and hinder team performance (e.g., Carnevale \& Probst, 1998; Lau \& Murnighan, 1998). On the other hand, some research suggests that moderate levels of conflict that is focused on the task (rather than interpersonal relationships) may be functional in that it leads to different perspectives and ideas that can help teams avoid groupthink and enhance their performance, particularly on nonroutine and creative tasks (Amason, 1996; Jehn, 1995). However, a recent meta-analysis by De Dreu and Weingart (2003) showed that both task and relationship conflict are negatively associated with team member satisfaction and team performance. In addition, they found that the negative relationship between conflict and team performance was stronger for teams performing complex, uncertain, rather than simple and routine, tasks. Kozlowski and Ilgen (2006) note that due to several unresolved issues, such as the causal ambiguity in the conflict-performance relationship, more work is needed to better specify the effects of conflict on team performance. 
Although much of the research on cohesion and conflict has examined their effects on team performance, emerging work has begun to explore the implications of these emergent states for learning in teams. Interest in these constructs has been driven, in part, by their potential to facilitate or inhibit critical team learning processes, such as collaboration and communication (Ellis \& Bell, 2005). Wong (2004) argued that stronger group cohesion should foster team learning "by increasing the motivation, trust, and cognitive familiarity for productive inquiry" (p. 647). In addition, researchers have posited that cohesion and conflict may be critical to deciphering the effects of diversity on team learning. It has been argued that teams whose members are heterogeneous with regard to background and perspective have the potential to pool their diverse knowledge and viewpoints, thereby facilitating team learning (Argote, Gruenfeld, \& Naquin, 2001). However, to realize this potential, diverse teams must overcome the disruptive effects of their differences (Mannix \& Neale, 2005). In particular, diversity can create social divisions that result in poor social integration and cohesion and lead to higher levels of conflict in teams (Roberson, Bell, \& Porter, 2008). Thus, diversity may lead to greater team learning, but only if teams are able to build a collective identity and effectively manage conflict when it occurs (Van der Vegt \& Bunderson, 2005).

Several articles provide evidence that cohesion is an important supporting condition for team learning. Wong (2004) examined both local team learning (i.e., learning within the group) and distal team learning (i.e., learning with individuals external to the group) among 78 teams drawn from four different organizations. Her results revealed a positive, linear relationship between group cohesion and distal learning. However, there was an inverted U-shaped relationship between group cohesion and local learning, suggesting that very high levels of social integration diminished learning among team members. These results contradict the popular belief that high levels of group cohesion may insulate a group from external ideas, and suggest 
that excessive levels of trust and cognitive familiarity may undermine important team learning processes (e.g., knowledge exchange, exploring new ideas). Van der Vegt and Bunderson (2005) examined the relationship of expertise diversity with team learning and team performance in multidisciplinary teams in the oil and gas industry. They found that these relationships were moderated by collective team identification, such that expertise diversity was negatively related to team learning and performance when collective identification was low, but these relationships were positive when collective team identification was high. These results suggest that diversity can be positively related to team learning, but only when members identify with their teams. It is important to note, however, that even under conditions of high collective interdependence, moderate levels of expertise diversity stimulated greater team learning than very high levels of diversity (i.e., inverted curvilinear relationship). Finally, a study by Kane, Argote, and Levine (2005) examined the effects of social identity on knowledge transfer across groups. The authors found that when a new member rotated into a group, the group was more likely to adopt his or her knowledge when the routine of the new member was superior to their own and both shared a superordinate identity (i.e., viewed themselves as part of a larger, shared group). When groups did not share a superordinate identity with the rotating member, they rarely adopted his or her routine, even when it represented superior knowledge.

Although a number of studies have examined the relationship between diversity and team learning processes and outcomes (e.g., Gibson \& Vermeulen, 2003; Drach-Zahavy \& Somech, 2001; Somech \& Drach-Zahavy, 2007; van Offenbeek, 2001), very few studies have directly explored the relationship between conflict and team learning. One exception is a study by Rau (2005), which examined relationship conflict as a moderator of the relationship between transactive memory and the performance of top management teams. The results revealed that the shared awareness of the location of expertise in the team was positively related to team 
performance when relationship conflict was low but unrelated to performance under high levels of relationship conflict. These results suggest that high levels of relationship conflict may prevent members from leveraging the expertise distributed throughout the team.

In a related stream of research, several studies have examined the effects of cooperation on team learning. Tjosvold, Yu, and Hui (2004), for example, examined the effects of different types of goals on the learning behaviors of teams drawn from a variety of Chinese organizations. They found evidence that cooperative goals are positively related to group problem solving and learning from mistakes, whereas competitive and independent goals are positively related to blaming within groups. It should be noted that the effects of blaming on reported team learning were mixed, with correlational analyses revealing a non-significant relationship but structural equation analyses suggesting a significant, positive relationship between blaming and learning from mistakes. As noted earlier, De Dreu (2007) found that team members' perceptions of cooperative outcome interdependence were positively related to information sharing, team learning, and team effectiveness. However, cooperative outcome interdependence was only related to these outcomes when task reflexivity was high, suggesting that learning requires teams to not only cooperate but also engage in the systematic processing of information. These results may help explain why, in the study by Wong (2004) discussed above, the teams with very high levels of cohesion (which may prevent critical analysis of information) failed to engage in mutual learning. Finally, Ellis et al. (2003) found that teams with higher levels of average agreeableness evidenced lower levels of team learning. Mirroring the arguments of De Dreu (2007), they conclude that high levels of agreeableness may lead to cohesion but also prevent a team from critically evaluating different opinions or conflicting pieces of information.

Conclusion. In summary, these studies suggest a complex relationship between cohesion, conflict, and team learning. The studies reviewed above generally suggest that cohesion 
enhances team learning processes and outcomes. At the same time, there is evidence that learning may be impeded when teams are characterized by excessive social integration or when cohesion is not supplemented with processes that facilitate the critical processing of information (e.g., team reflexivity, constructive conflict). These findings suggest that future research should focus on how to effectively manage cohesion and conflict toward promoting team learning (Kozlowski \& Ilgen, 2006). London, Polzer, and Omoregie (2005) present a model of group learning that suggests that team members engage in identity negotiation behaviors (e.g., sharing information about themselves), which influence interpersonal congruence (i.e., group members seeing themselves similarly) and ultimately group learning. They argue that interventions organized by the team leader or facilitator, such as multisource feedback, can strengthen the relationship between identity negotiation and interpersonal congruence. Gibson and Vermeulen (2003) empirically demonstrated that the presence of moderately strong subgroups stimulated team learning behavior, whereas very weak or very strong subgroups inhibited team learning behavior. In addition, they found that the effects of organizational design features, such as performance management by an external team leader, had different effects on team learning behavior depending on the strength of subgroups within the team. These findings suggest that different strategies may be needed to promote team learning depending on where a team falls on the continuum between being highly cohesive and highly fractured. A study by Zellmer-Bruhn and Gibson (2006) extends these findings by showing that team learning is shaped by not only these micro contextual features (e.g., team leadership) but also macro aspects of the context. Based on data collected from teams in the subsidiaries of several multinational organizations, they found that organizational contexts emphasizing global integration hindered team learning, whereas those emphasizing responsiveness and knowledge management increased team learning. These findings suggest that macro contextual features, such as strategy, culture, and resources, 
may play a role in promoting or inhibiting a supportive context for team learning. Overall, future work needs to explore how these micro and macro elements can be used to shape cohesion and conflict so to create a supportive environment for team learning.

\section{Team Learning Outcomes: Team Knowledge and Team Performance}

In this section, we review research that has examined the outcomes of team learning, with particular emphasis on the cognitive and knowledge-based outcomes that represent the most salient manifestations of learning as a psychological process. These outcomes include collective knowledge, shared cognition (transactive memory, team mental models), and macrocognition and team knowledge emergence. In addition, we discuss the findings of research that has examined the relationship between team learning and team performance. Prior research has tended to either focus on the process of team learning (e.g., team learning behaviors) or the outcomes of team learning, with few studies having integrated these two foci to examine the linkages between indicators of team learning processes and team learning outcomes. Our goal is to review the outcome representations of team learning and to conceptually explore their linkages to the processes and emergent states reviewed above.

\section{Collective Knowledge}

Cognitive theories of team learning generally argue that the sharing or exchange of information within a team should lead to a change in the collective knowledge of the group (Ellis \& Bell, 2005; Wilson et al., 2007). New knowledge, behaviors, or routines become distributed among the members of the group and are stored either in the memories of members or in different types of technological (e.g., databases) or structural repositories (e.g., rules and procedures). Accordingly, a number of researchers have defined team learning as a change in a team's collective level of knowledge and skills (e.g., Ellis et al., 2003), which expands on traditional conceptualizations of learning at the individual level. 
Although conceptually changes in collective knowledge represent a direct indication that team learning has taken place, very little empirical research has examined collective knowledge as an outcome of team learning. As Kozlowski and Ilgen (2006) note, past research has often not directly measured team learning and instead has inferred it from changes in team performance. Thus, few studies on team learning directly assess changes in collective knowledge. For example, Argote, Insko, Yovetich, and Romero (1995) conducted a laboratory study to examine the effects of turnover and task complexity on group performance. Three-person groups were asked to perform a production-task over six trials and the results revealed that group performance followed a learning curve trajectory, such that output improved significantly over time and this increase occurred at a decreasing rate. In addition, they found that groups not experiencing turnover outperformed those groups experiencing turnover and that the gap in performance was amplified over time and was greater for the simple than the complex task. Based on these findings, the authors suggest that turnover depletes the collective knowledge of a group, which undermines performance. In addition, they argue that turnover had less of an effect on groups performing the complex tasks because these groups produced innovations that made some of the knowledge of experienced members obsolete. Individual training of new team members failed to mitigate the effects of turnover, which they argue suggests that the knowledge members developed of their group's structure, culture, and work procedures (i.e., social knowledge) was more important for performance than task-specific knowledge. However, since the knowledge of group members was never measured, it is impossible to know whether the effects of turnover were due to changes in collective knowledge. It may be that turnover impacted team performance via mechanisms other than learning, such as by undermining coordination or communication processes (Kozlowski \& Bell, 2008). 
More recent theoretical and empirical work has attempted to focus more direct attention on collective knowledge and its antecedents and consequences. Zellmer-Bruhn (2003) examined the effects of interruptions on team knowledge acquisition. Using data from 46 operational teams in the pharmaceutical and medical products industry, the author found that teams that experienced more interruptive events (e.g., loss of a member, changes in machines, tools, or other technology) acquired more knowledge in the form of new routines. In addition, the results revealed that the effects of interruptions on team knowledge acquisition could be partially explained by the fact that interruptions led the teams to devote more effort to knowledge transfer activities, such as searching for new practices. Finally, exploratory analyses suggested that different types of interruptions may have differential effects on knowledge transfer effort and acquisition. For instance, changes in team structure positively affected team knowledge acquisition, whereas unusually disruptive events had a negative effect on knowledge acquisition. Griffith, Sawyer, and Neale (2003) proposed that team context, in particular a team's level of virtualness, may also influence collective knowledge, which they defined as tacit team knowledge. Because interpersonal interaction is critical to the development of tacit knowledge, they argue that highly virtual teams may have difficulty forming collective knowledge unless they are able to use media or other means to engage in rich communication. In addition, they suggest that the collective knowledge generated by virtual teams is more likely to be captured and made accessible through technology tools than the collective knowledge generated by less virtual teams, which is likely to remain more tacit. Unfortunately, very little research has examined the storage of knowledge in teams and more work is needed to understand the most effective means for different types of teams to store different types of knowledge (Wilson et al., 2007). As noted earlier, research on macrocognition has begun to explore this issue by exploring 
the concept of externalized knowledge that may be captured by the team in artifacts that they create (Fiore et al., 2010).

Some recent work has also started to explore the consequences of membership changes for a team's collective knowledge and the subsequent implications for team performance. Although it has been argued that new members can be beneficial for a team because they increase the group's knowledge stock, research also suggests that there are a number of factors that determine whether groups incorporate and leverage the knowledge of new members. Kane et al. (2005) conducted a laboratory study in which three-person groups performed a production task (constructing origami sailboats). Midway through the task a member from a different group rotated into each group. As noted earlier, they found that groups were more likely to adopt the routine of the rotating member when both shared a superordinate identity (i.e., they viewed themselves as part of a larger, shared group) and when the rotating member possessed a superior routine (i.e., a more efficient production routine than the one currently used by the group). In addition, they found that groups that shared a superordinate identity with the new member were likely to adopt a superior routine and reap the performance benefits, whereas groups that did not share a superordinate identity with the new member rarely adopted the superior routine and did not improve their performance. A recent laboratory study by Lewis, Belliveau, Herndon, and Keller (2007) further illustrates the challenges that teams face in leveraging the knowledge of new members. Three-person groups were trained to perform a telephone assembly task and then brought back one week later for a performance session. In the performance session, groups were assigned to one of three membership change conditions which left the original group either fully intact, partially intact (two members from the original group and one new member), or reconstituted (three members, each trained with a different group). They found that transactive memory system structure stability was greater in partially-intact groups than in the reconstituted 
groups. In other words, groups with partial membership changes were more likely to rely on the TMS structure developed by oldtimers, and newcomers were more likely to adapt to the existing structure. They also found evidence that this pattern was detrimental to performance because it created inefficient TMS processes in partially-intact groups relative to intact groups. In a supplemental study, they found that asking oldtimers to deliberately reflect on their collective knowledge (i.e., the breadth and depth of their own and other oldtimer's knowledge) made them more likely to adjust their specializations when new members were added. This led to a more elaborated TMS structure, improved TMS process efficiency, and generated higher levels of performance. It is important to note that the intervention did not change the overall structure of the group's expertise. Rather, the results suggest that forcing existing team members to evaluate their collective knowledge in the wake of a membership change allows for greater flexibility in integrating newcomer's expertise into the TMS structure.

Conclusion. Although recent work has begun to focus more attention on collective knowledge as an important outcome of team learning, there remain several unaddressed issues. One important issue concerns the implications of using different methods to aggregate individual knowledge to create a team-level construct. One approach has been to operationalize collective knowledge as either the sum or average of individual team members' knowledge. Ellis et al. (2003), for instance, assessed the collective knowledge of teams in their study by summing the efficiency and effectiveness with which individual team members engaged unknown tracks. Teams that performed better on this measure could be inferred as having shared more information with one another about the unknown tracks. However, recent research suggests that in some cases the average level of knowledge in a team may be less important than how that knowledge is distributed within a team. That is, the effects of collective knowledge may sometimes depend on exactly who knows what. Ellis, Bell, Ployhart, Hollenbeck, and Ilgen 
(2005) found that the knowledge of critical team members, or those who were central to the workflow of the team, had a greater impact on team performance than the knowledge of less critical team members. The uniqueness of team members' knowledge may also be important as this determines how much of the knowledge space is covered by the collective knowledge of the team (Hinsz, 1990). We address these distributional properties of collective knowledge in more detail below when we discuss shared mental models and transactive memory systems. However, given that collective knowledge is often considered in conjunction with these structural elements of team knowledge (e.g., Lewis et al., 2007), it raises the question as to whether collective knowledge represents a meaningful outcome of team learning in its own right. A second important issue concerns the effects of different types of collective knowledge on team performance. Reagans, Argote, \& Brooks (2005) found that surgical teams that had more relationship-specific knowledge (operationalized as the average amount of experience that team members had working with each other) took less time to complete their procedures. However, cumulative individual knowledge (operationalized as the average number of times each member of a team had performed a procedure) had a curvilinear relationship with completion times. Initial increases in individual experience hampered team performance, but continued increases in individual experience eventually reduced procedure completion time. These results suggest that the effects of collective knowledge on team performance may depend on how collective knowledge is conceptualized and operationalized. A final issue concerning collective knowledge is that it has been studied almost exclusively in the laboratory using small groups performing production tasks. More studies similar to the one conducted by Zellmer-Bruhn (2003) are needed that use field study methods to examine knowledge acquisition among real teams performing different types of tasks. 


\section{Team Mental Models}

Team mental models represent team members' shared, organized understanding and mental representation of knowledge or beliefs about key elements within a team's relevant environment (Klimoski \& Mohammed, 1994). They are shared, compositional, emergent characteristics that derive from the cognition of individual team members but manifest at the collective level (Kozlowski \& Chao, 2011; Kozlowski \& Klein, 2000; Marks et al., 2001). Cannon-Bowers et al. (1993) originally proposed four nonindependent content domains of team mental models. These domains include: (a) knowledge of the equipment or tools used by the team (equipment model); (b) understanding of the team's task, including its goals or performance requirements and the problems facing the team (task model); (c) awareness of team member characteristics, including their knowledge, skills, preferences, and habits (team or member model); and (d) team members' knowledge or beliefs regarding appropriate or effective team processes (teamwork or team interaction model). Team mental models can be distinguished from other forms of team cognition by their incorporation of a broader array of cognitive content (e.g., taskwork and teamwork) and their focus on the structure of the content (Mohammed et al., 2010).

The formation of shared team mental models is typically viewed as an important indicator of team development. Interest in team mental models grew out of research suggesting that teams whose members share models of both taskwork and teamwork will be better equipped to implicitly coordinate their behavior and improve their performance (Cannon-Bowers et al., 1993). Although much of the early work on team mental models was conceptual, Mohammed et al. (2010) note in their recent review that there has been a proliferation of empirical studies on the construct conducted over the past 15 years. Much of this research has examined the relationship between team mental model sharedness/convergence and team performance. For 
instance, Mathieu, Heffner, Goodwin, Salas, and Cannon-Bowers (2000) examined the effects of shared mental models on team processes and performance among 56 dyads performing a flight simulation. They found that team mental model convergence had a significant and positive effect on team performance and this effect was fully mediated by team processes (e.g., strategy formation, coordination, cooperation, and communication). However, they found that task mental model convergence did not significantly affect team performance, although it did have a positive influence on team processes suggesting an indirect effect. In another study, Waller, Gupta, and Giambatista (2004) examined shared mental model development among 14 nuclear power plant control room crews performing simulations. They found that when crews were faced with nonroutine situations, high-performing crews were more likely to act to develop a shared understanding of the situation or response than lower-performing crews. However, during monitoring or routine situations, there was no significant difference in the mental modeling activities of high and low performing crews. These results suggest that the ability to formulate shared understanding in abnormal, high workload situations may represent a key differentiator of high and low performing crews. Smith-Jentsch, Mathieu, and Kraiger (2005) examined the relationship between two types of shared mental models - team interaction model and task model - and team effectiveness in an air traffic control environment. Although neither type of mental model demonstrated a linear relationship with tower safety or efficiency, the two shared mental models interacted to predict effectiveness. In particular, tower safety and efficiency were highest when the air traffic controllers exhibited consistent team interaction and task shared mental models. It is interesting to note, however, that this interactive pattern was not found when the shared mental models were indexed in terms of agreement rather than consistency. Although most studies in this area have focused on the effects of team mental model sharedness or convergence, a growing number of studies have examined the effects of 
team mental model accuracy. The basic argument underlying this stream of research is that team mental models must be not only shared but also accurate if they are to have beneficial effects on team processes and performance. However, Mohammed et al. (2010) note that research on the effects of accuracy have yielded inconsistent findings, with some studies finding team mental model accuracy to be a stronger predictor of team performance than similarity (e.g., Edwards et al., 2006) and others failing to find a significant relationship between accuracy and performance (e.g., Mathieu, Heffner, Goodwin, Cannon-Bowers, \& Salas, 2005). One of the big challenges with the issue of accuracy is that one needs to have a indisputable mental model structure as the target criterion; outside of laboratory tasks (and they are problematic too!), this criterion is difficult to establish with certainty.

Recent qualitative (e.g., Mohammed et al., 2010) and quantitative (e.g., DeChurch \& Mesmer-Magnus, 2010b) reviews have concluded that the research in this area has firmly established positive relationship between team mental models and team processes and performance. DeChurch and Mesmer-Magnus (2010b) recently conducted a meta-analysis to examine the relationship between team cognition and team performance and the overall findings revealed that team cognition has a strong positive relationship with team behavioral processes, motivational states, and performance. Based on these findings, the authors conclude that "there is clearly a cognitive foundation to teamwork" (p. 44). However, they also note that the effects of team cognition varied based on three classes of moderators: cognitive underpinnings, task features, and study characteristics. For instance, they found that the effects of cognition on behavioral processes and team performance were stronger when emergence is represented through compilation (consistent with the transactive memory tradition) than composition (consistent with the shared mental model tradition). They suggest that the patterned knowledge that emerges through compilation offers greater predictive power because it is non-isomorphic to 
the individual-level cognitive content. In addition, they found that the effects of cognition depend on the type of tasks teams perform. Compositional cognition, for example, was more predictive of team process in action teams than in decision-making teams, and was more predictive of performance in project and decision-making teams than in action teams. In sum, the meta-analysis further demonstrates that although the effects of team cognition are generally positive, the magnitude of the effect often depends on the type of cognition being examined as well as the nature of the team, the tasks being performed, and the outcomes under investigation.

Having shown that team mental models predict process and performance, there is an emerging body of work that aims to understand the factors that influence the development of team mental models. The shared and complimentary cognitions that form the basis of these models emerge from the exchange of information, ideas, knowledge, and insights within a team over time (Kozlowski \& Bell, 2008). This exchange may occur through a variety of mechanisms, including informal and social interaction, shared task experiences, and formal interventions. Pearsall, Ellis, and Bell (2010) recently showed that the number of role identification behaviors (e.g., sharing or requesting information about roles) exhibited by a team during the early stages of their development was positively related to the development of teaminteraction mental models. Similarly, Levesque, Wilson, and Wholey (2001) found that as role differentiation increased in software development teams, there was a decline in shared mental models. They argue that as members' roles became increasingly specialized, there was a corresponding decrease in interaction in the group that led to a divergence in mental models over time.

Mohammed et al. (2010) suggest that the drivers of team mental models can be organized into three broad categories. The first category is team member characteristics and includes variables such as age, gender, and tenure. For example, Smith-Jentsch, Campbell, Milanovich, 
and Reynolds (2001) examined the similarity among the teamwork mental models of 176 Navy personnel. They found that there was greater similarity among high ranking (vs. low ranking) groups and among those groups that had high time in service (vs. low time in service). These results are consistent with the notion that mental models will become more similar and accurate as individuals gain experience. The second category of antecedents is team interventions, such as planning, reflexivity, and training. Gurtner, Tschan, Semmer, and Nägele (2007), for example, examined the effect of guided reflection on the similarity of team interaction models. Three-person teams were asked to perform a military simulation and were assigned to either a control condition or one of two reflexivity conditions (individual or group). Participants in the reflexivity conditions were instructed to engage in guided reflection on teamwork and the task. They found that the team interaction mental models were more similar in the individual and group reflexivity conditions than in the control conditions and that there was no significant difference between the two reflexivity conditions. A number of studies have found that various types of training, such as team self-correction and cross-training, can also increase team mental model similarity or accuracy (Cannon-Bowers, 2007; Marks, Sabella, Burke, \& Zaccaro, 2002; Smith-Jentsch, Cannon-Bowers, Tannenbaum, \& Salas, 2008). Moreover, Kozlowski and Ilgen (2006) suggest that leaders can play a central role in shaping the formation of team mental models. The final category mentioned by Mohammed et al. (2010) focuses on contextual factors that can influence team mental models, including stress, workload, and the novelty of the environment. Ellis (2006), for example, found that acute stress had a negative effect on both the accuracy and similarity of team interaction mental models. In addition, he found that team interaction mental models partially mediated the negative relationship between acute stress and team performance. 
Conclusion. Although the research on team mental models has matured more rapidly than in other areas of team cognition (Kozlowski \& Bell, 2003), there remain a number of issues to address moving forward. One issue that has always plagued this literature concerns the measurement of team mental models (e.g., Mohammed, Klimoski, \& Rentsch, 2000). As Mohammed et al. (2010) note, "Because of their context-dependent nature, there is no consistent methodology that has been used to measure TMMs" ( p. 884). Fortunately, some recent work has examined the implications associated with different measurement techniques. DeChurch and Mesmer-Magnus (2010a) conducted a meta-analysis to examine how the measurement of shared mental models influences relationships with team process and performance. Their results revealed that shared mental models only predict team process when the measurement techniques enable the representation of the structure or organization of knowledge, as is the case when similarity ratings (with Pathfinder network analysis for structural representation), concept mapping, or card sorting is used. When traditional rating scale techniques were used (e.g., rating scales or questionnaires), the relationship between shared mental models and team process was small and negative. However, shared mental models positively predicted team performance regardless of which measurement strategy was used, although the magnitude of the relationships differed across measurement method. Based on these findings, the authors conclude that whereas knowledge structure is predictive of both team process and performance, knowledge content is only predictive of team performance. A recent study by Resick et al. (2010) compared the validity of three team mental model measurement approaches: structural networks, priority rankings, and importance ratings. The authors found little convergent and considerable discriminant validity across the three measurement approaches, suggesting that the metrics measure different underlying constructs. In addition, they found that the structural networks approach predicted team adaptation and performance, whereas the other two approaches did not. 
Finally, they found that the quality of team member structural networks had a significant, positive effect on team adaptation and performance, whereas the similarity of structural networks did not. Yet, similarity moderated the effect of quality on adaptation, such that quality was most strongly related to adaptation when members had less similar structural networks. These studies along with other qualitative reviews of different measurement approaches (e.g., Langan-Fox, Code, \& Langfield-Smith, 2000; Mohammed et al., 2000) have begun to highlight some basic guidelines that researchers can follow when choosing a measurement approach, such as using a methodology that is capable of mapping the structure of the knowledge and aligning the measurement technique with the research question and team context under examination.

A second issue involves examining the relationship between team learning processes and team mental models. Although team mental models have long been viewed as an important indicator of team development, few studies have directly examined how different team learning processes foster the development of team mental models. Often these processes are inferred rather than directly assessed. For example, Rentsch and Klimoski (2001) found that team size was negatively related to teamwork schema agreement. They argue that team size serves as a rough estimate of team member interaction opportunity, but they do not study these interaction and communication processes directly. However, some recent work has proposed theoretical frameworks for the development of team mental models (e.g., Langan-Fox, 2003; McComb, 2008) and empirical studies have started to focus more specifically on the processes that influence the development of mental models (e.g., Pearsall et al., 2010). We believe more work is needed in this area. As Mohammed et al. (2010) note, "much remains to be known about the developmental processes by which TMMs evolve over time" (p. 901).

Finally, there is a need for research that challenges the presumption that an increased sharing of knowledge among team members is always necessary or beneficial. As Kozlowski 
and Ilgen (2006) suggest, "Although the notion of a common or shared team mental model has tended to dominate the research, there is recognition that team mental models may be more complex" (p. 83). In particular, it is important to recognize that team members may not necessarily need to have identical knowledge structures but rather may possess some sharing and also some unique structural information based on role distinctions. Thus, it is important to examine what roles in the teams may benefit from greater convergence of knowledge and which may be better served by complementary or distributed mental models (Mohammed et al., 2010). This conceptualization of distributed or networked knowledge is similar to the notion of transactive memory, which we turn to next.

\section{Transactive Memory}

The concept of transactive memory was introduced to explain how intimate relationships foster the development of common memory (Wegner, Giuliano, \& Hertel, 1985). Accordingly, transactive memory has often been studied within dyads, although over the past decade the construct has increasingly been applied to groups and teams. Within teams, transactive memory represents a group-level shared system for encoding, storing, and retrieving information that is distributed across group members (Wegner, 1986, 1995; Wegner et al., 1985). This distributed pattern suggests that transactive memory represents a compilation form of emergence (DeChurch \& Mesmer-Magnus, 2010; Kozlowski \& Chao, 2011). It is conceptualized as a set of distributed, individual memory systems that combine two components: (1) internal memory, or the knowledge possessed by particular team members, and (2) external memory, or the shared awareness of who knows what (Peltokorpi, 2008; Wegner, 1995). A transactive memory system functions through transactive processes, including directory updating, information allocation, and retrieval coordination (Lewis, Lange, \& Gillis, 2005; Wegner, 1986). Although past research has sometimes blurred the distinction between team mental models and transactive memory 
(Kozlowski \& Ilgen, 2006), there are a few features that distinguish transactive memory from other team cognitive constructs. Whereas shared mental models typically emphasize the overlap among team member knowledge (Mohammed \& Dumville, 2001), transactive memory focuses on the distribution or network of knowledge in the team (Kozlowski \& Ilgen, 2006). In addition, transactive memory is unique in its emphasis on the shared awareness of expertise and its focus on critical learning processes, particularly the retrieval of information (Mohammed \& Dumville, 2001; Peltokorpi, 2008). ${ }^{1}$

The emergence of transactive memory systems represents an important manifestation of team learning processes (Kozlowski \& Bell, 2008). These systems develop as groups gain experience and members communicate and update the information they have about other members' unique knowledge. Members keep track of other members' expertise, direct incoming information to those individuals with matching domain expertise, and use that tracking to access information from others in the system (Mohammed \& Dumville, 2001; Wegner, 1995). In essence, team members cultivate one another as external memory aids, thereby creating a compatible and differentiated memory system that is useful to the team (Kozlowski \& Bell, 2003). In addition to representing an emergent outcome of team learning, researchers have noted that transactive memory systems facilitate team learning. During the initial stages of transactive memory system development, a shared awareness of expertise allows individual members to specialize in different areas, which not only makes the group's knowledge more differentiated but also provides the freedom for members to develop more knowledge in their specialty areas (Lewis et al., 2005). In addition, as groups perform their tasks and engage in learning by doing, the transactive memory system is further refined to include higher order knowledge structures

\footnotetext{
${ }^{1}$ Mohammed et al. (2010) note that researchers have debated the importance of shared awareness in the development of team mental models and that this issue warrants additional conceptual and empirical attention.
} 
and stable patterns of interacting that allow learning to be transferred across functionally similar tasks. Thus, when viewed from a dynamic perspective, transactive memory serves as both an outcome of team learning processes and as a driver of team learning and transfer.

One of the first studies to examine the development of transactive memory systems in teams was conducted by Liang, Moreland, and Argote (1995), who compared the performance of groups whose members were trained individually to that of groups whose members were trained together on a radio assembly task. They found that groups whose members were trained together recalled more about the assembly procedure and produced higher quality radios than those groups whose members were trained alone. Based on an analysis of videotape data, they concluded that the performance benefits of group training were primarily due to the fact that it fostered the development of transactive memory among group members. Specifically, groups whose members were trained together exhibited greater memory differentiation, task coordination, and task credibility (trust in other members' expertise), and a composite of these three factors mediated the relationship between group training and performance. Several followup studies were conducted using the radio assembly paradigm to further test the role of transactive memory in explaining the benefits of group training. Moreland and Myaskovsky (2000) examined whether the benefits of group training may instead be due to improved communication among group members. They found that groups whose members were not allowed to communicate during training but received information about one another's skills performed equally as well as those groups trained together, and both of these groups outperformed the groups whose members were trained individually. These findings combined with the fact that the training method did not impact members' ratings of communication suggest that the performance benefits of group training are due to transactive memory not improved communication. In another study using the same experimental task, Rulke and Rau (2000) 
employed qualitative methods to examine the encoding process of transactive memory development during group training. Their findings revealed that groups with strong transactive memory (those in the group training condition) spent more time in the early periods of group interaction identifying who had what expertise in what domains. In addition, they found evidence that transactive encoding occurs through short, recurring encoding cycles and that the frequency of the different cycle elements (e.g., declaring expertise) vary over time.

Subsequent research has identified a number of other factors that influence the development of transactive memory systems. Several studies have shown that face-to-face communication is important for the emergence and refinement of transactive memory systems, but computer-mediated communication can present barriers to the development of transactive memory systems (Hollingshead, 1998a, 1998b; Lewis, 2004). Pearsall et al. (2010) also found that communication about roles and responsibilities early in a team's development was positively related to the development of transactive memory. Together, these studies suggest that copresence and communication are important to the development and modification of transactive memory systems (Brandon and Hollingshead, 2004). Several studies have also shown that changes in team membership (i.e., turnover) can have a detrimental effect on transactive memory systems (Akgün, Byrne, Keskin, Lynn, \& Imamoglu, 2005; Moreland, Argote, \& Krishnan, 1996). As discussed earlier, Lewis et al. (2005) showed that having remaining team members reflect on their collective knowledge may be beneficial to transactive memory system processes following turnover. Research has also shown that transactive memory development is influenced by task and outcome interdependence (Hollingshead, 2001; Lewis, 2003; Zhang, Hempel, Han, \& Tjosvold, 2007), acute stress (Ellis, 2006), and team member personality (Pearsall \& Ellis, 2006).

The development of transactive memory systems is important as conceptually such 
systems should offer teams the advantage of cognitive efficiency. Through the encoding and information allocation processes, individual knowledge becomes progressively more specialized and differentiated. The knowledge specialization that team members develop within a transactive memory system reduces cognitive load, increases the knowledge stock of the team, and reduces redundancy of effort (Hollingshead, 1998b). However, the complexity of transactive memory can create confusion, such as when important information is not captured or is directed to the wrong team member (Wegner, 1986; Pearsall, Ellis, \& Bell, 2008). In addition, potential delays associated with retrieving information can negatively affect team effectiveness in time-critical situations (Kozlowski \& Bell, 2003). These challenges are likely more salient for larger teams. Empirical research has generally found support for a positive relationship between transactive memory and team effectiveness (e.g., Ellis, 2006; Pearsall \& Ellis, 2006; Pearsall et al., 2010; Zhang et al., 2007). Austin (2003), for instance, examined the effects of different dimensions of transactive memory on the performance of 27 groups in an apparel and sporting goods company. He found that transactive memory accuracy and specialization were significantly and positively related to internal and external performance evaluations, and accuracy also predicted external ratings of group goal attainment. Lewis et al. (2005) found that a developed transactive memory allows groups to develop abstract knowledge of the task domain after experience with several tasks, which can facilitate the transfer of learning to functionally similar tasks. Finally, using computational modeling to run virtual experiments, Ren, Carley, and Argote (2006) found that transactive memory enhances the quality of performance for small groups and improves the efficiency of performance for large groups and groups operating in dynamic task environments and volatile knowledge environments.

Conclusion. Kozlowski and Ilgen (2006) note that research on transactive memory is still in its infancy. Although recent studies have helped to expand our understanding of transactive 
memory systems, more work is needed in this area. Although measurement of transactive memory has not garnered much attention in the literature, we think it is an important issue that merits examination. At its conceptual roots, transactive memory is a distributed memory structure (i.e., unique knowledge linked in a network) and, in that sense, it is a compilation construct (Kozlowski \& Klein, 2000). Yet, the instrument used to assess it most often (i.e., Lewis, 2003) does not assess that distributed structure directly. Rather, team member perceptions of knowledge distribution are assessed, ratings are examined for restricted within group variance (i.e., justification for aggregating a composition construct; Kozlowski \& Klein, 2000), and the mean ratings are used as indicators of transactive memory facets. Although the facets specialization, credibility, and coordination - are consistent with the underlying theoretical content of transactive memory (Liang et al., 1995) and meta-analytic evidence shows that they relate to team performance (DeChurch \& Mesmer-Magnus, 2010b), this conceptual inconsistency (i.e., structure vs. content; compilation conceptualization vs. composition operationalization) creates questions as to what is actually being captured by the measure (Kozlowski \& Chao, 2011). Given the different findings for content versus structure (DeChurch \& Mesmer-Magnus, 2010b), this issue merits more research attention.

Another important issue that needs to be examined concerns the development of transactive memory in geographically distributed or virtual teams. As noted above, several studies have found that computer-mediated communication impedes the development of transactive memory systems. Future work is needed to understand the mechanisms that explain these effects and to identify strategies for inducing the co-presence and communication cues necessary to develop transactive memory through remote communication (Kozlowski \& Ilgen, 2006). In addition, future research needs to continue to examine the role of the team and task context in shaping transactive memory. Peltokorpi (2008) notes that the transactive memory 
literature often assumes that groups members have egalitarian relationships and are motivated to share their knowledge. Yet, conflict, power differentials, and hierarchy can influence the dynamics of information sharing within teams, and research on hidden profiles suggests that unshared information does not automatically emerge through communication (Stasser \& Titus, 2003). In addition, several of the studies reviewed above suggest that role interdependencies influence the importance of knowledge distribution in teams. Thus, research is needed that examines the contingencies that influence both the development of transactive memory as well as its importance to team effectiveness.

\section{Macrocognition and Team Knowledge Emergence}

The last form of team knowledge representation we address in this section is a conceptual typology that is based on the macrocognition meta-model (Fiore et al., 2010) described previously as a team learning process. Kozlowski and Chao (in press), and their research team (Kozlowski et al., 2011), have developed a team knowledge typology that is designed to capture knowledge resulting from the key process components of the macrocognition meta-model. Their typology is a conceptual framework for representing macrocognitive team knowledge that explicitly incorporates our theoretical foci - it is multilevel, dynamic, and emergent - and, while it is not an explicit integration, it also incorporates aspects of each of the prior forms of team knowledge reviewed in this section - collective knowledge, team mental models, and transactive memory.

First, like collective knowledge, it is focused on the pool of relevant knowledge that teams acquire as they endeavor to perform their task, solve the problem, or make a decision. However, unlike collective knowledge, there is an explicit focus on understanding how individual knowledge contributes to the collective pool. Second, like team mental models, it is 
concerned with shared team knowledge. However, unlike team mental models, it is explicitly concerned with how knowledge becomes shared; how it moves from the individual to the team level. And, third, like transactive memory it is focused on the distribution of knowledge. However, unlike transactive memory, it is explicitly concerned with how uniquely held knowledge (specific to a team member) and common knowledge (available to all team members) emerge to form a shared pool that the team can apply to perform, problem solve, or render a decision.

As noted previously, the conceptual foundation for the team knowledge typology is formulated around our core theoretical foci - multilevel, dynamic, and emergent. It is a synthesis of regulatory processes that underlie individual and team learning (DeShon et al., 2004), progressive knowledge compilation (Fiore et al., 2010; Kozlowski \& Bell, 2008), and composition and compilation forms of knowledge emergence across levels (Kozlowski \& Klein, 2000). The theoretical driver of the typology is the macrocognition meta-model shown in Figure 8 (Fiore et al., 2010). The learning process of Individual Knowledge Building yields Internalized Knowledge, which is the knowledge individual team members acquire and the knowledge that the team possesses collectively. Internalized knowledge influences both subsequent individual knowledge building and Team Knowledge Building, which represents team-level learning processes that yield Externalized Team Knowledge. It is externalized knowledge in the sense that it has to be made tangible; it is explicitly communicated, discussed, and shared - perhaps used to create an artifact (a note, a posting to a map) - and is available to be acquired by other team members who did not previously know it. Thus, it influences subsequent individual learning, is captured as internalized knowledge, and can influence subsequent team knowledge building and externalized team knowledge. In the macrocognition meta-model, learning and knowledge representation are intertwined, such that team knowledge building and externalized team 
knowledge influence team problem solving effectiveness.

From this synthesis, the typology captures forms of knowledge that emerge from macrocognitive processes that represent (a) pools of individual and collective team knowledge; (b) configurations in the knowledge pool that represent patterns of distinct individual, dyadic, and collective knowledge; and (c) variance in the rates of knowledge acquisition and its emergence at the team level, both within and across teams. The typology is a conceptual model, thus the operationalization of a knowledge type has to be grounded in a specific task and knowledge domain. In that sense, it is designed to provide measurement comparability across qualitatively different collaborative team tasks.

An assumption inherent in this framework is that each team member can acquire both common (available to all) and unique knowledge (specific to team member expertise) that represent the problem space. Thus, the sum of the total pool of common and unique knowledge specifies all the knowledge relevant for solving the problem or making a decision. For example, one could have a product design team composed of a design engineer, production manager, and market researcher each with common knowledge about a new product and also access to specialized knowledge about product features, production capabilities, and consumer preferences, respectively. How can these individual and team patterns of knowledge be captured, and how can changes in these patterns be represented as team members discuss the problem and collaborate to make a decision?

Figure 9 illustrates the typology and defines the knowledge types. The most basic type captures individual knowledge as the proportion of the total pool of knowledge relevant to solving the problem or making a decision that is possessed by one team member at any one point in time (individual level, internalized knowledge). It captures individual level knowledge, but it 
does not account for any redundancy among team members. The knowledge pool accounts for this overlap and captures the proportion of the total pool held by the team as a whole (team level composition measure, internalized and externalized knowledge). Although this represents what is known collectively, it is not diagnostic of how the knowledge is distributed across individuals, dyads, and the team as a collective. The knowledge configuration metrics capture this distribution as a set of proportions (team level compilation measures, internalized and externalized knowledge). As team members acquire information about the problem space, and share their knowledge, the patterns of knowledge held across members is dynamic and evolves. These dynamics and the emergence of knowledge can be captured as knowledge acquisition or the rate of growth of individual knowledge (i.e., how rapidly the Venn diagram expands for a team member; individual level internalized and externalized knowledge). Of course, numerous factors including individual differences, team composition, and the context will influence the rate of individual learning, how much individuals share what they learn, and how well team members will learn from one another. These factors yield knowledge variability in the within team rates of acquisition (team level internalized and externalized knowledge acquisition). As Kozlowski and Chao (in press) note, "A basic principle of team learning (Kozlowski \& Bell, 2008) is that the most rapid rates of knowledge acquisition with low within team variance, yields optimum team learning. Thus, within team variance in the rates of knowledge acquisition is likely to impede team knowledge building processes, the development of externalized team knowledge, and team problem solving outcomes" (p. 14; team level internalized and externalized knowledge). Finally, knowledge emergence can be captured within and between teams by tracking the rates of growth for the knowledge pool, knowledge configuration, and knowledge variability (between team only). As dynamic indices, they provide metrics to represent how quickly team members internalize, share, and externalize knowledge relevant to the problem at hand. In complex, ill- 
defined, time pressured situations (Klein et al., 2003) teams that can better build and externalize relevant knowledge are more likely to make effective decisions.

Conclusion. The macrocognition meta-model and the linked team knowledge typology are recent conceptual developments, so there is very little direct research at this point that can be used to evaluate their value. However, they have some novel conceptual features that we think will contribute to a better understanding of team learning processes and knowledge outcomes. First, these models explicitly incorporate our theoretical foci; they are explicitly multilevel, dynamic, and emergent. We believe all three theoretical foci are essential to unpack team learning, so the models are constructed on a solid theoretical foundation. Second, the macrocognition meta-model makes a clear distinction between learning processes and learning outcomes and the team knowledge typology provides metrics to capture knowledge outcomes. Research is underway to validate the meta-model and the linked metrics. Third, we believe that efforts to examine the models will necessitate research advances that, thus far, have only been lightly probed in industrial and organizational psychology. In particular, the research will have to address the dynamics of emergence (see DeShon, this volume; Kozlowski, in press). Imagine that rather than a collage of snapshots (single shot, cross sectional designs), our understanding of team learning and knowledge emergence was a movie (multilevel, longitudinal) ${ }^{2}$. That is where this research is headed.

\section{Team Performance}

The ultimate goal of team learning is an improvement in team performance or effectiveness. Indeed, if we view learning as an expansion in a team's repertoire of potential behaviors, and collective knowledge as an instantiation of learning potential, then it follows that

\footnotetext{
${ }^{2}$ This metaphor is adapted from a talk by Dinges (2010).
} 
this potential must be realized in performance improvement, capacity, and adaptation. Thus, it is surprising that few studies have focused attention on the relationship between team learning and performance. This is not to say that performance has been ignored within this literature; many studies of team learning have measured team performance. However, in the majority of these studies, team learning is inferred from changes in team performance (Kozlowski \& Ilgen, 2006; Stagl, Salas, \& Day, 2008). That is, research has used improvements in team performance as evidence that team learning has occurred, which confounds team learning and team performance and often makes it impossible to tie the performance improvements to the team learning processes or emergent states we have discussed.

One area in which this practice has been common is in research that has examined learning-curves within teams. Studies within the learning-curve tradition have typically been designed to document and explain differences in rates of performance improvement across teams (Edmondson et al., 2007). Teams have been studied in a variety of different field settings, including manufacturing and service, and performance efficiency is typically measured in terms of cost, productivity, or time. Edmondson et al. (2007) note that the research is this area possesses many strengths, including its use of objective outcome variables and its focus on challenges in real work settings and organizations. However, studies within this tradition typically do not measure the mechanisms that are thought to explain the performance differences across teams. For example, Darr et al. (1995) examined learning among 36 pizza stores owned by 10 different franchises. They found that as the stores gained experience (produced more pizzas) the cost of production decreased at a decreasing rate (i.e., a learning curve), but there were also significant differences in learning across stores. They found evidence that stores were able to learn from the knowledge gained by other stores in the same franchise but not stores owned by other franchisees, and they suggest that these differences may be due to the more 
frequent communication that occurred in same-owned stores in the form of phone calls, personal acquaintances, and meetings. However, communication was never measured and the authors note that, "a greater understanding of the micro processes underlying the transfer of knowledge is needed" (p. 1761).

One of the problems of using performance as a proxy for team learning is that researchers have noted that teams can learn yet not experience any changes in their performance. Likewise, performance can change without any learning actually taking place, and sometimes learning can result in dysfunctional outcomes. Wilson et al. (2007), for example, explain that a team can learn something but be unable to apply the learning in a way that impacts its performance, team performance can improve due to environmental changes (having nothing to do with learning), and teams can engage in superstitious learning that has negative implications for team functioning. Edmondson (2002) also notes that team learning does not always translate into organizational learning. Groups may fail to communicate what they have learned with others in the organization or may be unable to convince others to adopt the new work practices. The underlying message is that changes in team or organizational performance do not always serve as an accurate indicator of team learning.

In recent years, a growing body of research has examined the relationship between team learning and performance. These studies differ in that some examine team learning as a process (e.g., by measuring specific team learning behaviors), whereas others examine it as an outcome (e.g., collective knowledge or skills). This dual-conceptualization of team learning is characteristic of the broader literature (Edmondson et al., 2007). However, in these studies performance is measured separately from team learning, so the relationship between the two constructs can be tested. Although this represents an important step toward understanding the outcomes of team learning, it is important to note that these studies have often suffered from 
other methodological limitations. A number of studies have used self-report data to assess both team learning and performance (e.g., Jeong, Lee, Kim, Lee, \& Kim, 2006; Van den Bossche et al., 2006), which raises concerns about whether common method bias may be inflating observed relationships. In addition, a number of studies have examined the link between team learning and team performance using individual-level data (e.g., Chan, Pearson, \& Entrekin, 2003; Jeong et al., 2006; Yeh \& Chou, 2005). The use of single respondents raises concerns about the reliability of the ratings of team learning and performance, and this practice also ignores the nesting that is often inherent within the data (e.g., respondents nested within teams and/or departments/units).

Despite some limitations, this body of work provides evidence that team learning is positively associated with team performance. Van der Vegt and Bunderson (2005) examined the effects of team learning behaviors on the performance of multidisciplinary teams in the oil and gas industry. They found that team learning was positively associated with supervisor-ratings of team performance and that team learning mediated the effect of expertise diversity and collective identification on team performance. Ellis et al. (2003) reported that team learning behaviors were positively related to the performance of four-person teams performing a military command and control simulation. Druksat and Kayes (2000) also found a moderate, positive relationship between team learning behaviors and the performance of MBA project teams. However, the relationship did not achieve significance, likely due to the small number of teams included in the study $(\mathrm{n}=26)$. A number of field studies using qualitative methods have also provided evidence of a connection between team learning behaviors and team performance outcomes (e.g., Bondarouk \& Sikkel, 2005; Mittendorff, Geijsel, Hoeve, de Laat, \& Nieuwenhuis, 2005).

As noted above, a number of studies have also examined the relationship between team learning measured as an outcome and team performance. Hirschfeld, Jordan, Feild, Giles, and 
Armenakis (2006), for example, studied 92 teams participating in a United States Air Force officer development program aimed at developing transportable teamwork knowledge and skills. They found that the average teamwork knowledge within a team was positively related to the team's performance in a variety of tasks (e.g., field operations, problem-solving exercises, physical tasks) as well as observer ratings of effective teamwork. Further, they found that average teamwork knowledge significantly predicted teamwork ratings even after controlling for task proficiency.

Conclusion. Although these studies suggest that there generally exists a positive relationship between team learning and team performance, there is also emerging evidence that this relationship may be moderated by a number of factors. Kirkman et al., (2006) studied 40 geographically distributed teams in the travel industry. During the launch of these teams, members participated in an online training program designed to enhance their teamwork skills and allow them to deliver better customer service through teamwork. The authors discovered a complex relationship between teams' average training proficiency and team performance (customer satisfaction). Specifically, average training proficiency had positive associations with customer satisfaction when team trust and technology support were higher, rather than lower, and when team leaders had longer, rather than shorter, tenure. Consistent with our discussion earlier in this chapter, these results suggest that teams may only be able to apply their learning when certain conditions are present (e.g., trust, support). In another study, Wong (2004) examined the effects of team learning activities across 78 teams from four different firms. As noted earlier, she found that local team learning (i.e., learning with individuals in the immediate team) was significantly and positively related to group efficiency, whereas distal team learning (i.e., learning with individuals external to the group) was significantly and positively related to group innovativeness. In addition, she found that local learning was significantly associated with 
group efficiency when distal learning was low or moderate, but unrelated to efficiency when distal learning was high. These results suggest that there may exist performance tradeoffs associated with focusing on either local or distal learning, and that attempts to emphasize both may undermine the benefits of local learning for group efficiency. Although these studies provide important insight into the effects of team learning, more research is needed to identify the conditions under which team learning enhances team effectiveness.

\section{Discussion}

In this chapter, we have reviewed roughly two decades of literature addressing the phenomenon of team learning with the goal of providing an integrative understanding of where the field has made conceptual advances and research progress and where new theoretical developments and research resources can be profitably applied. Unlike many reviews of this domain, our review is founded on a clear distinction between team learning as a process and the team knowledge outcomes that emerge from learning, which are often confabulated with learning and / or team performance. Moreover, we conceptualized team emergent states (or "processes" like collective efficacy and cohesion) as supportive, reciprocal emergent phenomena that arise from the leaning processes, but also feed-forward to shape team learning . Collectively and dynamically, these team learning processes, reciprocal emergent states, and team knowledge outcomes influence team effectiveness (see Figure 1). Consistent with our integrative heuristic, our review highlighted three foundational theoretical foci that we believe are essential for advancing understanding of team learning as a complex, systems phenomenon. Team learning is multilevel, dynamic, and emergent. Taking these theoretical foci to heart will necessitate advances in theory and the use of new, creative, and sophisticated research methodologies. In this final section we highlight key conceptual insights, research findings, and future research foci 
to better illuminate the nature of team learning, its outcomes, and its implications for team effectiveness. 


\section{Team Learning Process Models}

Table 1 summarizes the results of our review of several team learning process models that have received significant attention within this literature and / or hold the potential to offer new insights and research opportunities. We reviewed a number of different models and approaches, which can be categorized under three broad theoretical umbrellas - regulation, information processing, and macrocognition. Although each of the models offers a different theoretical lens through which to interpret team learning processes, we view these different perspectives as complementary and synergistic, rather than competing, and believe that together they offer a rich conceptual foundation for future work in this area.

It is important to note that some of these models and approaches have received greater research support than others. The regulation models have received the greatest research attention to date. There is meta-analytic support for the models of group goal setting and action regulation / emergent team processes, and in recent years we have witnessed a growing base of theory and primary studies for the model of team action regulation and the model of team learning and development. The information processing models also represent a popular approach to understanding the functional process mechanisms of team learning. Yet, research aimed at understanding information processing in teams has often suffered from conceptual and methodological inconsistencies as well as segregation across disciplines or research thrusts. Research on information sharing in teams has been more systematic, but this approach has been criticized for being conceptual stagnant (Mohammed \& Dumville, 2001). Fortunately, researchers have recently introduced new, integrative models of group information processing (Wilson et al., 2007) and have provided novel insights into information sharing (De Dreu, 2007), which bode well for the future. The final model, which focuses on macrocognitive knowledge building processes, is derived from established research in areas such as macrocognitive team 
decision making and team communication processes, but the meta-model has not yet been subjected to direct empirical tests. Although future research is needed to refine and apply the model, this framework offers a novel perspective and is conceptually very promising.

An evaluation of the different process models using our there theoretical foci reveals significant advances in recent years. Research on team action regulation has moved from focusing on the parallelism inherent in multilevel models of action regulation to examining the cross-level linkages that bind individual and team regulation. There has also been greater emphasis on modeling the episodic dynamics involved in the emergence of teamwork processes and team development activities. More recent models of group information processing have demonstrated renewed attention to issues surrounding levels of analysis and time, and the macrocognition meta-model is explicitly designed to capture team knowledge development as a multilevel, dynamic, and emergent phenomenon. Given these recent developments, we believe these different models offer a robust theoretical platform on which to build a greater understanding of team learning as a multilevel, dynamic, and emergent process.

\section{Team Emergent States}

Table 2 summarizes the results of our review of team emergent states that can support and shape the team learning process. All four of the emergent states we addressed - team goal orientation, psychological safety, team efficacy, and cohesion / conflict - arise from learning and also have the potential to influence how teams regulate their actions, process and share information, and capture knowledge and foster shared meaning. Yet, the relationship between these states and team learning is also dynamic and iterative, such that the states not only shape and support team learning but also emerge from the interactions inherent in team learning that support or constrain learning processes and knowledge generation. 
Our review reveals that the volume and nature of research support varies across the four emergent states. Although team goal orientation and psychological safety have received significant attention in recent years, these are relatively newer constructs that have not been studied as extensively as team efficacy, cohesion, and conflict. However, psychological safety has been studied almost exclusively in the context of team learning and there is growing support that links team goal orientation to team learning and adaptation. In contrast, there is a voluminous and systematic body of evidence that links team efficacy, cohesion, and conflict to team performance, but few studies that have examined the relationship between these states and team learning. Thus, the research recommendations are somewhat different across these areas. In terms of team goal orientation and psychological safety, there is a need for continuing research that refines our understanding of how these states relate to team learning. Future research needs to identify the contingencies within both the team and task context that shape the relationships between these states and team learning. In contrast, prior work provides valuable information about the contingencies that shape the effects of team efficacy, conflict, and cohesion, but there exists a need to evaluate the extent to which these findings generalize when team learning is the outcome of interest. The findings of individual-level research and studies that have explored linkages between these states and team performance can serve as a valuable guide for research in this area. Yet, preliminary evidence also suggests that different patterns of results may emerge when these states are examined across levels of analysis and in the context of team learning, which implies caution in overextending past findings.

There is also a need for future research on these emergent states to more explicitly incorporate our key theoretical foci. Future studies in this area need to focus greater attention on multilevel issues, such as the implications of measuring and conceptualizing team goal orientation as compositional variable as opposed to a shared, climate-like state, the similarities 
and dissimilarities in the antecedents and consequences of efficacy beliefs across levels of analysis, and the effects of both micro and macro contextual features on the relationship between cohesion / conflict and team learning. Similarly, we need a better understanding of the dynamic and emergent relationships that exist between these states and team learning. Research should examine the temporal dynamics that underlie the emergence of psychological safety perceptions and the critical antecedents and consequences of these perceptions at different stages in a team's lifecycle. Similarly, research should further explore the reciprocal relationships that likely exist between team efficacy and emergent team outcomes, such as shared mental models.

\section{Team Knowledge Outcomes}

Table 3 summarizes our review of research that has examined the knowledge outcomes of team learning. Although we placed particular emphasis on the cognitive and knowledgebased outcomes that represent the most salient manifestations of team learning, we also examined research that examined the effects of team learning on team performance. As noted previously, research examining the outcomes of team learning has suffered from several limitations, including the confabulation of team learning, team knowledge, and team performance and the failure to clearly establish the distinctiveness of specific knowledge-based outcomes of team learning. Yet, when the research on these different outcomes is compiled, there is convincing evidence that team learning is an important driver of team effectiveness.

As with the other areas we have covered, there exists varying levels of support for the different team learning outcomes. Research in the area of shared cognition (i.e., team mental models and transactive memory) has matured more rapidly than research in some of the other areas. Recent meta-analyses (De Church \& Mesmer-Magnus, 2010a, 2010b) have established the relationship between shared cognition and team processes and performance, have highlighted the moderators of these relationships, and have demonstrated the implications of different 
approaches to measuring shared cognition. Future research can further refine these findings by examining the effects of different mental model structures and extending research on transactive memory across different team and task contexts. There also exists some emerging research that has examined the antecedents and consequences of collective knowledge and team knowledge acquisition. Yet, more work is needed in this area to refine existing theory, examine different conceptualizations and operationalizations of collective knowledge and the implications for team learning and performance, and to focus on the dynamic aspects of how individual learning and knowledge building emerge dynamically to shape multilevel configurations of team knowledge and its application to problem solving and performance. This is the promise of research on team macrocognition and macrocognitive team knowledge representations. Although there is yet very little direct research on the macrocognition meta-model and the linked team knowledge typology, these frameworks incorporate novel features that we believe have the potential to expand our understanding of knowledge outcomes. In particular, these frameworks explicitly incorporate our theoretical foci; they are multilevel, dynamic, and emergent. Accordingly, they can help unpack team learning and create a clear distinction between learning processes and learning outcomes, which is essential for understanding the consequences of team learning for team effectiveness. Finally, direct examinations of the relationship between team learning and team performance are rare but generally supportive. Future research that disentangles the team learning process from team learning outcomes is needed along with targeted investigations of the conditions (e.g., trust) and factors (e.g., type of team learning) that serve as contingencies of the team learning - performance relationship.

\section{Conclusion}

The intended purpose of this chapter was to organize, synthesize, and integrate the diffuse literature addressing team learning that has developed in organizational science over the 
last two to three decades. Our review sought to balance breadth of coverage - to capture a range of useful conceptualizations - and depth - to focus our attention on conceptualizations that are most relevant, best supported by the research, and most promising for future advances. Although much progress has been made in the last 20 years, it is also the case that team learning is a diverse, sprawling, and messy conceptual domain. We believe that the organization and integration inherent in our heuristic, synthesis offered by our review of the literature, and - in particular - conceptual contribution of our foundational theoretical foci - that team learning is multilevel, emergent, and dynamic - offers novel and exciting prospects for future theoretical, empirical, and application advances in this important domain. 


\section{References}

Akgün, A. E., Byrne, J., Keskin, H., Lynn, G. S., \& Imamoglu, S. Z. (2005). Knowledge networks in new product development projects: A transactive memory perspective. Information \& Management, 42, 1105-1120.

Amason, A. C. (1996). Distinguishing the effects of functional and dysfunctional conflict on strategic decision making: Resolving a paradox for top management teams. Academy of Management Journal, 39(1), 123-148.

Anderson, J. R. (1987). Skill acquisition: Compilation of weak-method problem situations. Psychological Review, 94(2), 192-210.

Argote, L., Gruenfeld, D. H., \& Naquin, C. (2001). Group learning in organizations. In M. Turner (Ed.), Groups at work: Theory and research (pp. 369-411). Mahwah, NJ: Lawrence Erlbaum Associates, Publishers.

Argote, L., Insko, C. A., Yovetich, N., \& Romero, A. A. (1995). Group learning curves: The effects of turnover and task complexity on group performance. Journal of Applied Social Psychology, 25, 512-529.

Austin, J. R. (2003). Transactive memory in organizational groups: The effects of content, consensus, specialization, and accuracy on group performance. Journal of Applied Psychology, 88(5), 866-878.

Bandura, A. (1977). Self-efficacy: Toward a unifying theory of behavioral change. Psychological Review, 84(2), 191-215.

Bandura, A. (1991). Social cognitive theory of self-regulation. Organizational Behavior and Human Decision Processes, 50, 248-287.

Bandura, A. (1997). Self-efficacy: The exercise of control. New York: Freeman.

Bandura, A., \& Locke, E. A. (2003). Negative self-efficacy and goal effects revisited. Journal of Applied Psychology, 88 (1), 87-99.

Beal, D. J., Cohen, R. R., Burke, M. J., \& McLendon, C. L. (2003). Cohesion and performance in groups: A meta-analytic clarification of construct relations. Journal of Applied Psychology, 88(6), 989-1004.

Bell, B. S., \& Kozlowski, S. W. J. (2002). Adaptive guidance: Enhancing self-regulation, knowledge, and performance in technology-based training. Personnel Psychology, 55(2), 267-306.

Bell, B. S., \& Kozlowski, S. W. J. (2008). Active learning: Effects of core training design elements on self-regulatory processes, learning, and adaptability. Journal of Applied Psychology, 93, 296-316. 
Bondarouk, T., \& Sikkel, K. (2005). Explaining IT implementation through group learning. Information Resources Management Journal, 18 (1), 42-60.

Brandon, D. P., \& Hollingshead, A. B. (2004). Transactive memory systems in organizations: Matching tasks, expertise, and people. Organization Science, 15 (6), 633-644.

Bunderson, J. S., \& Sutcliffe, K. A. (2003). Management team learning orientation and business unit performance. Journal of Applied Psychology, 88, 552-560.

Burke, C. S., Salas, E., Wilson-Donnelly, K., \& Priest, H. (2004). How to turn a team of experts into an expert medical team: guidance from the aviation and military communities. Quality and Safety in Health Care, 13, i96-i104.

Button, S. B., Mathieu, J. E., \& Zajac, D. M. (1996). Goal orientation in organizational research: A conceptual and empirical foundation. Organizational Behavior and Human Decision Processes, 67, 26-48.

Cacciabue, P. C., \& Hollnagel, E. (1995). Simulation of cognition: Applications. In J. M. Hoc, P. C. Cacciabue, \& E. Hollnagel (Eds.), Expertise and technology: Cognition and Human-Computer Cooperation (pp. 55-73). Mahwah, NJ: Lawrence Erlbaum Associates.

Cannon, M. D., \& Edmondson, A. C. (2001). Confronting failure: antecedents and consequences of shared beliefs about failure in organizational work groups. Journal of Organizational Behavior, 22, 161-177.

Cannon-Bowers, J. A. (2007). Fostering mental model convergence through training. In F. Dansereau \& F. Yammarino (Eds.), Multi-level issues in organizations and time (pp. 149157). San Diego, CA: Elsevier.

Cannon-Bowers, J. A., Salas, E., \& Converse, S. A. (1993). Shared mental models in expert team decision making. In N. J. Castellan (Ed.), Individual and group decision making: Current issues (pp. 221-246). Hillsdale, NJ: LEA.

Carnevale, P. J., \& Probst, T. M. (1998). Social values and social conflict in creative problem solving and categorization. Journal of Personality and Social Psychology, 74, 1300-1309.

Carver, C. S., \& Scheier, M. F. (1981). Attention and self-regulation: A control-theory approach to human behavior. New York: Springer-Verlag.

Chan, C. C. A., Pearson, C., \& Entrekin, L. (2003). Examining the effects of internal and external team learning on team performance. Team Performance Management, 9, 174181.

Chen, G., \& Kanfer, R. (2006). Toward a systems theory of motivated behavior in work teams. Research in Organizational Behavior, 27, 223-267. 
Chen, G., Kanfer, R., DeShon, R. P., Mathieu, J. E., \& Kozlowski, S. W. J. (2009). The motivating potential of teams: Test and extension of Chen and Kanfer's (2006) crosslevel model of motivation in teams. Organizational Behavior and Human Decision Processes, 110, 45-55.

Chen, G., Thomas, B., \& Wallace, J. C. (2005). A multilevel examination of the relationships among training outcomes, mediating regulatory processes, and adaptive performance. Journal of Applied Psychology, 90, 827-841.

Chen, G., Webber, S. S., Bliese, P. D., Mathieu, J. E., Payne, S. C., Born, D. H., \& Zaccaro, S. J. (2002). Simultaneous examination of the antecedents and consequences of efficacy beliefs at multiple levels of analysis. Human Performance, 15, 381-409.

Chiocchio, F., \& Essiembre, H. (2009). Cohesion and performance: A meta-analytic review of disparities between project teams, production teams, and service teams. Small Group Research, 40 (4), 382-420.

Cohen, S. G., \& Gibson, C. B. (2003). In the beginning: Introduction and framework. In C. B. Gibson \& S. G. Cohen (Eds.), Virtual teams that work: Creating conditions for virtual team effectiveness (pp. 1-13). San Francisco: Jossey-Bass.

Cooke, N. J., Gorman, J. C., \& Preston, K. A. (2008). Communication as team-level cognitive processing. In M.P. Letsky, N.W. Warner, S.M. Fiore, \& C.A.P. Smith (Eds.), Macrocognition in teams: Theories and methodologies (pp. 51-64). Burlington, VT: Ashgate Publishing.

Cyert, R., \& March, J. (1963). Behavioral theory of the firm. Oxford: Blackwell.

Darr, E. D., Argote, L., \& Epple, D. (1995). The acquisition, transfer, and depreciation of knowledge in service organizations: Productivity in franchises. Management Science, 41 (11), 1750-1762.

Day, D. V. (in press). Leadership. In S. W. J. Kozlowski (Ed.), The Oxford handbook of organizational psychology. New York: Oxford University Press.

De Dreu, C. K. W. (2007). Cooperative outcome interdependence, task reflexivity, and team effectiveness: A motivated information processing perspective. Journal of Applied Psychology, 92 (3), 628-638.

De Dreu, C. K. W., \& Carnevale, P. J. D. (2003). Motivational bases for information processing and strategic choice in conflict and negotiation. In M. P. Zanna (Ed.), Advances in experimental social psychology (Vol. 35, pp. 235-291). New York: Academic Press.

De Dreu, C. K. W., \& Weingart, L. R. (2003). Task versus relationship conflict, team performance, and team member satisfaction: A meta-analysis. Journal of Applied Psychology, 88(4), 741-749. 
DeChurch, L. A., \& Mesmer-Magnus, J. R. (2010a). Measuring shared team mental models: A meta-analysis. Group Dynamics: Theory, Research, and Practice, 14, 1-14.

DeChurch, L. A., \& Mesmer-Magnus, J. R. (2010b). The cognitive underpinnings of effective teamwork: A meta-analysis. Journal of Applied Psychology, 95 (1), 32-53.

DeShon, R. P. (in press). Multivariate Dynamics in Organizational Science. In S. W. J. Kozlowski (Ed.), The Oxford handbook of organizational psychology. New York: Oxford University Press.

DeShon, R. P., \& Gillespie, J. Z. (2005). A motivated action theory account of goal orientation. Journal of Applied Psychology, 90 (6), 1096-1127.

DeShon, R. P., Kozlowski, S. W. J., Schmidt, A. M., Milner, K. R., \& Wiechmann, D. (2004). A multiple goal, multilevel model of feedback effects on the regulation of individual and team performance. Journal of Applied Psychology, 89, 1035-1056.

DeShon, R. P., Kozlowski, S. W. J., Schmidt, A. M., Wiechmann, D., \& Milner, K. A. (2001). Developing team adaptability: Shifting regulatory focus across levels. Presented at the $16^{\text {th }}$ Annual Conference of the Society for Industrial and Organizational Psychology, San Diego, CA.

Devine, D. J., Clayton, L. D., Phillips, J. L., Dunford, B. B., \& Melner, S. B. (1999). Teams in organizations: Prevalence, characteristics, and effectiveness. Small Group Research, 30(6), 678-711.

Dinges, D. (2010, December). Maintaining human behavioral capability: Where biology meets technology. Keynote address presented at Human-Systems Integration at the National Academies: A celebration of 30 years (1980-2010). Committee on Human-Systems Integration, National Research Council. Washington, DC.

Drach-Zahavy, A., \& Somech, A. (2001). Understanding team innovation: The role of team processes and structures. Group Dynamics: Theory, Research, and Practice, 5 (2), 111123.

Druskat, V. U, \& Kayes, D. C. (2000). Learning versus performance in short-term project teams. Small Group Research, 31 (3), 328-353.

Dweck, C. S. (1986). Motivational processes affecting learning. American Psychologist, 41(10), 1040-1048.

Edmondson, A. C. (1996). Learning from mistakes is easier said than done: Group and organizational influences on the detection and correction of human error. Journal of Applied Behavioral Science, 32, 5-28. 
Edmondson, A. C. (1999). Psychological safety and learning behavior in work teams. Administrative Science Quarterly, 44, 350-383.

Edmondson, A. C. (2002). The local and variegated nature of learning in organizations: A group-level perspective. Organization Science, 13 (2), 128-146.

Edmondson, A. C. (2003). Speaking up in the operating room: How team leaders promote learning in interdisciplinary action teams. Journal of Management Studies, 40 (6), 14191452.

Edmondson, A. C., Bohmer, R. M., \& Pisano, G. P. (2001). Disrupted routines: Team learning and new technology implementation in hospitals. Administrative Science Quarterly, 46, 685-716.

Edmondson, A. C., Dillon, J. R., \& Roloff, K. S. (2007). Three perspectives on team learning. The Academy of Management Annuals, 1, 269-314.

Edwards, B. D., Day, E. A., Arthur, W., \& Bell, S. T. (2006). Relationships among team ability composition, team mental models, and team performance. Journal of Applied Psychology, 91, 727-736.

Elliot, A. J., \& Church, M. A. (1997). A hierarchical model of approach and avoidance achievement motivation. Journal of Personality and Social Psychology, 72, 218-232.

Ellis, A. P. J. (2006). System breakdown: The role of mental models and transactive memory in the relationship between acute stress and team performance. Academy of Management Journal, 49 (3), 576-589.

Ellis, A. P. J., \& Bell, B. S. (2005). Capacity, collaboration, and commonality: A framework for understanding team learning. In L. L. Neider \& C. A. Shriesheim (Eds.), Understanding teams: A volume in research in management (pp. 1-25). Greenwich, CT: Information Age.

Ellis, A. P. J., Bell, B. S., Ployhart, R. E., Hollenbeck, J. R., \& Ilgen, D. R. (2005). An evaluation of generic teamwork skills training with action teams: Effects on cognitive and skillbased outcomes. Personnel Psychology, 58, 641-672.

Ellis, A. P. J., Hollenbeck, J. R., Ilgen, D. R., Porter, C. O. L. H., West, B. J., \& Moon, H. (2003). Team learning: Collectively connecting the dots. Journal of Applied Psychology, $88(5), 821-835$.

Farr, J. L., Hofmann, D. A., \& Ringenbach, K. L. (1993). Goal orientation and action control theory: Implications for industrial and organizational psychology. In C. L. Cooper \& I. T. Robertson (Eds.), International review of industrial and organizational psychology (pp. 193-232). New York, NY: Wiley.

Festinger, L. (1950). Informal social communication. Psychological Review, 57, 271-282. 
Fiore, S. M., Rosen, M. A., Smith-Jentsch, K. A., Salas, E., Letsky, M., \& Warner, N. (2010). Toward an understanding of macrocognition in teams: Predicting processes in complex collaborative contexts. Human Factors, 52, 203-224.

Fiore, S. M., Smith-Jentsch, K. A., Salas, E., Warner, N., \& Letsky, M. (in press). Toward an Understanding of Macrocognition in Teams: Developing and Defining Complex Collaborative Processes and Products. Theoretical Issues in Ergonomic Science

Fitts, P. M., \& Posner, M. I. (1967). Human performance. Oxford, England: Brooks/Cole.

Fleishman, E. A., \& Zaccaro, S. J. (1992). Toward a taxonomy of team performance functions. In R. W. Swezey \& E. Salas (Eds.), Teams: Their training and performance (pp. 31-56). Norwood, NJ: Ablex.

Ford, J. K., \& Kraiger, K. (1995). The application of cognitive constructs and principles to the instructional systems model of training: Implications for needs assessment, design, and transfer. In C. L. Cooper \& I. T. Robertson (Eds.), International review of Industrial and Organizational Psychology (vol. 10, pp. 1-48). New York: Wiley.

Gibson, C., \& Vermeulen, F. (2003). A healthy divide: Subgroups as a stimulus for team learning behavior. Administrative Science Quarterly, 48, 202-239.

Gist, M. E. (1987). Self-efficacy: Implications for organizational behavior and human resource management. Academy of Management Review, 12, 472-485.

Griffith, T. L., Sawyer, J. E., \& Neale, M. A. (2003). Virtualness and knowledge in teams: Managing the love triangle of organizations, individuals, and information technology. MIS Quarterly, 27 (2), 265-287.

Gully, S. M., Incalcaterra, K. A., Joshi, A., \& Beaubien, J. M. (2002). A meta-analysis of teamefficacy, potency, and performance: Interdependence and level of analysis as moderators of observed relationships. Journal of Applied Psychology, 87(5), 819-832.

Gully, S. M., \& Phillips, J. M. (2005). A multilevel application of learning and performance orientations to individual, group, and organizational outcomes. Research in Personnel and Human Resources Management, 24, 1-51.

Gurtner, A., Tschan, F., Semmer, N. K., \& Nägele, C. (2007). Getting groups to develop good strategies: Effects of reflexivity interventions on team process, team performance, and shared mental models. Organizational Behavior and Human Decision Processes, 102, 127-142.

Hinsz, V.B. (1990). Cognitive and consensus processes in group recognition memory performance. Journal of Personality and Social Psychology, 59, 705-718. 
Hinsz, V. B., Tindale, R. S., \& Vollrath, D. A. (1997). The emerging conceptualization of groups as information processors. Psychological Bulletin, 121(1), 43-64.

Hirschfeld, R. R., Jordan, M. H., Feild, H. S., Giles, W. F., \& Armenakis, A. A. (2006). Becoming team players: Team members' mastery of teamwork knowledge as a predictor of team task proficiency and observed teamwork effectiveness. Journal of Applied Psychology, 91 (2), 467-474.

Hirst, G., Van Knippenberg, D., \& Zhou, J. (2009). A cross-level perspective on employee creativity: Goal orientation, team learning behavior, and individual creativity. Academy of Management Journal, 52 (2), 280-293.

Hollingshead, A. B. (1998a). Communication, learning, and retrieval in transactive memory systems. Journal of Experimental Social Psychology, 34, 423-442.

Hollingshead, A. B. (1998b). Retrieval processes in transactive memory systems. Journal of Personality and Social Psychology, 74, 659-671.

Hollingshead, A. B. (2001). Cognitive interdependence and convergent expectations in transactive memory. Jounal of Personality and Social Psychology, 81, 1080-1089.

Hsu, M., Chen, I. Y., Chiu, C., \& Ju, T. L. (2007). Exploring the antecedents of team performance in collaborative learning of computer software. Computer \& Education, 48, 700-718.

Huber, G. P. (1991). Organizational learning: The contributing processes and the literatures. Organization Science, 2 (1), 88-115.

Ilgen, D. R., Hollenbeck, J. R., Johnson, M., \& Jundt, D. (2005). Teams in organizations: From ip-o models to imoi models. Annual Review of Psychology.

Jehn, K. A. (1995). A multimethod examination of the benefits and detriments of intragroup conflict. Administrative Science Quarterly, 40(2), 256-282.

Jeong, S. H., Lee, T., Kim, I. S., Ha, M., \& Kim, M. J. (2007). The effect of nurses' use of the principles of learning organization on organizational effectiveness. Journal of Advanced Nursing, 58 (1), 53-62.

Johnson, M. D., \& Hollenbeck, J. R. (2007). Collective wisdom as an oxymoron: team-based structures as impediments to learning. In J. Langan-Fox, C. L. Cooper, \& R. J. Klimoski (Eds.), Research companion to the dysfunctional workplace (pp. 319-331). Northampton, MA: Edward Elgar.

Kane, A. A., Argote, L., \& Levine, J. M. (2005). Knowledge transfer between groups via personnel rotation: Effects of social identity and knowledge quality. Organizational Behavior and Human Decision Processes, 96, 56-71. 
Kanfer, R. (1990). Motivation theory and industrial and organization psychology. In M. D. Dunnette \& L. M. Hough (Eds.), Handbook of industrial and organizational psychology ( $2^{\text {nd }}$ ed., Vol. 1, pp. 75-170). Palo Alto, CA: Consulting Psychologists Press.

Kanfer, R., Chen, G., \& Pritchard, R. (2008). The three C's of work motivation: Content, context, and change. In R. Kanfer, G. Chen, \& R. D. Pritchard (Eds.), Work motivation: Past, present, and future (pp. 1-16). New York, NY: Routledge Academic.

Karoly, P. (1993). Mechanisms of self-regulation: A systems view. Annual Review of Psychology, 44, 23-52.

Katz, D., \& Kahn, R. L. (1966). The social psychology of organizations. New York: Wiley.

Kernan, M. C., \& Lord, R. G. (1990). Effects of valence, expectancies, and goal-performance discrepancies in single and multiple goal environments. Journal of Applied Psychology, 75, 194-203.

Kirkman, B. L., Rosen, B., Tesluk, P. E., \& Gibson, C. B. (2006). Enhancing the transfer of computer-assisted training proficiency in geographically distributed teams. Journal of Applied Psychology, 91 (3), 706-716.

Klein, G. Ross, K., Moon, B. M., Klein, D. E., Hoffman, R. R., \& Hollnagel, E. (2003). Macrocognition. IEEE Intelligent Systems, May/June, 81-84.

Kleingeld, A., van Mierlo, H., \& Arends, L. (in press). The effect of goal setting on group performance: A meta-analysis. Journal of Applied Psychology.

Klimoski, R. J., \& Mohammed, S. (1994). Team mental model: Construct or metaphor? Journal of Management, 20, 403-437.

Kozlowski, S. W. J. (in press). Groups and teams in organizations: Studying the multilevel dynamics of emergence. In A. B. Hollingshead \& M. S. Poole (Eds.), Methods for studying small groups: A behind-the-scenes guide. New York, NY: Routledge Academic.

Kozlowski, S. W. J., \& Bell, B. S. (2003). Work groups and teams in organizations. In W. C. Borman, D. R. Ilgen \& R. J. Klimoski (Eds.), Handbook of psychology: Industrial and organizational psychology (Vol. 12, pp. 333-375). London: Wiley.

Kozlowski, S. W. J., \& Bell, B. S. (2006) Disentangling achievement orientation and goal setting: Effects on self-regulatory processes. Journal of Applied Psychology, 91, 900916.

Kozlowski, S. W. J., \& Bell, B. S. (2007). A theory-based approach for designing distributed learning systems. In S. M. Fiore \& E. Salas (Eds.), Toward a science of distributed learning (pp. 15-39). Washington, DC: APA. 
Kozlowski, S. W. J., \& Bell, B. S. (2008). Team learning, development, and adaptation. In V. I. Sessa \& M. London (Eds.), Work Group learning (pp. 15-44). Mahwah, NJ: LEA.

Kozlowski, S. W. J. \& Chao, G. T. (in press). Macrocognition, team learning, and team knowledge: Origins, emergence, and measurement. In E. Salas, S. Fiore, \& M. Letsky (Eds.), Theories of team cognition: Cross-disciplinary perspectives. New York, NY: Routledge Academic.

Kozlowski, S. W. J. \& Chao, G. T. (2011). The dynamics of emergence: Cognition and cohesion in work teams. Managerial and Decision Economics. Manuscript under review.

Kozlowski, S. W. J., Chao, G. T., Grand, J., Keeney, J., Braun, M., \& Kuljanin, G. (2011, April). Macrocognition and teams: The emergence and measurement of team knowledge In G. T. Chao \& S. W. J. Kozlowski (Chairs), Macrocognition: The next frontier for team cognition research. Symposium to be presented at the $26^{\text {th }}$ Annual Conference of the Society for Industrial and Organizational Psychology, Chicago, IL.

Kozlowski, S. W. J., Gully, S. M., Brown, K. G., Salas, E., Smith, E. M., \& Nason, E. R. (2001). Effects of training goals and goal orientation traits on multidimensional training outcomes and performance adaptability. Organizational Behavior and Human Decision Processes, 85, 1-31.

Kozlowski, S. W. J., Gully, S. M., McHugh, P. P., Salas, E., \& Cannon-Bowers, J. A. (1996). A dynamic theory of leadership and team effectiveness: Developmental and task contingent leader roles. In G. R. Ferris (Ed.), Research in personnel and human resource management (Vol. 14, pp. 253-305). Greenwich, CT: JAI Press.

Kozlowski, S. W. J., Gully, S. M., Nason, E. R., \& Smith, E. M. (1999). Developing adaptive teams: A theory of compilation and performance across levels and time. In D. R. Ilgen \& E. D. Pulakos (Eds.), The changing nature of work performance: Implications for staffing, personnel actions, and development (pp. 240-292). San Francisco: Jossey-Bass.

Kozlowski, S. W. J., Gully, S. M., Salas, E., \& Cannon-Bowers, J. A. (1996). Team leadership and development: Theory principles, and guidelines for training leaders and teams. In M. Beyerlein, D. Johnson \& S. Beyerlein (Eds.), Advances in interdisciplinary studies of work teams: Team leadership (Vol. 3, pp. 251-289).

Kozlowski, S. W. J., \& Ilgen, D. R. (2006). Enhancing the effectiveness of work groups and teams. Psychological Science, 7(3), 77-124.

Kozlowski, S. W. J., \& Klein, K. J. (2000). A multilevel approach to theory and research in organizations: Contextual, temporal, and emergent processes. In K. J. Klein \& S. W. J. Kozlowski (Eds.), Multilevel theory, research, and methods in organizations: Foundations, extensions, and new directions (pp. 3-90). San Francisco: Jossey-Bass.

Kozlowski, S. W. J., Watola, D., Jensen, J. M., Kim, B., \& Botero, I. (2009). Developing adaptive teams: A theory of dynamic team leadership. In E. Salas, G. F. Goodwin \& C. S. 
Burke (Eds.), Team effectiveness in complex organizations: Cross-disciplinary perspectives and approaches (pp. 109-146). New York, NY: Routledge Academic.

Langan-Fox, J. (2003). Skill acquisition and the development of the team mental model: An integrative approach to analyzing organizational teams. In M. West, D. Tjosvold, \& K. G. Smith (Eds.), International handbook of organizational teamwork and co-operative working (pp. 321-360). London: Wiley.

Langan-Fox, J., Code, S., \& Langfield-Smith, K. (2000). Team mental models: Techniques, methods, and analytic approaches. Human Factors, 42 (2), 242-271.

Lau, D. C., \& Murnighan, J. K. (1998). Demographic diversity and faultlines: The compositional dynamics of organizational groups. Academy of Management Review, 23(2), 325-340.

Lawler, E. E., Mohrman, S. A., \& Ledford, G. E. (1995). Creating high performance organizations: Practices and results of employee involvement and total quality management in fortune 1000 companies. San Francisco: Jossey-Bass.

LePine, J. A. (2005). Adaptation of teams in response to unforeseen change: Effects of goal difficulty and team composition in terms of cognitive ability and goal orientation. 90(6), 1153-1167.

LePine, J. A., Piccolo, R. F., Jackson, C. L., Mathieu, J. E., \& Saul, J. R. (2008). A metaanalysis of teamwork processes: Tests of a multidimensional model and relationships with team effectiveness criteria. Personnel Psychology, 61, 273-307.

Letsky, M., Warner, N., Fiore, S. M., Rosen, M. A., \& Salas, E. (2007). Macrocognition in complex team problem solving. In Proceedings of the $12^{\text {th }}$ International Command and Control Research and Technology Symposium. Washington, DC: U. S. Department of Defense Command and Control Research Program. Retrieved from http://www.dodccrp.org/events/12th_ICCRTS/CD/html/papers/239.pdf.

Letsky, M. P., \& Warner, N. W. (2008). Macrocognition in teams. In M.P. Letsky, N.W. Warner, S.M. Fiore, \& C.A.P. Smith (Eds.), Macrocognition in teams: Theories and methodologies (pp. 1-13). Burlington, VT: Ashgate Publishing.

Levesque, L. L., Wilson, J. M., \& Wholey, D. R. (2001). Cognitive divergence and shared mental models in software development project teams. Journal of Organizational Behavior, 22, 135-144.

Lewis, K. (2003). Measuring transactive memory systems in the field: Scale development and validation. Journal of Applied Psychology, 88(4), 587-604.

Lewis, K. (2004). Knowledge and performance in knowledge-worker teams: A longitudinal study of transactive memory systems. Management Science, 50(11), 1519-1533. 
Lewis, K., Belliveau, M., Herndon, B., \& Keller, J. (2007). Group cognition, membership change, and performance: Investigating the benefits and detriments of collective knowledge. Organizational Behavior and Human Decision Processes, 103, 159-178.

Lewis, K., Lange, D., \& Gillis, L. (2005). Transactive memory systems, learning, and learning transfer. Organization Science, 16 (6), 581-598.

Liang, D. W., Moreland, R. L., \& Argote, L. (1995). Group versus individual training and group performance: The mediating role of transactive memory. Personality and Social Psychology Bulletin, 21, 384-393.

Lindsley, D. H., Brass, D. J., \& Thomas, J. B. (1995). Efficacy-performance spirals: A multilevel perspective. Academy of Management Review, 20, 645-678.

Locke, E. A., \& Latham, G. P. (1990). A theory of goal-setting and task performance. Englewood Cliffs, NJ: Prentice-Hall.

London, M., Polzer, J. T., \& Omoregie, H. (2005). Interpersonal congruence, transactive memory, and feedback processes: An integrative model of group learning. Human Resource Development Review, 4 (2), 114-135.

London, M., \& Sessa, V. I. (2006). Group feedback for continuous learning. Human Resource Development Review, 5 (3), 303-329.

Mannix, E., \& Neale, M. A. (2005). What differences make a difference? The promise and reality of diverse teams in organizations. Psychological Science in the Public Interest, 6, 31-55.

Marks, M. A., Sabella, M. J., Burke, C. S., \& Zaccaro, S. J. (2002). The impact of cross-training on team effectiveness. Journal of Applied Psychology, 87(1), 3-13.

Marks, M. A., Mathieu, J. E., \& Zaccaro, S. J. (2001). A temporally based framework and taxonomy of team processes. Academy of Management Review, 26(3), 356-376.

Mathieu, J. E., Gilson, L. L., \& Ruddy, T. M. (2006). Empowerment and team effectiveness: An empirical test of an integrated model. Journal of Applied Psychology, 91 (1), 97-108.

Mathieu, J. E., Heffner, T. S., Goodwin, G. F., Cannon-Bowers, J. A., \& Salas, E. (2005). Scaling the quality of teammates' mental models: equifinality and normative comparisons. Journal of Organizational Behavior, 26, 37-56.

Mathieu, J. E., Heffner, T. S., Goodwin, G. F., Salas, E., \& Cannon-Bowers, J. A. (2000). The influence of shared mental models on team process and performance. Journal of Applied Psychology, 85(2), 273-283. 
Mathieu, J. E., Rapp, T. L., Maynard, M. T., \& Mangos, P. M. (2010). Interactive effects of team and task shared mental models as related to air traffic controllers' collective efficacy and effectiveness. Human Performance, 23, 22-40.

McComb, S. A. (2008). Shared mental models and their convergence. In M.P. Letsky, N.W. Warner, S.M. Fiore, \& C.A.P. Smith (Eds.), Macrocognition in teams: Theories and methodologies (pp. 35-50). Burlington, VT: Ashgate Publishing.

Mento, A. J., Steel, R. P., \& Karren, R. J. (1987). A meta-analytic study of the effects of goalsetting on task performance - 1966-1984. Organizational Behavior and Human Decision Processes, 39(1), 52-83.

Miller, G. A., Galanter, E., \& Pribram, K. H. (1960). Plans and the structure of behavior. New York, NY: Henry Holt and Co.

Mittendorff, K., Geijsel, F., Hoeve, A., de Laat, M., \& Nieuwenhuis, L. (2006). Communities of practice as stimulating forces for collective learning. Journal of Workplace Learning, 18 (5), 298-312.

Mohammed, S., \& Dumville, B. C. (2001). Team mental models in a team knowledge framework: Expanding theory and measurement across disciplinary boundaries. Journal of Organizational Behavior, 22, 89-106.

Mohammed, S., Ferzandi, L., \& Hamilton, K. (2010). Metaphor no more: A 15-year review of the team mental model construct. Journal of Management, 36 (4), 876-910.

Mohammed, S., Klimoski, R. J., \& Rentsch, J. R. (2000). The measurement of team mental models: We have no shared schema. Organizational Research Methods, 3(2), 123-165.

Moreland, R. L., Argote, L., \& Krishnan, R. (1996). Socially shared cognition at work: Transactive memory and group performance. In J. L. Nye \& A. M. Brower (Eds.), What's social about social cognition? Research on socially shared cognition in small groups (pp. 57-84). Thousand Oaks, CA: Sage.

Moreland, R. L., \& Myaskovsky, L. (2000). Exploring the performance benefits of group training: Transactive memory or improved communication? Organizational Behavior and Human Decision Processes, 82 (1), 117-133.

Morgeson, F. P., \& Hofmann, D. A. (1999). The structure and function of collective constructs: Implications for research and theory development. Academy of Management Review, 24, 249-265.

Nembhard, I. M., \& Edmondson, A. C. (2006). Making it safe: The effects of leader inclusiveness and professional status on psychological safety and improvement efforts in health care teams. Journal of Organizational Behavior, 27, 941-966. 
O'leary-Kelly, A. M., Martocchio, J. J., \& Frink, D. D. (1994). A review of the influence of group goals on group-performance. Academy of Management Journal, 37(5), 1285-1301.

Payne, S. C., Youngcourt, S. S., \& Beaubien, J. M. (2007). A meta-analytic examination of the goal orientation nomological net. Journal of Applied Psychology, 92 (1), 128-150.

Pearsall, M. J., \& Ellis, A. P. J. (2006). The effects of critical team member assertiveness on team performance and satisfaction. Journal of Management, 32 (4), 575-594.

Pearsall, M. J., Ellis, A. P. J., \& Bell, B. S. (August, 2008). Slippage in the system: The Effects of Errors in Transactive Memory Behavior on Team Performance. Academy of Management Annual Meeting Proceedings.

Pearsall, M. J., Ellis, A. P. J, \& Bell, B. S. (2010). Building the infrastructure: The effects of role identification behaviors on team cognition development and performance. Journal of Applied Psychology, 95, 192-200.

Peltokorpi, V. (2008). Transactive memory systems. Review of General Psychology, 12 (4), 378-394.

Peterson, E., Mitchell, T. R., Thompson, L., \& Burr, R. (2000). Collective efficacy and aspects of shared mental models as predictors of performance over time in work groups. Groups Processes \& Intergroup Relations, 3 (3), 296-316.

Phillips, J. M., Hollenbeck, J. R., \& Ilgen, D. R. (1996). The prevalence and prediction of positive discrepancy creation: An integration of episodic and non-episodic theories of motivation. Journal of Applied Psychology, 81, 498-511.

Pinder, C. C., \& Bourgeois, V. W. (1982). Controlling tropes in administrative science. Administrative Science Quarterly, 27 (4), 641-652.

Ployhart, R. E., \& Bliese, P. D. (2006). Individual adaptability (I-ADAPT) theory: Conceptualizing the antecedents, consequences, and measurement of individual differences in adaptability. In S. Burke, L. Pierce, \& E. Salas (Eds.), Understanding Adaptability: A Prerequisite for Effective Performance Within Complex Environments (pp. 3-39). Elsevier.

Porter, C. O. L. H. (2005). Goal orientation: Effects on backing up behavior, performance, efficacy, and commitment in teams. Journal of Applied Psychology, 90, 811-818.

Porter, C. O. L. H. (2008). A multilevel, multiconceptualization perspective of goal orientation in teams. In V. L. Sessa \& M. London (Eds.), Work group learning: Understanding, improving \& assessing how groups learn in organizations (pp. 149-173). New York: Erlbaum. 
Porter, C. O. L. H., Webb, J. W., \& Gogus, C. I. (2010). When goal orientations collide: Effects of learning and performance orientation on team adaptability in response to workload imbalance. Journal of Applied Psychology, 95 (5), 935-943.

Powers, W. T. (1973). Behavior: The control of perception. Chicago: Aldine.

Pritchard, R. D., Jones, S. D., Roth, P. L., Stuebing, K. K., \& Ekeberg, S. E. (1988). The effects of feedback, goal setting, and incentiveson organizational productivity. Journal of Applied Psychology, 73, 337-358.

Pritchard, R. D., Harrell, M. M., DiazGranados, D., \& Guzman, M. J. (2008). The productivity measurement and enhancement system: A meta-analysis. Journal of Applied Psychology, 93 (3), 540-567.

Prussia, G. E., \& Kinicki, A. J. (1996). A motivational investigation of group effectiveness using social-cognitive theory. Journal of Applied Psychology, 81(2), 187-198.

Pulakos, E. D., Arad, S., Donovan, M. A., \& Plamondon, K. E. (2000). Adaptability in the workplace: Development of a taxonomy of adaptive performance. Journal of Applied Psychology, 85 (4), 612-624.

Rau, D. (2005). The influence of relationship conflict and trust on the transactive memory: Performance Relation in top management teams. Small Group Research, 36 (6), 746771.

Reagans, R., Argote, L., \& Brooks, D. (2005). Individual experience and experience working together: Predicting learning rates from knowing who knows what and knowing how to work together. Management Science, 51 (6), 869-881.

Ren, Y., Carley, K. M., \& Argote, L. (2006). The contingent effects of transactive memory: When is it more beneficial to know what others know? Management Science, 52 (5), 671-682.

Rentsch, J. R., Delise, L. A., \& Hutchinson, S. (2008). Transferring and developing cognitive similarity in decision-making teams: Collaboration and meaning analysis process. In M.P. Letsky, N.W. Warner, S.M. Fiore, \& C.A.P. Smith (Eds.), Macrocognition in teams: Theories and methodologies (pp. 127-142). Burlington, VT: Ashgate Publishing.

Rentsch, J. R., \& Klimoski, R. J. (2001). Why do 'great minds' think alike?: antecedents of team member schema agreement. Journal of Organizational Behavior, 22, 107-120.

Resick, C. J., Murase, T., Bedwell, W. L., Sanz, E., Jiménez, M., \& DeChurch, L. A. (2010). Mental model metrics and team adaptability: A multi-facet multi-method examination. Group Dynamics: Theory, Research, and Practice, 14 (4), 332-349.

Roberson, Q. M., Bell, B. S., \& Porter, S. C. (2008). The language of bias: A linguistic approach to understanding intergroup relations. In K. Phillips (Ed.), Research in 
Managing Groups and Teams: Diversity \& Groups (vol. 11, pp. 267-294). Bingley, UK: Emerald.

Rowe, A. (2008). Unfolding the dance of team learning: A metaphorical investigation of collective learning. Management Learning, 39 (1), 41-56.

Rulke, D. L., \& Rau, D. (2000). Investigating the encoding process of transactive memory development in group training. Group and Organizational Management, 25, 373-396.

Salas, E., Rosen, M. A., \& DiazGranados, D. (in press). Decision Making in Naturalistic Environments. In S. W. J. Kozlowski (Ed.), The Oxford handbook of organizational psychology. New York: Oxford University Press.

Seijts, G. H., Latham, G. P., Tasa, K., \& Latham, B. W. (2004). Goal setting and goal orientation: An integration of two different yet related literatures. Academy of Management Journal, 47, 227-239.

Senge, P. M. (1990). The fifth discipline: The art and practice of the learning organization. New York: Doubleday.

Shea, G. P., \& Guzzo, R. A. (1987). Groups as human resources. In K. M. Rowland \& G. R. Ferris (Eds.), Research in personnel and human resource management (Vol. 5, pp. 323356). Greenwich, CT: JAI Press.

Shiffrin, R. M., \& Schneider, W. (1977). Controlled and automatic human information processing: II. Perceptual learning, automatic attending, and a general theory. Psychological Review, 84 (2), 127-190.

Simon, H. A. (1973). The organization of complex systems. In H. H. Pattee (Ed.), Hierarchy theory (pp. 1-27). New York: Braziller.

Smith, Jentsch, K. A., Campbell, G. E., Milanovich, D. M., \& Reynolds, A. M. (2001). Measuring teamwork mental models to support training needs assessment, development, and evaluation: two empirical studies. Journal of Organizational Behavior, 22, 179-194.

Smith-Jentsch, K. A., Cannon-Bowers, J. A., Tannenbaum, S. I., \& Salas, E. (2008). Guided team self-correction: Impacts on team mental models, processes, and effectiveness. Small Group Research, 39, 303-327.

Smith-Jentsch, K. A., Mathieu, J. E., \& Kraiger, K. (2005). Investigating linear and interactive effects of shared mental models on safety and efficiency in a field setting. Journal of Applied Psychology, 90 (3), 523-535.

Sole, D., \& Edmondson, A. (2002). Situated knowledge and learning in dispersed teams. British Journal of Management, 13, S17-S34. 
Somech, A., \& Drach-Zahavy, A. (2007). Schools as team-based organizations: A structureprocess-outcomes approach. Group Dynamics: Theory, Research, and Practice, 11 (4), 305-320.

Stagl, K. C., Salas, E., \& Day, D. V. (2008). Assessing team learning outcomes: Improving team learning and performance. In V. I. Sessa \& M. London (Eds.), Work Group learning (pp. 367-390). Mahwah, NJ: LEA.

Stajkovic, A. D., \& Luthans, F. (1998). Self-efficacy and work-related performance: A metaanalysis. Psychological Bulletin, 124(2), 240-261.

Stasser, G., Taylor, L. A., \& Hanna, C. (1989). Information sampling in structured and unstructured discussions of three- and six-person groups. Journal of Personality and Social Psychology, 57, 67-78.

Stasser, G., \& Titus, W. (1985). Pooling of unshared information in group decision making: Biased information sampling during discussion. Journal of Personality and Social Psychology, 48, 1467-1478.

Stasser, G., \& Titus, W. (1987). Effects of information load and percentage of shared information on the dissemination of unshared information during group discussion. Journal of Personality and Social Psychology, 53, 81-93.

Stasser, G., \& Titus, W. (2003). Hidden profiles: A brief history. Psychological Inquiry, 14 (3/4), 304-313.

Steiner, I. D. (1972). Group process and productivity. New York: Academic Press.

Tompkins, T. C. (1995). Role of diffusion in collective learning. International Journal of Organizational Analysis, 3 (1), 69-85.

Tjosvold, D., Yu, Z., \& Hui, C. (2004). Team learning from mistakes: The contribution of cooperative goals and problem-solving. Journal of Management Studies, 41, 1223-1245.

Vancouver, J. B. (2005). The depth of history and explanation as benefit and bane of psychological control theories. Journal of Applied Psychology, 90 (1), 38-52.

Van den Bossche, P., Gijselaers, W. H., Segers, M., \& Kirschner, P. A. (2006). Social and cognitive factors driving teamwork in collaborative learning environments: Team learning beliefs and behaviors. Small Group Research, 37 (5), 490-521.

Van der Vegt, G. S., \& Bunderson, J. S. (2005). Learning and performance in multidisciplinary teams: The Importance of collective team identification. Academy of Management Journal, 48, 532-547.

Van Offenbeek, M. (2001). Processes and outcomes of team learning. European Journal of Work and Organizational Psychology, 10 (3), 303-317. 
VandeWalle, D. (1997). Development and validation of a work domain goal orientation instrument. Educational and Psychological Measurement, 57, 995-1015.

Von Bertalanffy, L. (1972). The history and status of general systems theory. Academy of Management Journal, 15 (4), 407-426.

Waller, M. J., Gupta, N., \& Giambatista, R. C. (2004). Effects of adaptive behaviors and shared mental models on control crew performance. Management Science, 50 (11), 1534-1544.

Walsh, J. P. (1995). Managerial and organizational cognition: Notes from a trip down memory lane. Organization Science, 6 (3), 280-321.

Walsh, J. P., \& Ungson, G. R. (1991). Organizational memory. Academy of Management Review, 16 (1), 57-91.

Wegner, D. M. (1986). Transactive memory: A contemporary analysis of the group mind. In B. Mullen \& G. R. Goethals (Eds.), Theories of group behavior (pp. 185-205). New York: Springer-Verlag.

Wegner, D. M. (1995). A computer network model of human transactive memory. Social Cognition, 13, 319-339.

Wegner, D. M., Giuliano, T., \& Hertel, P. (1985). Cognitive interdependence in close relationships. In W. J. Ickes (Ed.), Compatible and incompatible relationships (pp. 253276). New York: Springer-Verlag.

Weingart, L. R. (1992). Impact of group goals, task component complexity, effort, and planning on group performance. Journal of Applied Psychology, 77 (5), 682-693.

Wiener, N. (1948). Cybernetics: Control and communication in the animal and machine. Paris: Hermann \& Cie.

Wilson, J. M., Goodman, P. S., \& Cronin, M. A. (2007). Group learning. Academy of Management Review, 32, 1041-1059.

Winters, D., \& Latham, G. P. (1996). The effect of learning versus outcome goals on a simple versus a complex task. Group \& Organization Management, 21, 236-250.

Wittenbaum, G. M., \& Park, E. S. (2001). The collective preference for shared information. Current Directions in Psychological Science, 10 (2), 70-73.

Wittenbaum, G. M., \& Stasser, G. (1996). Management of information in small groups. In J. L. Nye \& A. M. Brower (Eds.), What's social about social cognition? Social cognition research in small groups (pp. 3-28). Thousand Oaks, CA: Sage. 
Wong, S. (2004). Distal and local group learning: Performance trade-offs and tensions. Organization Science, 15 (6), 645-656.

Yeh, Y., \& Chou, H. (2005). Team composition and learning behaviors in cross-functional teams. Social Behavior and Personality, 33 (4), 391-402.

Zellmer-Bruhn, M. E. (2003). Interruptive events and team knowledge acquisition. Management Science, 49 (4), 514-528.

Zellmer-Bruhn, M., \& Gibson, C. (2006). Multinational organization context: Implications for team learning and performance. Academy of Management Journal, 49 (3), 501-518.

Zhang, Z., Hempel, P. S., Han, Y, \& Tjosvold, D. (2007). Transactive memory system links work team characteristics and performance. Journal of Applied Psychology, 92 (6), 1722-1730. 
Table 1. Team Learning Process Models: Support and Recommendations

\begin{tabular}{|c|c|c|}
\hline Model/Approach & Support & Comments and Recommendations \\
\hline \multicolumn{3}{|c|}{ Regulation Models } \\
\hline Group goal setting & $\begin{array}{l}\text { Meta-analytic support for the effect of group } \\
\text { goals on performance }\end{array}$ & $\begin{array}{l}\text { Needs research examining contingencies (e.g., difficulty, goal content, } \\
\text { feedback) that influence the effectiveness of group goal setting }\end{array}$ \\
\hline $\begin{array}{l}\text { Team action regulation, } \\
\text { learning, and } \\
\text { performance }\end{array}$ & $\begin{array}{l}\text { Preliminary empirical support for models of } \\
\text { team action regulation }\end{array}$ & $\begin{array}{l}\text { Initial research promising; additional research needed on multilevel and } \\
\text { cross-level regulation process during learning and skill acquisition }\end{array}$ \\
\hline $\begin{array}{l}\text { Action regulation and } \\
\text { emergent team } \\
\text { processes }\end{array}$ & $\begin{array}{l}\text { Meta-analytic support for multidimensional } \\
\text { theory of teamwork processes }\end{array}$ & $\begin{array}{l}\text { Need to examine linkages between action regulation behaviors and other } \\
\text { cognitive and motivational-affective team processes (e.g., team efficacy, } \\
\text { shared mental models) }\end{array}$ \\
\hline $\begin{array}{l}\text { Team regulation, learning, } \\
\text { and development }\end{array}$ & $\begin{array}{l}\text { Indirect support for the regulatory } \\
\text { mechanisms and team learning phases }\end{array}$ & $\begin{array}{l}\text { Needs direct evaluations of the core principles (e.g., regulatory } \\
\text { mechanisms, developmental transitions, leader influence) of the meta } \\
\text { theoretical framework }\end{array}$ \\
\hline
\end{tabular}

\section{Information Processing Models}

Groups as information processors

Information sharing
Support limited by conceptual and measurement inconsistencies

Body of systematic theory and laboratory research
Promising new theoretical models; continuing research to refine a multilevel, dynamic theory of information-processing in teams; research on neglected processes (e.g., group-level storage and retrieval)

Conceptual advances beyond information sampling model needed; continue to expand research to intact organizational teams

\section{Macrocognition}

Macrocognitive knowledge Indirect support but no direct tests of the Conceptual framework is promising and offers a novel perspective; building processes meta-model systematic empirical research is needed to refine and apply the model

(C) Copyright 2011 B. S. Bell \& S. W. J. Kozlowski. All rights reserved worldwide. Used with permission. 
Table 2. Team Emergent States: Support and Recommendations

\section{Emergent State} Comments and Recommendations
Goal orientation

Preliminary support for effects on team processes, performance, and adaptation
Need to examine the effects of goal orientation over time and across levels, identify contingencies within the team and task context, and better understand the implications of conceptualizing and measuring team goal orientation as a compositional variable vs. as a shared, climate-like state

\begin{tabular}{lcc}
\hline Psychological safety & $\begin{array}{c}\text { Quantitative and qualitative support for } \\
\text { effects on team learning behaviors and } \\
\text { performance; leader actions identified as } \\
\text { key antecedent }\end{array}$ & $\begin{array}{c}\text { Need to extend research to different team and task contexts and to } \\
\text { examine temporal dynamics underlying emergence of psychological } \\
\text { safety perceptions and critical antecedents and consequences over time }\end{array}$ \\
\hline Team efficacy & $\begin{array}{c}\text { Meta-analytic support for effect on team } \\
\text { performance; inconsistent support for link } \\
\text { to team learning behaviors and outcomes }\end{array}$ & $\begin{array}{c}\text { Continuing research to refine and extend individual-level findings to team- } \\
\text { level; need longitudinal research to examine reciprocal relationships } \\
\text { between efficacy and emergent team learning outcomes (e.g., shared } \\
\text { mental models) }\end{array}$ \\
\hline Cohesion and conflict & $\begin{array}{l}\text { Meta-analytic support for link to team } \\
\text { performance; preliminary evidence } \\
\text { suggests a complex relationship between } \\
\text { cohesion, conflict, and team learning }\end{array}$ & $\begin{array}{c}\text { Additional research needed to clarify the effects of cohesion and conflict on } \\
\text { team learning; need to examine effects of both micro and macro } \\
\text { contextual features on cohesion, conflict, and team learning }\end{array}$ \\
\hline
\end{tabular}

(C) Copyright 2011 B. S. Bell \& S. W. J. Kozlowski. All rights reserved worldwide. Used with permission. 
Table 3. Team Knowledge Outcomes: Support and Recommendations

\begin{tabular}{|c|c|c|}
\hline Emergent State & Support & Comments and Recommendations \\
\hline Collective knowledge & $\begin{array}{l}\text { Changes in collective knowledge often not } \\
\text { examined; theory and emerging research } \\
\text { examining antecedents and consequences } \\
\text { of collective knowledge and team } \\
\text { knowledge acquisition }\end{array}$ & $\begin{array}{l}\text { Continuing research to refine theory; need to examine different } \\
\text { conceptualizations and operationalizations of collective knowledge and } \\
\text { implications for team performance; needs more field-based } \\
\text { investigations }\end{array}$ \\
\hline Team mental models & $\begin{array}{l}\text { Body of systematic theory and research; } \\
\text { meta-analytic findings }\end{array}$ & $\begin{array}{l}\text { Continuing research to refine measurement guidelines and understand } \\
\text { development processes; need to examine different mental model } \\
\text { structures (e.g., complementary and distributed mental models) }\end{array}$ \\
\hline Transactive memory & $\begin{array}{l}\text { Theory and emerging research examining } \\
\text { antecedents and consequences }\end{array}$ & $\begin{array}{l}\text { Initial research promising; needs continued research across different team } \\
\text { and task contexts }\end{array}$ \\
\hline $\begin{array}{l}\text { Macrocognition and team } \\
\text { knowledge emergence }\end{array}$ & No direct tests of conceptual typology & Needs research to validate the typology and the linked metrics \\
\hline Team performance & $\begin{array}{l}\text { Often used as a surrogate for team learning; } \\
\text { direct examinations of relationship } \\
\text { between team learning and team } \\
\text { performance are rare but supportive }\end{array}$ & $\begin{array}{l}\text { Needs targeted research on the conditions (e.g., trust) and factors (e.g., } \\
\text { type of team learning) that serve as contingencies of team learning - } \\
\text { performance relationship }\end{array}$ \\
\hline
\end{tabular}

(C) Copyright 2011 B. S. Bell \& S. W. J. Kozlowski. All rights reserved worldwide. Used with permission. 
Figure 1. Theoretical Integration of Team Learning

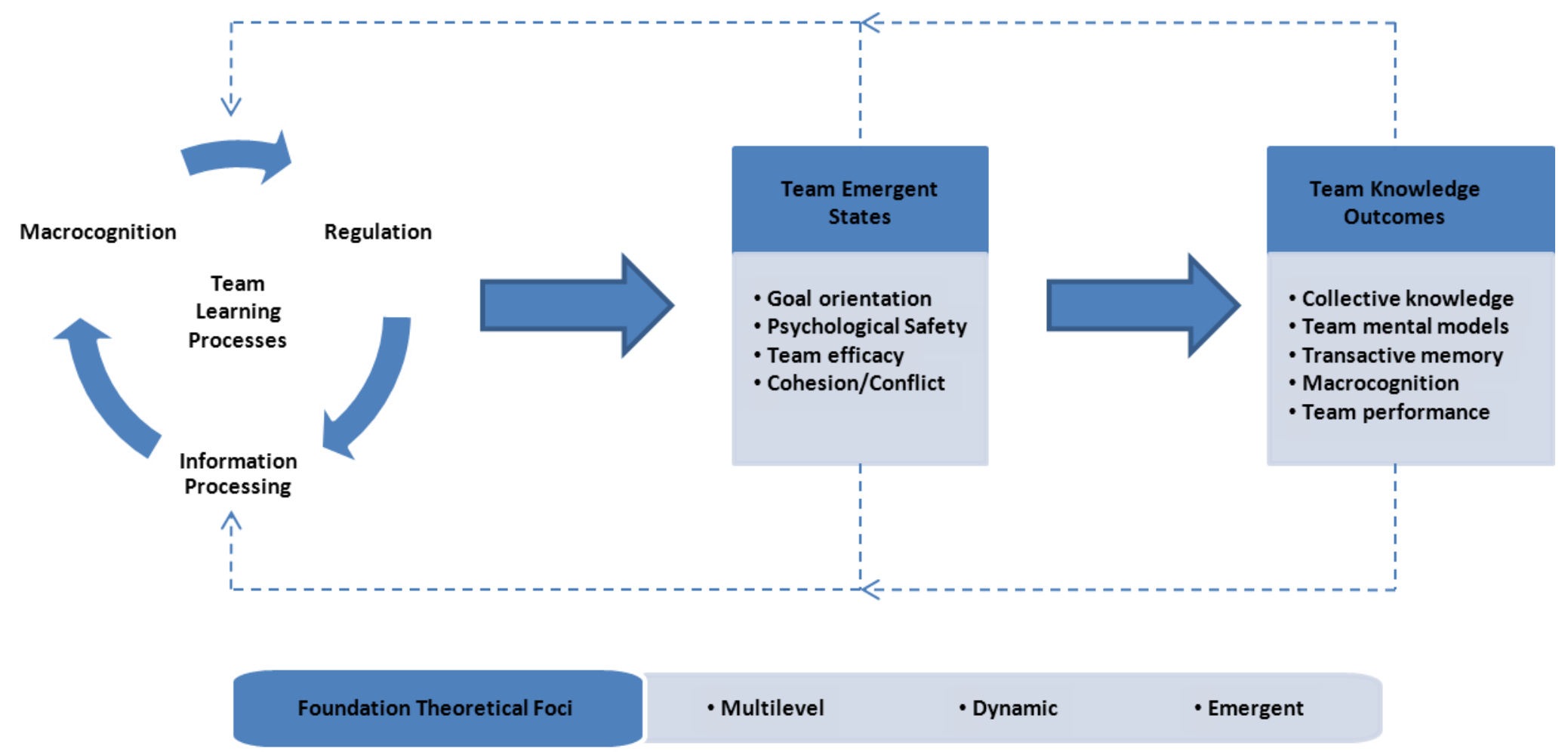

(C) Copyright 2011 B. S. Bell \& S. W. J. Kozlowski. All rights reserved worldwide. Used with permission. 
Figure 2. Knowledge Compilation

Basic
Knowledge and Skill Complexity
Advanced

\begin{tabular}{|l|c|c|c|c|}
\hline Knowledge Type: & $\begin{array}{c}\text { Declarative } \\
\text { Knowledge } \\
\text { [DATA] }\end{array}$ & $\begin{array}{c}\text { Procedural Knowledge } \\
\text { \& Skill } \\
\text { [INFORMATION] }\end{array}$ & $\begin{array}{c}\text { Strategic Knowledge } \\
\text { \& Skill } \\
\text { [KNOWLEDGE] }\end{array}$ & $\begin{array}{c}\text { Adaptive Knowledge } \\
\text { \& Skill } \\
\text { [ADAPTATION] }\end{array}$ \\
\hline $\begin{array}{l}\text { Knowledge } \\
\text { Capability: }\end{array}$ & $\begin{array}{c}\text { Facts, concepts, rules; } \\
\text { Definition, meaning } \\
\text { (What?) }\end{array}$ & $\begin{array}{c}\text { Contexualized rule } \\
\text { application; } \\
\text { Conditional if-then } \\
\text { rules } \\
(\text { How? }\end{array}$ & $\begin{array}{c}\text { Synthesis; } \\
\text { Task contingencies; } \\
\text { Selective resource } \\
\text { allocation } \\
\text { (When, Where, Why?) }\end{array}$ & $\begin{array}{l}\text { Generalization of task } \\
\text { rules, principles, \& } \\
\text { contingencies to new } \\
\text { situations } \\
\text { (What now, What next?) }\end{array}$ \\
\hline
\end{tabular}

Adapted with permission from:

Kozlowski, S. W. J., \& Bell. B. S. (2007). A theory-based approach for designing distributed learning systems. In S. M. Fiore \& E. Salas (Eds.), Where is the learning in distance learning? Toward a science of distributed learning and training (pp. 15-39). Washington, DC: APA Books.

(C) Copyright 2002, 2007, 2010 S. W. J. Kozlowski and B. S. Bell. All rights reserved worldwide. Used with permission. 
Figure 3. A Multiple Goal, Multilevel Model of Individual and Team Regulation

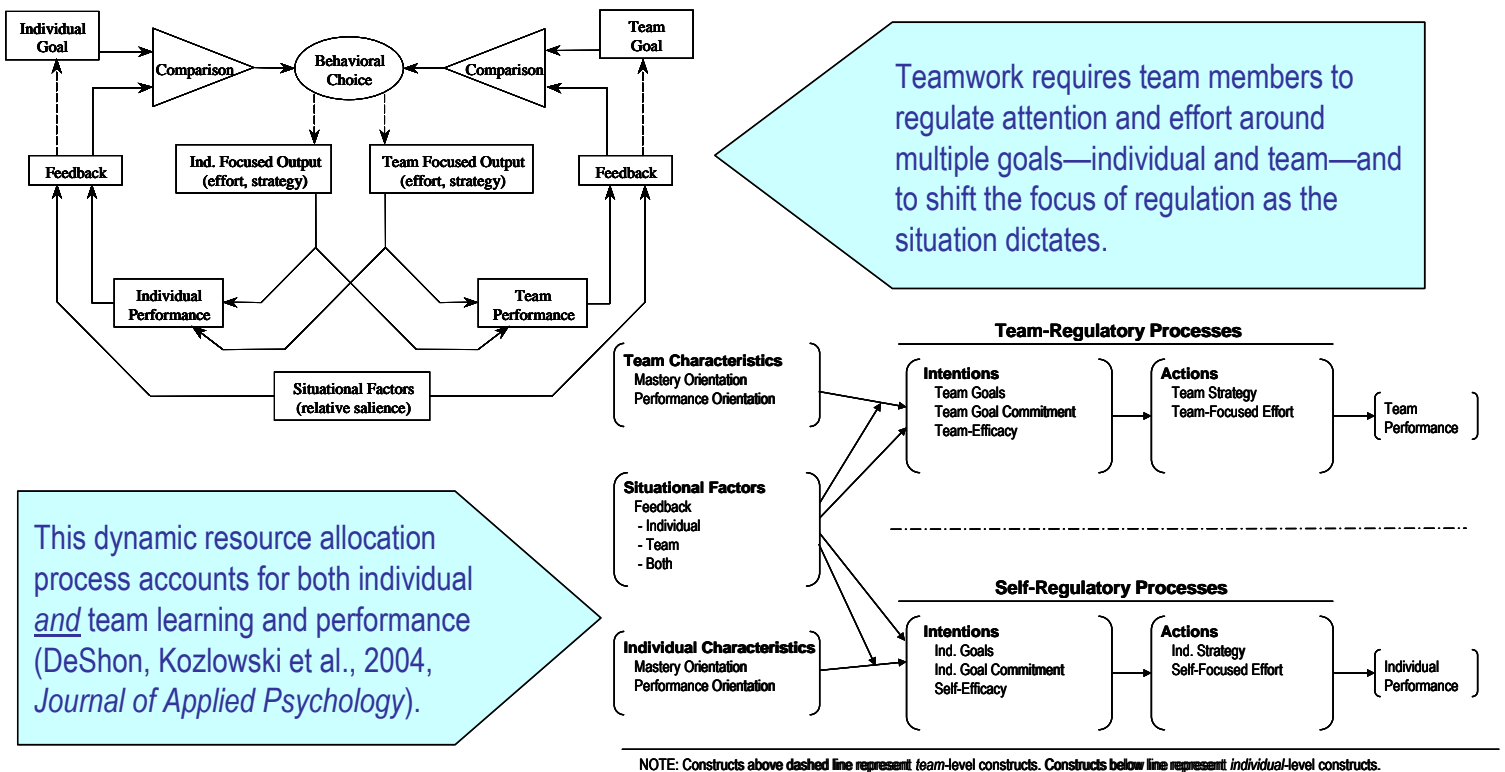

Adapted with permission from:

DeShon, R. P., Kozlowski, S. W. J., Schmidt, A. M., Milner, K. R., \& Wiechmann, D. (2004). A multiple goal, multilevel model of feedback effects on the regulation of individual and team performance. Journal of Applied Psychology, 89, 1035-1056. Published by the American Psychological Association. Adapted with permission. 
Figure 4. A Multilevel Model of Training Outcomes and Posttraining Adaptive Performance

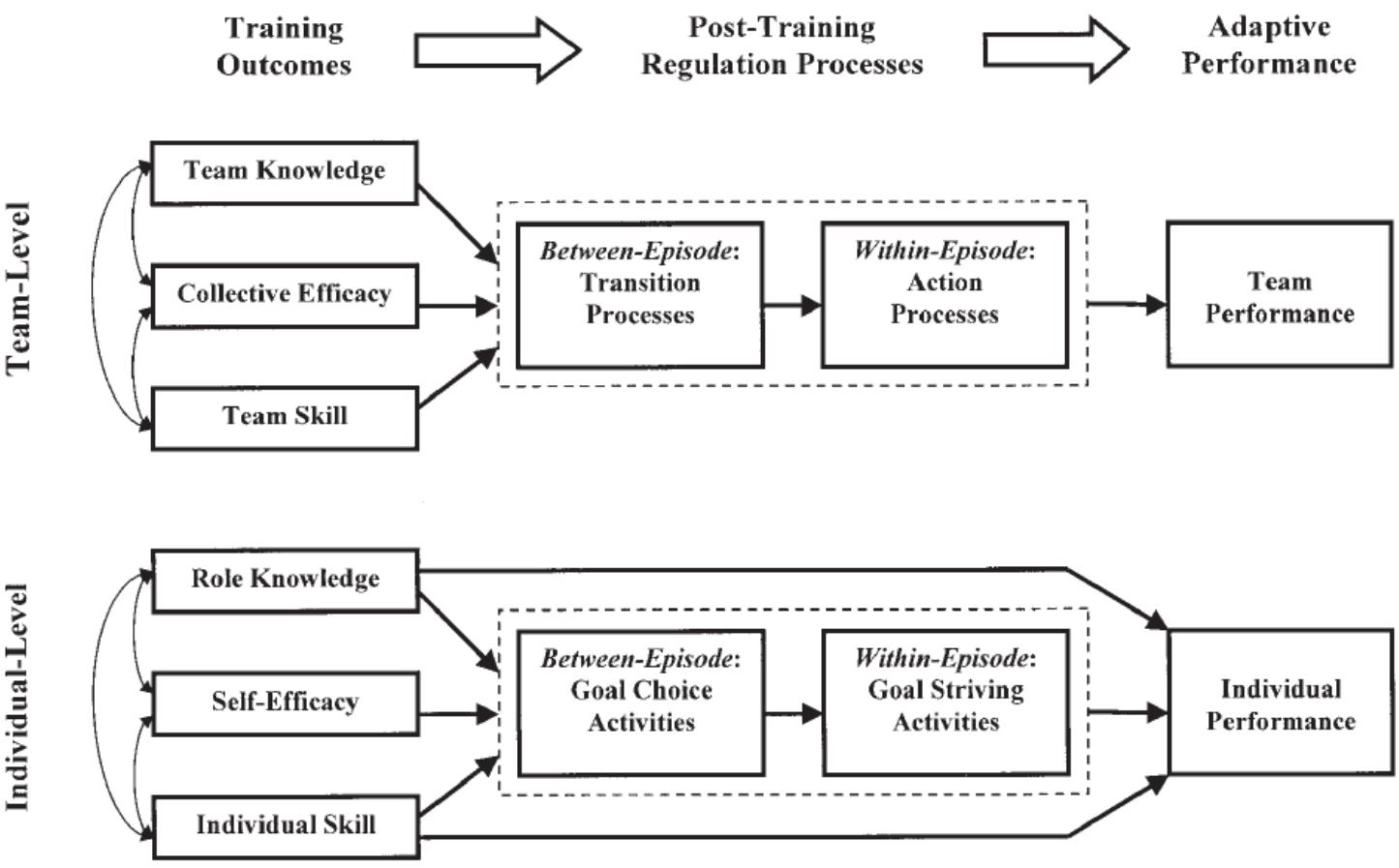

Reprinted with permission from:

Chen, G., Thomas, B., \& Wallace, J. C. (2005). A multilevel examination of the relationships among training outcomes, mediating regulatory processes, and adaptive performance. Journal of Applied Psychology, 90, 827-841. Published by the American Psychological Association. Published by the Academic Press. Reprinted with permission. 
Figure 5. Hypothesized Multilevel Model of Motivation and Performance in Teams

\footnotetext{
Thu 5. Hypothesized Multilevel Model of Motivation and Petformance in Teans
}

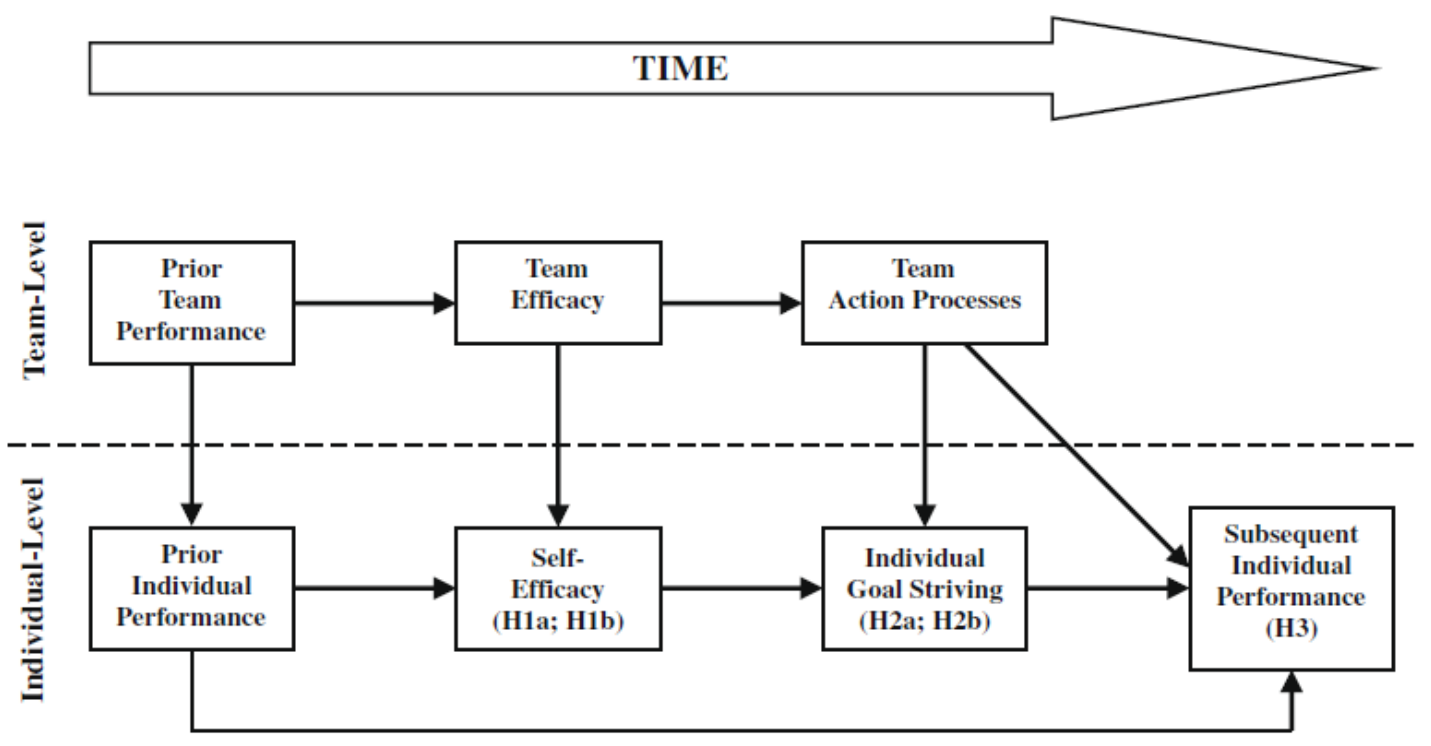

Reprinted with permission from:

Chen, G., Kanfer, R., DeShon, R. P., Mathieu, J. E., \& Kozlowski, S. W. J. (2009). The motivating potential of teams: Test and extension of Chen and Kanfer's (2006) crosslevel model of motivation in teams. Organizational Behavior and Human Decision Processes, 110, 45-55. Published by the Academic Press. Reprinted with permission. 
Figure 6. Team Compilation Model

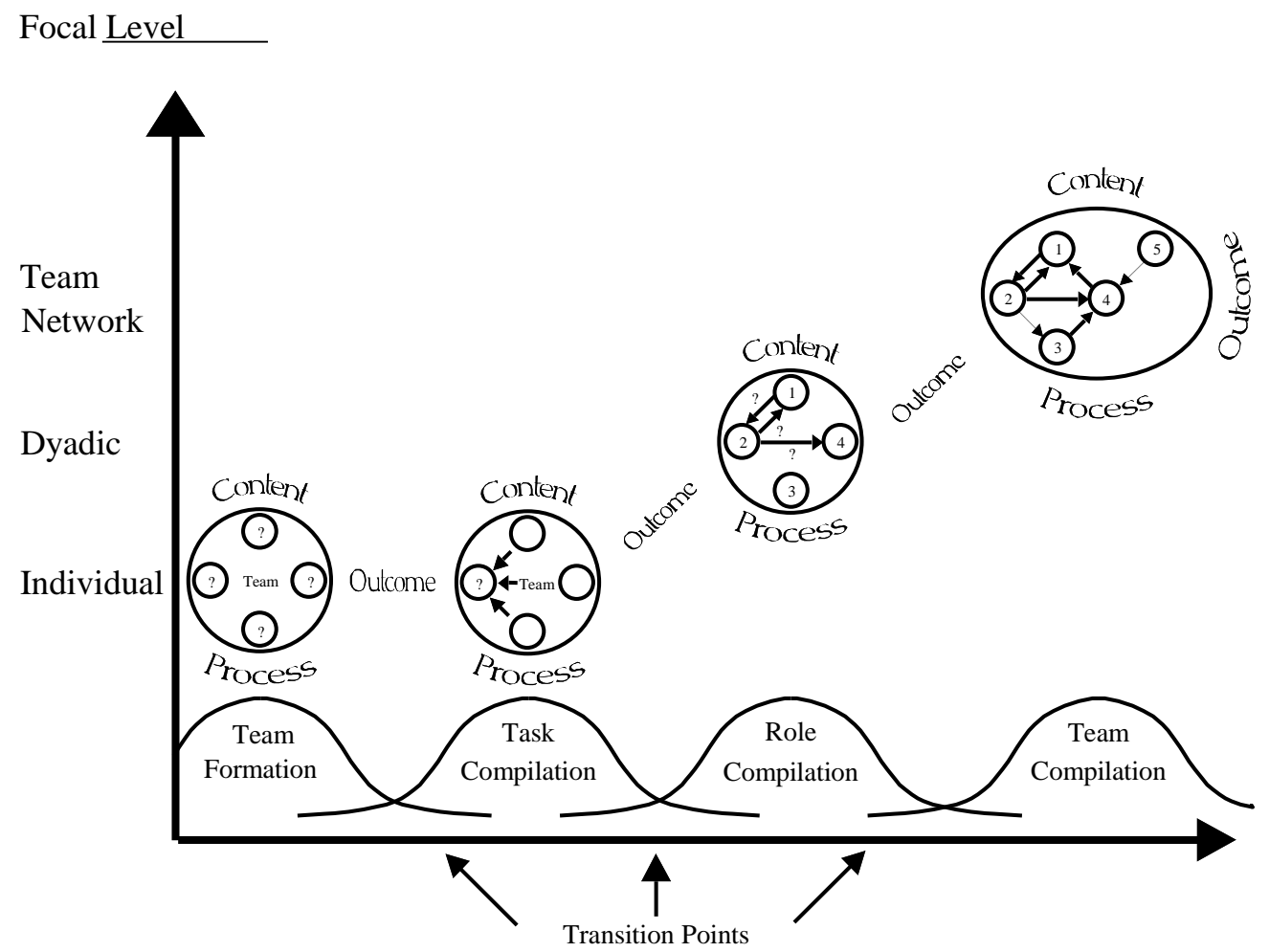

Developmental Continuum

Adapted from:

Kozlowski, S. W. J., Gully, S. M., Nason, E. R., \& Smith, E. M. (1999). Developing adaptive teams: A theory of compilation and performance across levels and time. In D. R. Ilgen \& E. D. Pulakos (Eds.), The changing nature of work performance: Implications for staffing, personnel actions, and development (pp. 240-292). San Francisco: Jossey-Bass.

Copyright (C 1997, 2006, 2010 S. W. J. Kozlowski. All rights reserved worldwide. Used with permission. 
Figure 7. An Information-Processing Model of Team Learning

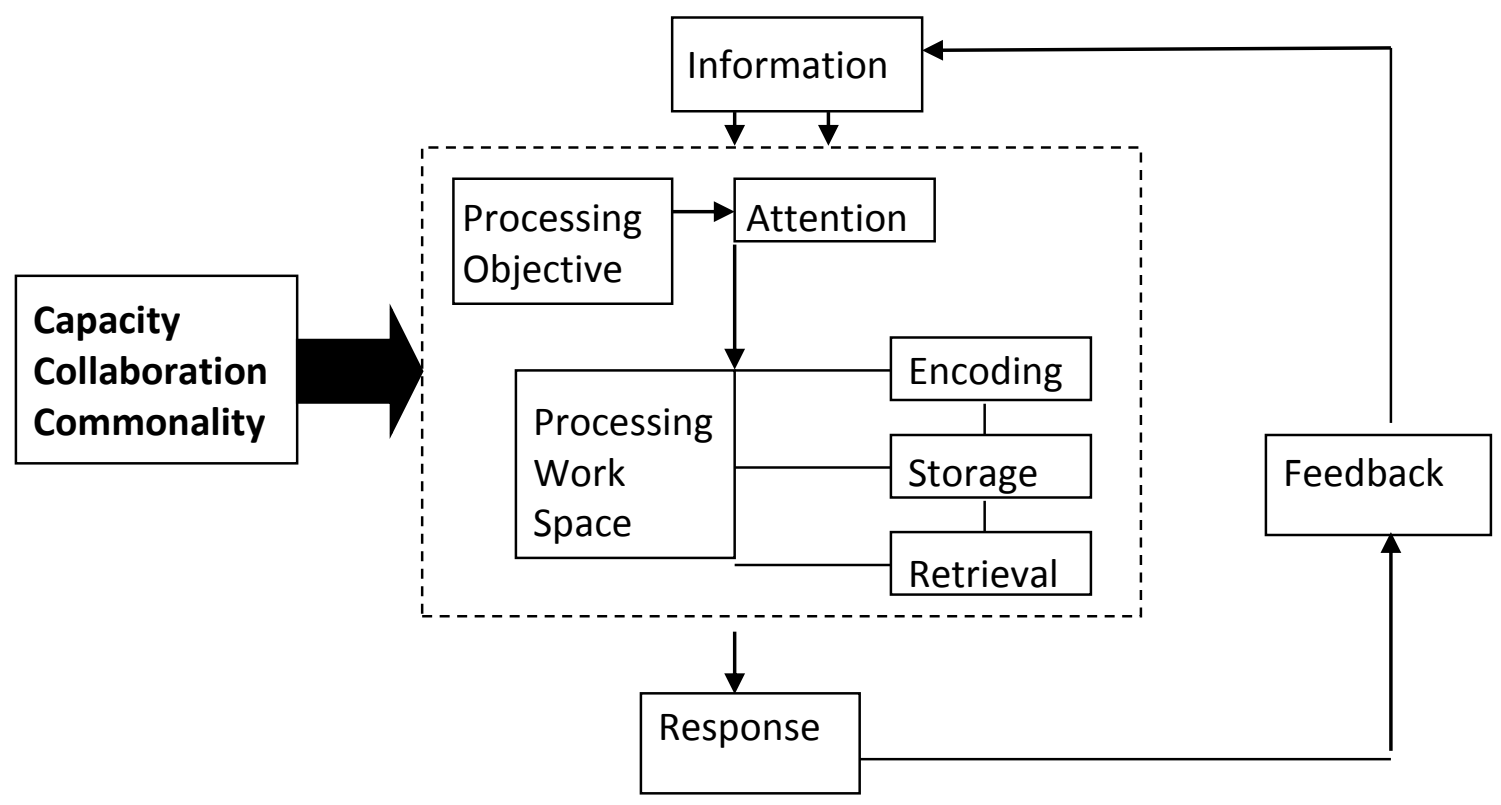

Adapted with permission from:

Ellis, A. P. J., \& Bell, B. S. (2005). Capacity, collaboration, and commonality: A framework for understanding team learning. In L. L. Neider \& C. A. Shriesheim (Eds.), Understanding teams: A volume in research in management (pp. 1-25). Greenwich, CT: Information Age. () 2005 Information Age Publishing. Adapted with permission. 
Figure 8. Meta-model of team macrocognition

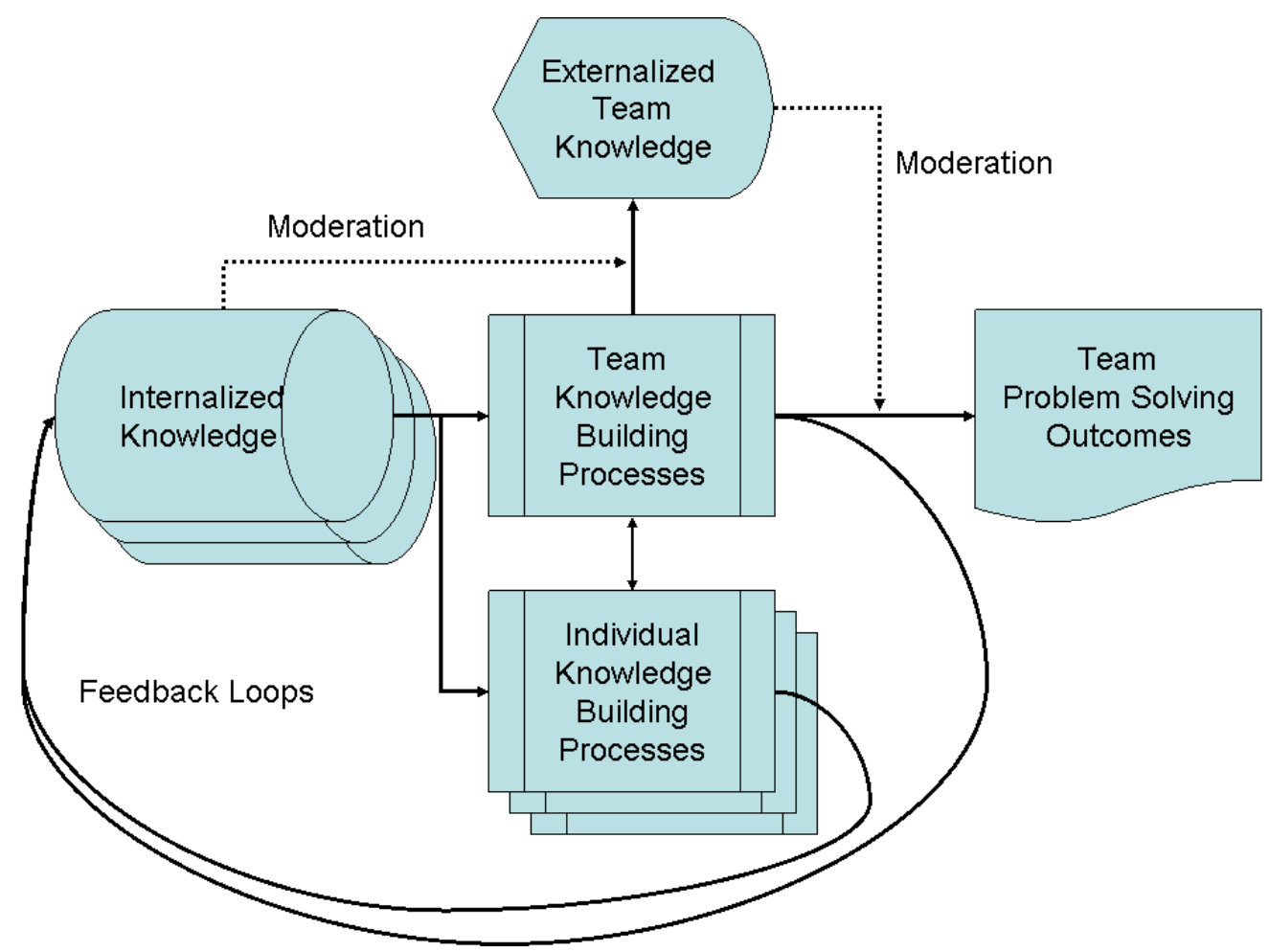

Legend:

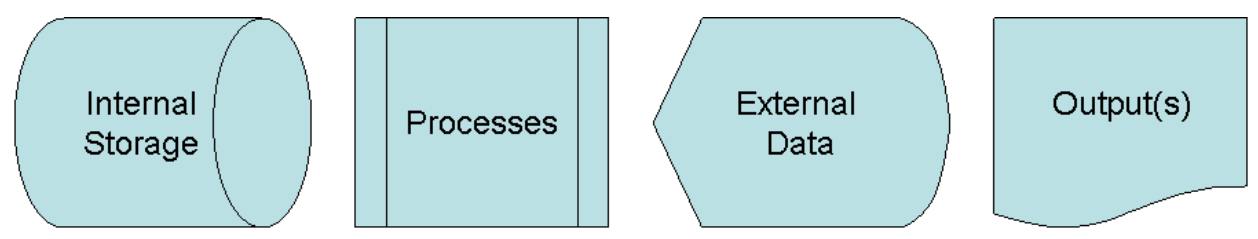

Note: Multiple overlapping symbols indicate representations for multiple team members.

Reprinted with permission from:

Fiore, S. M., Rosen, M. A., Smith-Jentsch, K. A., Salas, E., Letsky, M., \& Warner, N. (2010). Toward an understanding of macrocognition in teams: Predicting processes in complex collaborative contexts. Human Factors, 52, 203-224. Published by the Human Factors and Ergonomics Society. Reprinted with permission. 
Figure 9. Team Knowledge Typology.

\begin{tabular}{|c|c|c|}
\hline $\begin{array}{l}\text { Knowledge } \\
\text { Metrics }\end{array}$ & Brief Description & Example \\
\hline $\begin{array}{l}\text { Individual } \\
\text { Knowledge }\end{array}$ & $\begin{array}{l}\text { The proportion of the total } \\
\text { pool of possible knowledge } \\
\text { possessed by each team } \\
\text { member separately }\end{array}$ & $\begin{array}{l}\text { The amount of } \\
\text { knowledge individuals } \mathrm{i}, \mathrm{j} \text {, } \\
\text { and keach possess } \\
\text { within the problem space }\end{array}$ \\
\hline $\begin{array}{l}\text { Knowledge } \\
\text { Pool }\end{array}$ & $\begin{array}{l}\text { The proportion of the total } \\
\text { pool of possible knowledge } \\
\text { possessed by the team } \\
\text { collectively }\end{array}$ & $\begin{array}{l}\text { The proportion of the } \\
\text { total knowledge among } \\
\text { individual team members } \\
\text { accounting for overlap }\end{array}$ \\
\hline $\begin{array}{l}\text { Knowledge } \\
\text { Configuration }\end{array}$ & $\begin{array}{l}\text { The proportion of the total } \\
\text { pool shared in common by } \\
\text { team members and the } \\
\text { pattern of unique knowledge } \\
\text { held across individuals }\end{array}$ & $\begin{array}{l}\text { Understanding what is } \\
\text { common and what is } \\
\text { unique knowledge } \\
\text { among team members }\end{array}$ \\
\hline $\begin{array}{l}\text { Knowledge } \\
\text { Acquisition }\end{array}$ & $\begin{array}{l}\text { The rate of knowledge } \\
\text { compiled by each team } \\
\text { member over time }\end{array}$ & $\begin{array}{l}\text { How fast an individual } \\
\text { learns (expands a circle in } \\
\text { above venn diagrams) }\end{array}$ \\
\hline $\begin{array}{l}\text { Knowledge } \\
\text { Variability }\end{array}$ & $\begin{array}{l}\text { Within team variance in the } \\
\text { rates of knowledge } \\
\text { acquisition }\end{array}$ & $\begin{array}{l}\text { Different rates of } \\
\text { knowledge acquisition can } \\
\text { affect a team's learning }\end{array}$ \\
\hline $\begin{array}{l}\text { Knowledge } \\
\text { Emergence } \\
\text { (within team) }\end{array}$ & $\begin{array}{l}\text { The rates of growth for } \\
\text { Knowledge Pool and } \\
\text { Knowledge Configuration }\end{array}$ & $\begin{array}{l}\text { Changes } \\
\text { over time }\end{array}$ \\
\hline $\begin{array}{l}\text { Knowledge } \\
\text { Emergence } \\
\text { (between) }\end{array}$ & $\begin{array}{l}\text { Comparing growth rates for } \\
\text { Knowledge Variability, } \\
\text { Knowledge Pool, and } \\
\text { Knowledge Configuration } \\
\text { across teams }\end{array}$ & \\
\hline
\end{tabular}

Used with permission from:

Kozlowski, S. W. J. \& Chao, G. T. (in press). Macrocognition, team learning, and team knowledge: Origins, emergence, and measurement. In E. Salas, S. Fiore, \& M. Letsky (Eds.), Theories of team cognition: Cross-disciplinary perspectives. New York, NY: Routledge Academic.

Copyright (C) 2010 S. W. J. Kozlowski \& G. T. Chao. All rights reserved worldwide. Used with permission. 